January 2015

\title{
An In-Vitro Comparison of Different Palatal Sites for Orthodontic Miniscrew Insertion: The Effect of Bone Quality and Quantity on Primary Stability
}

Carine Bourassa, The University of Western Ontario

Supervisor: Dr Ali Tassi, The University of Western Ontario

A thesis submitted in partial fulfillment of the requirements for the Master of Clinical Science degree in Orthodontics

(C) Carine Bourassa 2015

Follow this and additional works at: https://ir.lib.uwo.ca/etd

Part of the Orthodontics and Orthodontology Commons

\section{Recommended Citation}

Bourassa, Carine, "An In-Vitro Comparison of Different Palatal Sites for Orthodontic Miniscrew Insertion: The Effect of Bone Quality and Quantity on Primary Stability" (2015). Electronic Thesis and Dissertation Repository. 2672.

https://ir.lib.uwo.ca/etd/2672

This Dissertation/Thesis is brought to you for free and open access by Scholarship@Western. It has been accepted for inclusion in Electronic Thesis and Dissertation Repository by an authorized administrator of Scholarship@Western. For more information, please contact wlswadmin@uwo.ca. 
AN IN-VITRO COMPARISON OF DIFFERENT PALATAL SITES FOR ORTHODONTIC MINISCREW INSERTION: THE EFFECT OF BONE QUALITY AND QUANTITY ON PRIMARY STABILITY

(Thesis format: Monograph)

by

Carine Bourassa

Graduate Program in Orthodontics

A thesis submitted in partial fulfillment of the requirements for the degree of Master of Clinical Dentistry

The School of Graduate and Postdoctoral Studies

Western University

London, Ontario, Canada

(C) Carine Bourassa 2015 


\begin{abstract}
Introduction: The maxillary hard palate is a desirable location for orthodontic miniscrew (OMS) placement. The related anatomy is well known, but little data exists regarding the primary stability of palatal OMSs.

Purpose: To assess the quality and quantity of human cadaveric palatal bone at different insertion sites using microCT imaging, and to determine their effect on the primary stability of OMSs.
\end{abstract}

Materials and methods: One hundred and thirty OMSs (VectorTAS ${ }^{\mathrm{TM}}, 6 \mathrm{~mm}$ ) were inserted into ten human cadaveric maxillary hard palates and maximal insertion torques (IT) were recorded. MicroCT images were obtained before and after OMS insertion for assessment of bone quality and quantity [bone mineral density (BMD), bone thickness (BT) and length of screw engagement (LSE)]. Statistical analyses were carried out to assess differences in BMD, BT, LSE and IT at the different insertion sites, as well as correlations between IT and measurements of BMD, BT and LSE. Perforations into the nasal cavity were recorded.

Results: Significant differences $(p<0.0005)$ were found among insertion sites for IT, $\mathrm{BT}$, and LSE, but not BMD $(p=0.004)$. Correlations were found between IT and BMD $\left(r_{s}=0.42, p<0.0005\right)$; IT and BT $\left(r_{s}=0.58, p<0.0005\right)$; and IT and LSE $\left(r_{s}=0.58, p<\right.$ 0.0005). A high number of OMS perforations into the nasal cavity were recorded posterior to the permanent second premolars.

Conclusions: The primary stability of OMSs is moderately affected by bone quality and quantity. Higher primary stability may be obtained anterior to the second premolars and parasagittally at the level of the permanent first molars. The posterior palate is more susceptible to OMS perforations into the nasal cavity.

Keywords: miniscrew, orthodontic miniscrew, temporary anchorage device, TAD, bone density, bone thickness, bone height, primary stability, insertion torque, microCT. 


\section{Co-Authorship Statement}

The execution of this thesis was possible due to the contribution of several individuals. Its completion would not have been possible without their precious time and efforts.

\section{Carine Bourassa: DMD}

Master of Clinical Dentistry Candidate

Contribution: $\quad$ Study design, data collection and analysis, wrote manuscript

Yara Hosein: $\quad$ BSc, PhD, Post-doctoral Fellow, Schulich School of Medicine and Dentistry, Western University

Collaborator

Contribution: $\quad$ Study design, data collection and analysis, reviewed manuscript
Ali Tassi:
BSc, DDS, MCID
Supervisor
Assistant Professor, Dentistry; Clinic Director, Division of
Graduate Orthodontics, Schulich School of Medicine \& Dentistry, Western University
Contribution: $\quad$ Study design, data analysis, reviewed manuscript
Khadry Galil: $\quad$ DDS, D. Oral \& Maxillofacial Surgery, Ph.D, FAGD., FADI., Cert. Periodontist
Co-supervisor
Professor of Dentistry, Associate Professor of Anatomy Department of Orthodontics, Periodontics and Clinical Anatomy Schulich School of Medicine \&Dentistry, Western University
Contribution: $\quad$ Study design, reviewed manuscript 


\section{Acknowledgments}

It is with gratitude that I would like to express my sincere thanks to all of those that contributed directly or indirectly in the completion of this project.

First, I would like to thank the orthodontic supply company, Ormco ${ }^{T M}$ for its generous donation of orthodontic miniscrews. This donation was of major help in making this project feasible.

I also wish to express thankfulness to my thesis supervisor, Dr. Ali Tassi. I am grateful for all the time and effort he has invested in making the best out of this project. It is without a doubt that his assistance was of precious help all along this journey.

My greatest recognition is to my colleague, Yara Hosein. She has been my right arm throughout every step of this endeavor. Her expertise, suggestions and critiques were unquestionably very precious. This research would not have been possible without her help. I am forever grateful.

Another set of thanks goes to the whole team of the Anatomy and Cellular Biology department. First, I would like to acknowledge the valuable participation of Dr. Khadry Galil and his graduate student, Jillian Philips. Their collaboration made this work much more complete and enjoyable. I also would like to thank Mr. Kevin Walker and Ms. Haley Lintlaker and all the ones that indirectly contributed to this project.

To the Robarts Research institute, I would like to thank Dr. David Holdsworth and his team for their valuable help. I would like to recognize the work of Mr. Joseph Umoh for his assistance with the imaging process. I would also like to acknowledge the contribution of Mr. Steven Pollmann for the development of a computer software algorithm for microCT images analysis.

To the physics and astronomy machine shop, thousand thanks to Mr. Brian Dalrymple and Mr. Frank Van Sas for their help in making the insertion apparatus.

To Dr. Antonios Mamandras, thank you for welcoming me into such an amazing program. Thank you for everything you do to make your residents feel at home, for believing in our capacities and for providing such a pleasant daily environment. I am also forever recognizant to the staff members; Barbara Merner, Jo Ann Pfaff, Evelyn Larios, Patricia Vanin, Jacqueline Geneau and all the clinical instructors for their hard work and constant assistance in the clinical settings. You will forever be my "London family".

To my classmates Brian Phee and Harbinder Sangha, I am really fortunate to have shared this experience with you. Being the middle sister, I could not have asked for better "brothers". To my past and current fellow residents I will leave London with a handful of unforgettable memories. I am looking forward to many more future opportunities we will have to share time together.

Finally, to my family and loved ones, thank you for your understanding and for your constant encouragement. I will forever be grateful for your beliefs in my dreams. I can't wait to come back to you and resume where we left off. 


\section{Dedication}

À Céline Pâquet et Laurent Bourassa

En foi de l'expression de ma reconnaissance éternelle pour votre support continu, votre amour inconditionnel, ainsi que pour croire en mes rêves et aspirations. 


\section{Table of Contents}

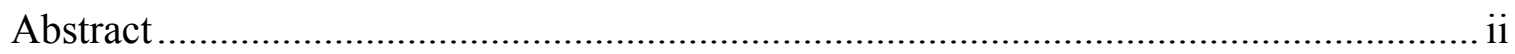

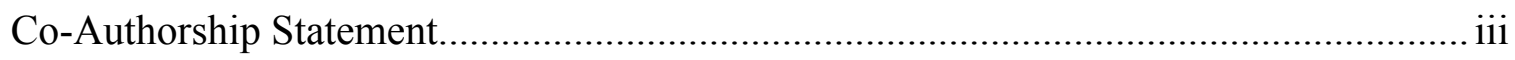

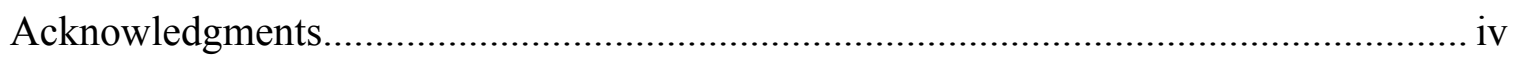

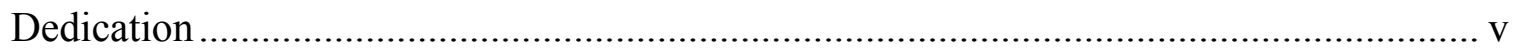

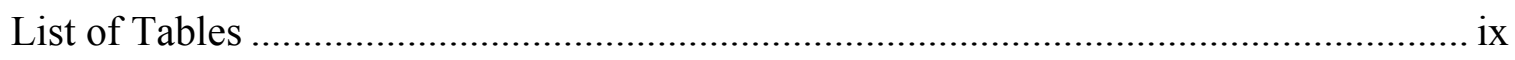

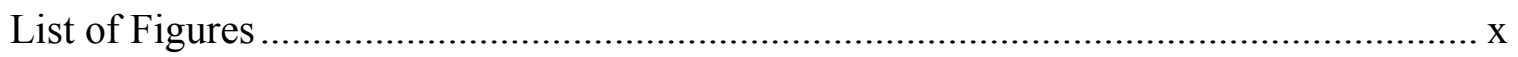

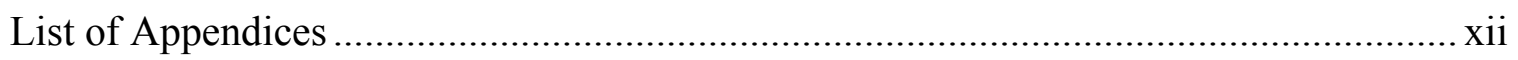

List of Abbreviations and Symbols..................................................................... xiii

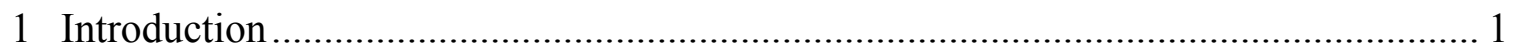

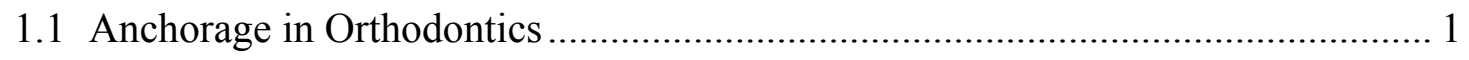

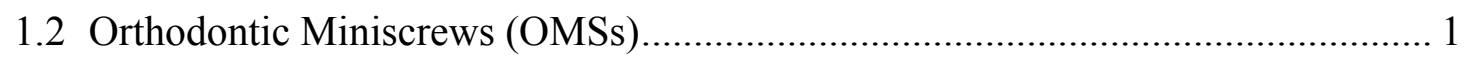

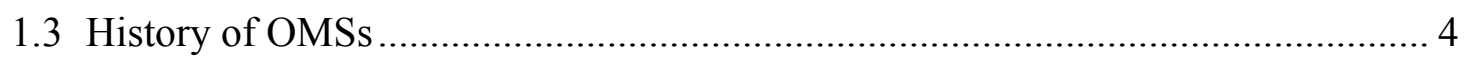

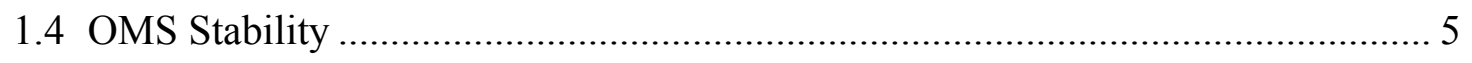

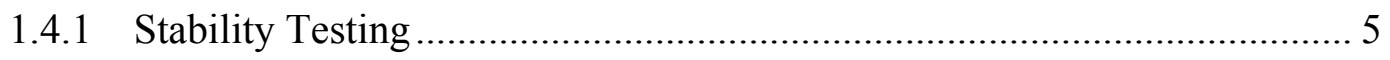

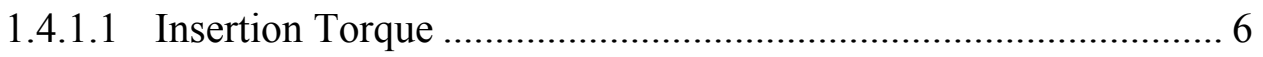

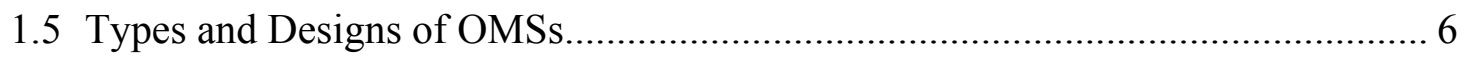

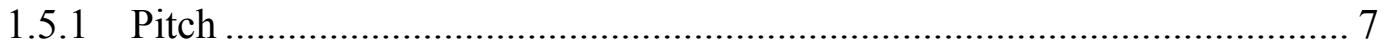

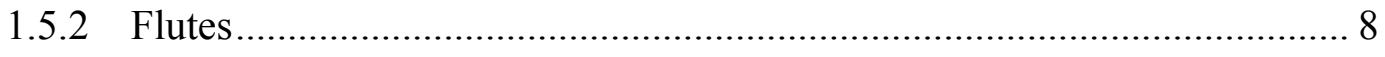

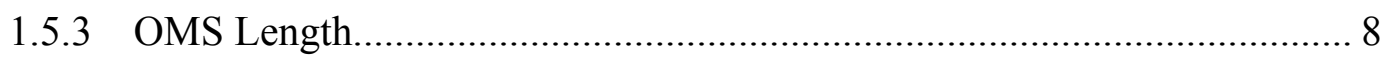

1.5.3.1 Length of screw engagement (LSE) ................................. 9

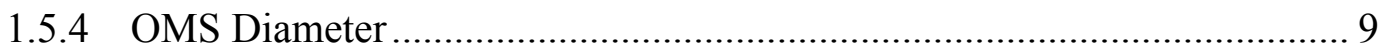

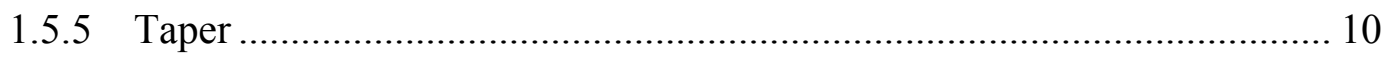


1.5.6 Self-Drilling and Self-Tapping Designs ……...................................... 10

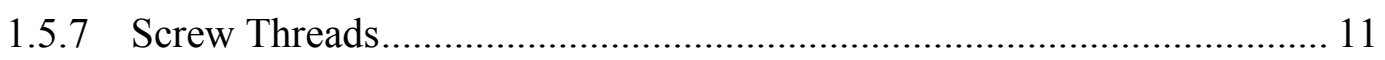

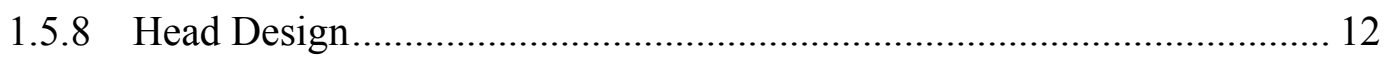

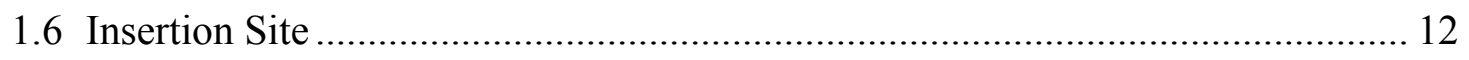

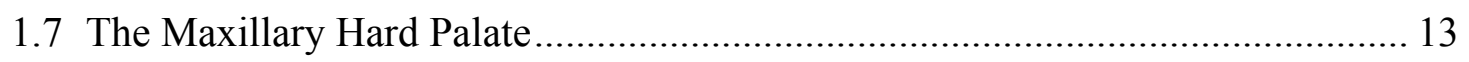

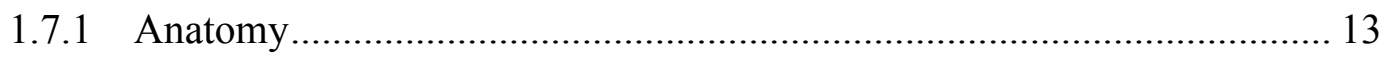

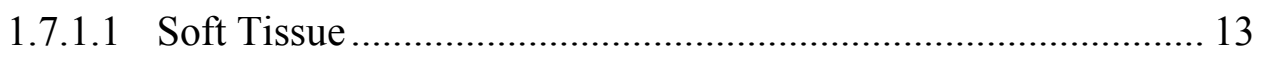

1.7.1.2 Bone Characteristics .............................................................. 14

1.7.2 Medical Imaging in OMS Treatment.................................................... 15

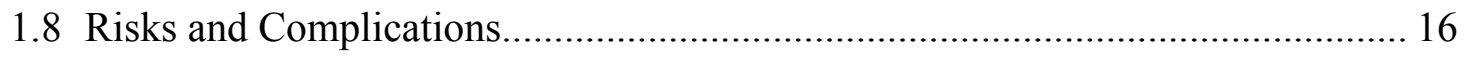

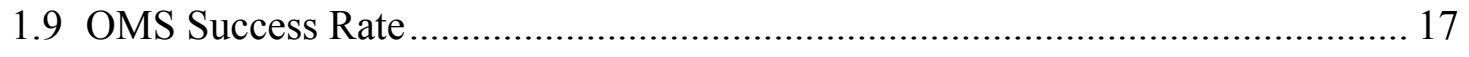

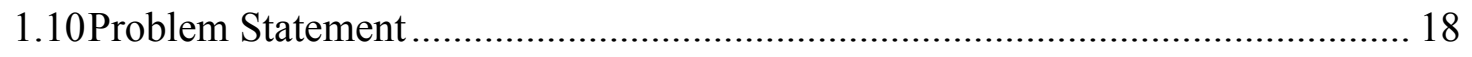

1.11 Purpose

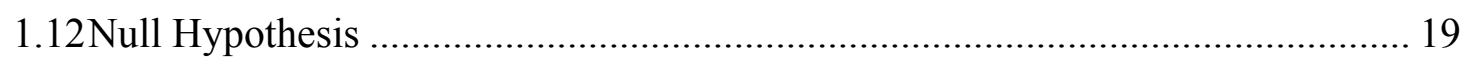

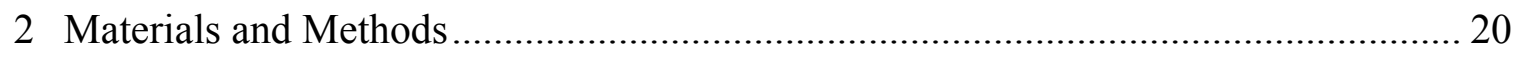

2.1 Selection of Palatal Sites and Grid Design ........................................................ 20

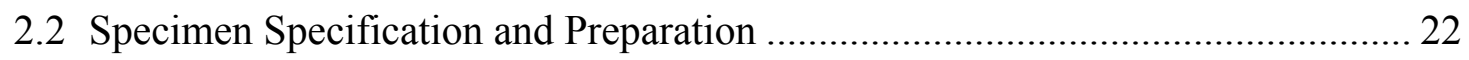

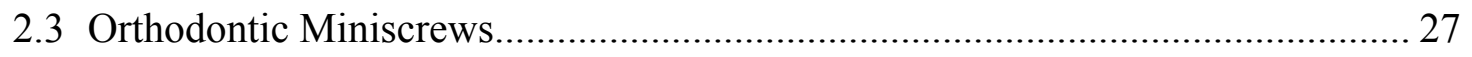

2.4 Insertion Mechanics and Primary Stability …………....................................... 28

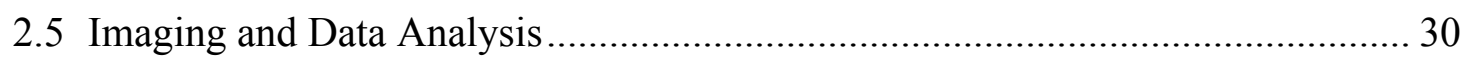

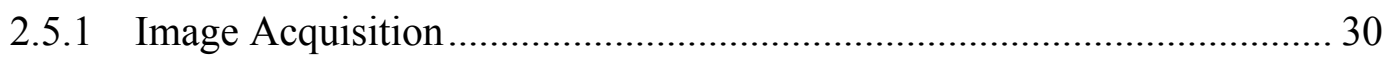

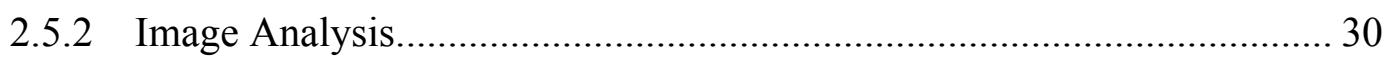

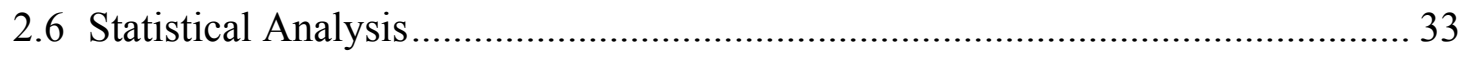

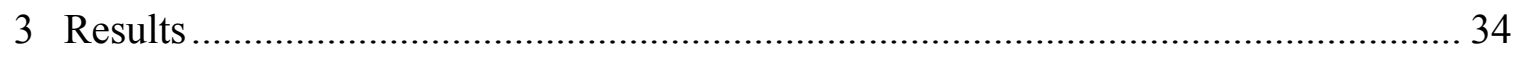

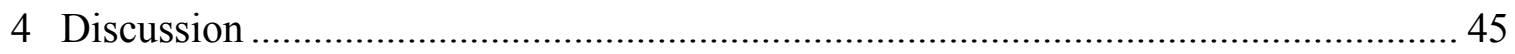




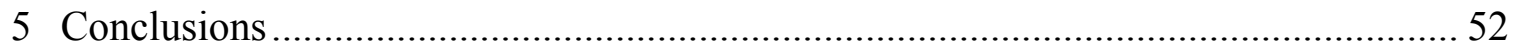

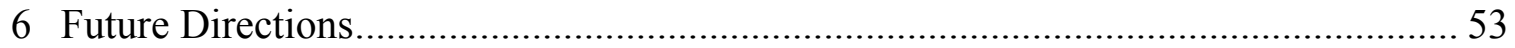

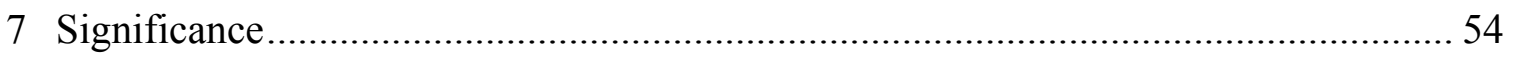

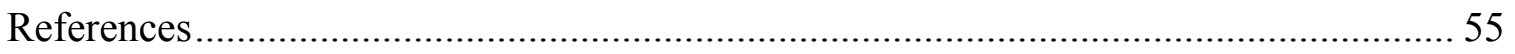

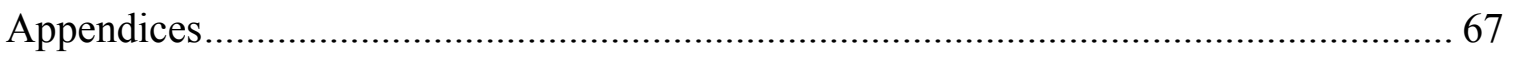

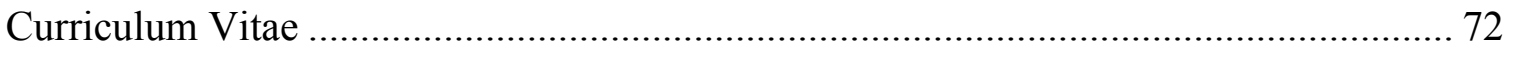




\section{List of Tables}

Table 1. Descriptive statistics for BMD, BT, LSE, IT and perforation at each insertion

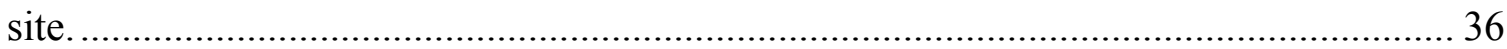




\section{List of Figures}

Figure 1. OMS use in orthodontic treatment. ........................................................ 2

Figure 2. Variety of OMSs available from different manufacturers.............................. 3

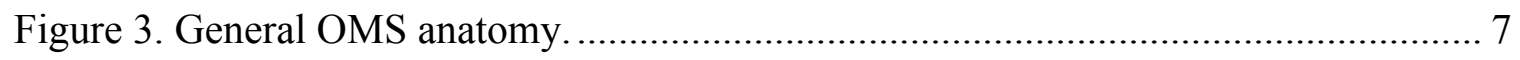

Figure 4. Length of screw engagement................................................................. 9

Figure 5. Different screw thread designs ................................................................ 11

Figure 6. Lateral cephalometric radiograph of the case described in Figure 1............... 12

Figure 7. Grid system representing the pre-determined insertion sites. ......................... 20

Figure 8. Anterior view of a specimen after isolation and dissection........................... 22

Figure 9. Posterior view of a specimen embedded in acrylic block. ............................ 23

Figure 10. Occlusal view of a specimen embedded in acrylic block........................... 24

Figure 11. Position of the specimen under PMMA stencil......................................... 25

Figure 12. Methodology for transferring of the grid system onto the specimens............ 26

Figure 13. Insertion sites marked on specimen with fabric paint. .............................. 26

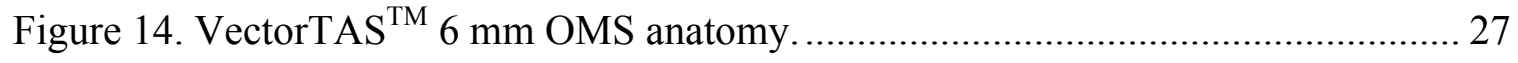

Figure 15. Custom apparatus used for OMS insertion......................................... 28

Figure 16. Computer software program used for collection of insertion data................ 29

Figure 17. Computer software depicting the cylindrical ROI and the longitudinal OMS

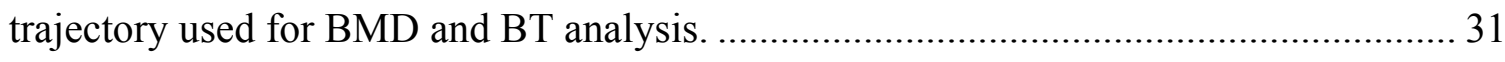


Figure 18. Line profile along the longitudinal OMS trajectory.

Figure 19. Box and Whisker plots for BMD at each insertion site.............................. 37

Figure 20. Box and Whisker plots for BT at each insertion site................................. 38

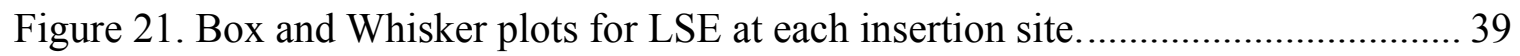

Figure 22. Box and Whisker plots for IT at each insertion site.................................. 40

Figure 23. Percentage of perforations for each insertion site. ....................................... 41

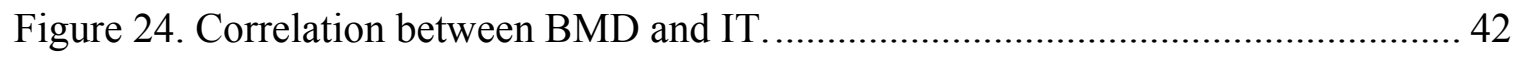

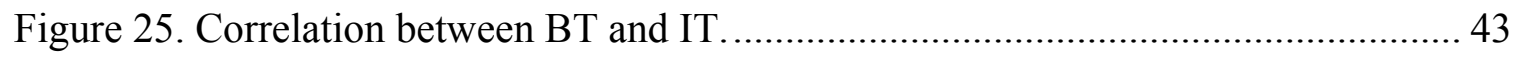

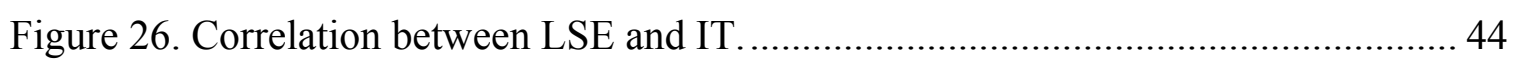




\section{List of Appendices}

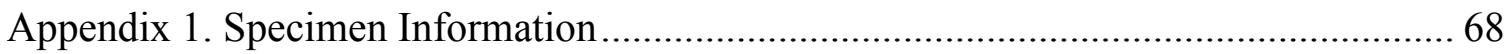

Appendix 2. PMMA stencil used for grid reproduction onto the specimens.................... 69

Appendix 3. Occlusal view of specimens after OMSs insertion ..................................... 70

Appendix 4. Visual inspection of OMS perforation into nasal cavity .............................. 71 


\section{List of Abbreviations and Symbols}

\begin{tabular}{|c|c|}
\hline $3 \mathrm{D}$ & Three-Dimensional \\
\hline A-P & Antero-Posterior \\
\hline $\mathrm{BMD}$ & Bone Mineral Density \\
\hline BT & Bone Thickness \\
\hline CBCT & Cone Beam Computed Tomography \\
\hline $\mathrm{CT}$ & Computed Tomography \\
\hline HA & Hydroxyapatite \\
\hline $\mathrm{HU}$ & Hounsfield Unit \\
\hline IT & Insertion Torque \\
\hline $\mathrm{L}$ & Lateral \\
\hline LSE & Length of Screw Engagement \\
\hline MicroCT & Micro Computed Tomography \\
\hline M-L & Medio-Lateral \\
\hline $\mathrm{Ncm}$ & Newton $\bullet$ centimeter \\
\hline $\mathrm{Nm}$ & Newton $\bullet$ meter \\
\hline OMS & Orthodontic Miniscrew \\
\hline PMMA & Poly(methyl methacrylate) \\
\hline POS & Pull-Out Strength \\
\hline
\end{tabular}




$\begin{array}{ll}\text { PS } & \text { Para-Sagittal } \\ r_{s} & \text { Spearman's rank correlation coefficient } \\ \text { ROI } & \text { Region of Interest } \\ \text { RPM } & \text { Revolutions per minute } \\ \text { S } & \text { Sagittal } \\ \text { SPSS } & \text { Statistical Package for Social Sciences } \\ \text { TAD } & \text { Temporary Anchorage Device } \\ \text { TAS } & \text { Temporary Anchorage System } \\ \text { TSAD } & \text { Temporary Skeletal Anchorage Device } \\ \text { VBH } & \text { Vertical Bone Height }\end{array}$




\section{Introduction}

\subsection{Anchorage in Orthodontics}

Tooth movement is possible due to a biological response that occurs at the level of the periodontal ligament following the continuous application of a force. ${ }^{1}$ To apply forces to a tooth or a group of teeth, anchorage is needed from adjacent teeth in the same or opposing arch. The term "anchorage", in orthodontics, is defined as the resistance to unwanted tooth movement. ${ }^{2}$ Orthodontic tooth movement obeys Newton's third law of physics: for every (desired) action, there is an equal and opposite reaction. ${ }^{2}$ As it might be expected, reaction forces from appliances can also move the teeth to which the appliance is anchored. Therefore, the anchorage system is chosen by the orthodontist to move the desired tooth or group of teeth, while limiting the unwanted side effect to the remainder of the dentition. To reinforce the anchorage system, a group of teeth can be consolidated as a unit. Appliances can also be anchored to the palate, to the opposing arch (i.e. elastics or springs) or extraorally using the head or neck (i.e. occipital, cervical, combination or reverse headgear). Unfortunately, the use of headgear and elastics requires patient compliance to be successful in controlling reciprocal forces. ${ }^{1}$ As such, to increase the chances of treatment success, orthodontic miniscrews (OMSs) have been developed as an alternative anchorage device to reduce the dependence on patient compliance, resulting in a possible decrease in overall treatment time..$^{3-5}$

\subsection{Orthodontic Miniscrews (OMSs)}

Orthodontic miniscrews (OMSs) are small surgical bone screws that are placed at specific bony locations in the oral cavity as a source of rigid, bone-supported anchorage to facilitate orthodontic tooth movements (Figure 1). ${ }^{1,6}$ Within the literature, they are commonly referred to as orthodontic mini-implants (OMIs) ${ }^{7}$, miniscrews $^{8}$, microscrews $^{9}$, temporary anchorage devices (TADs) ${ }^{10}$ and temporary skeletal anchorage devices (TSADs). ${ }^{11}$ 


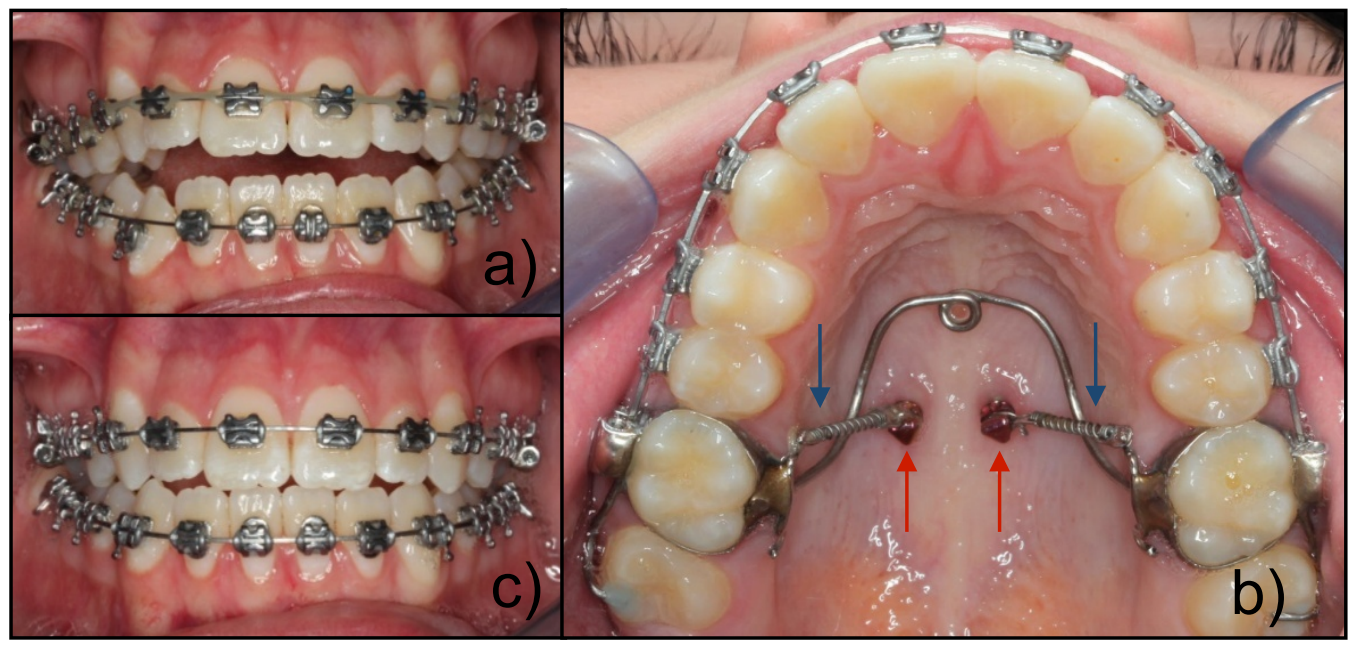

Figure 1. OMS use in orthodontic treatment.

Female patient (19 y, $4 \mathrm{~m}$ ) from the Graduate Orthodontic Clinic at Western University undergoing intrusion of posterior teeth with the use of palatal OMSs for skeletal anchorage, in order to close an anterior open-bite.

a) Early stage of orthodontic treatment, before palatal OMS placement. Note the anterior open-bite present.

b) Orthodontic Appliance Design: a transpalatal arch is anchored to the maxillary right and left first permanent molars; occlusal rests are present on the maxillary second permanent molars; OMSs (red arrows) were inserted laterally to the midpalatal suture; close coil springs (blue arrows) are attached from the orthodontic appliance to the OMSs producing an intrusive force.

c) Treatment progress photograph after 6 months of maxillary posterior teeth intrusion with OMSs. Note that the anterior open-bite is closing favourably.

The extended terminology brings confusion in choosing the proper term to define these bone screws. The American Association of Orthodontists ${ }^{12}$ suggests avoiding the adjunct use of the terms micro and screw since micro refers to a metric measurement of $10^{-6}$, something that must be viewed using a microscope. Nanda et $\mathrm{al}^{1}$ stress the improper use of implant since this is a device that is retained in bone by osseointegration as opposed to mechanical retention. Choo et $a 1^{13}$, suggest that $\mathrm{TAD}$ is a misnomer if referring to absolute anchorage since other removable appliances such as headgear and mandibular lingual holding arches could be included in this nomenclature. ${ }^{13}$ In light of these considerations, the terms orthodontic miniscrew (OMS) and temporary skeletal anchorage device (TSAD) are preferred. 
Orthodontic miniscrews were originally made of stainless steel ${ }^{2}$ but are currently made of a titanium alloy (i.e. Ti-6-Al-4V, made of Ti grade V). ${ }^{2,3,14}$ OMSs are manually inserted into the bone and their usage is meant to be temporary. Their surface is designed to prevent osseointegration, and as such, they are retained mechanically in the bone and are subsequently removed after use. ${ }^{6}$ OMSs are manufactured by various companies and are now available in different designs, lengths and diameters (Figure 2). ${ }^{6}$

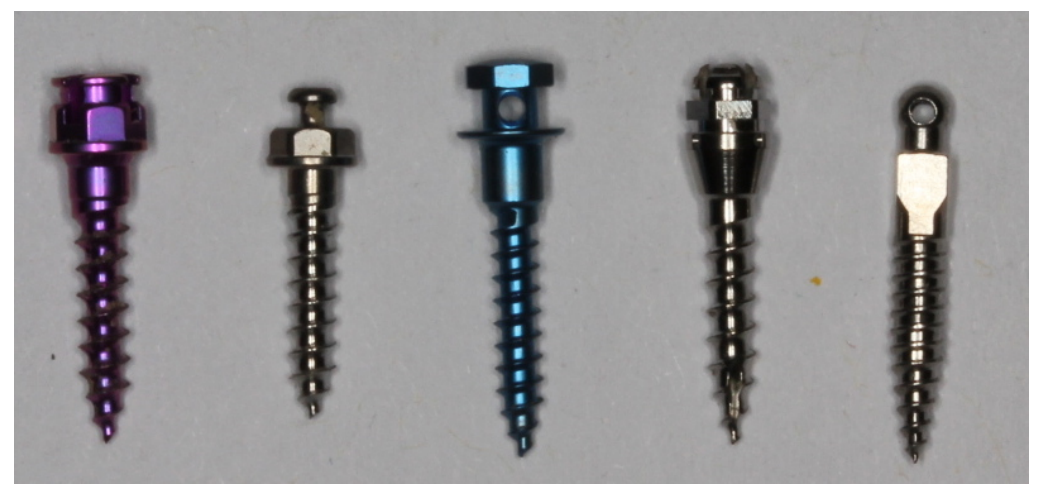

Figure 2. Variety of OMSs available from different manufacturers.

The use of OMSs as skeletal anchorage devices has expanded the possibilities in orthodontic tooth movement. ${ }^{15}$ With their application, clinicians are able to satisfactorily treat malocclusions that previously required orthognathic surgery in order to obtain optimal results. ${ }^{16,17}$ The philosophy of "minimally invasive treatment" is a current topic of discussion in both dental and medical literature. ${ }^{18,19}$ With this approach in mind, numerous orthodontic appliances have been developed to efficiently achieve orthodontic tooth movement, eliminating the need for a surgical procedure. ${ }^{20,21}$ Authors have reported intrusion of posterior teeth ${ }^{22}$, molar distalization and retraction as well as protraction of entire dentitions as now being possible with the use of OMSs. ${ }^{23-25}$ These techniques appear to be a promising treatment alternative. Careful long-term follow-up of treatment stability is still required to determine if TSAD facilitated tooth movement can be as successful as orthognathic surgery, which remains the gold standard. ${ }^{26}$ 


\subsection{History of OMSs}

The use of bone screws for obtaining absolute anchorage in orthodontic treatment was first reported in $1945 .{ }^{27}$ Gainsfort et $a^{28}$ used small Vitallium screws placed in the ascending ramus of dogs to retract canines. The introduction of dental implants by Branemark in 1969 offered the possibility of developing orthodontic anchors that can remain stationary in bone due to osseointegration. ${ }^{29}$

The use of implants in clinical orthodontics was first reported by Linkow in $1970 .^{30}$ Linkow used endosseous blade implants to create a space maintainer that prevented drifting of teeth and created posterior anchorage in patients with posterior edentulous segments. He also developed the idea of using mandibular implants to support Class II elastics for antero-posterior correction without side effects on the lower dentition. ${ }^{1,30}$ Since Linkow, many others have contributed to the development of applications for the use of dental implants, mini-implants and miniscrews in the field. ${ }^{31-33}$

Orthodontic specialists were at first resistant in adopting the concept of miniscrews in orthodontics. In the 1970s to 1990s, published articles in the orthodontic literature focused on the use of onplants, ${ }^{34,35}$ palatal implants, ${ }^{36-39}$ dental implants ${ }^{40-44}$ and ankylosed teeth ${ }^{45}$ rather than miniscrews. These types of implants were proven to have a high success rate in maximizing anchorage. ${ }^{46}$ However, due to their osseointegration, and large width and length, their insertion and removal protocols were more time-consuming and extensive. As a consequence, their use was associated with increased patient morbidity. ${ }^{27}$ Orthodontic miniscrews, on the contrary, do not osseointegrate and are therefore associated with a significantly reduced level of morbidity. They are also more cost-effective and require a simpler insertion and removal protocol. For these reasons, they are practical for routine placement in the orthodontic office setting. ${ }^{27}$

Within recent years there has been a dramatic increase in the use of bone screws as direct adjuncts to orthodontic treatment. ${ }^{4}$ In 1997, Kanomi $^{32}$ described a temporary skeletal anchorage device (TSAD) designed for orthodontics. Since its introduction, clinicians have migrated towards miniscrews for reinforced anchorage of orthodontic appliances, recognizing the significant advantages that they provide over osseointegrating techniques. 
As a result, there has been a remarkable increase in publications regarding the use of TSADs in orthodontics over the last $\operatorname{decade}^{27}$ and many case reports have been published. $^{22,47-49}$

\subsection{OMS Stability}

The clinical success of OMSs in orthodontic treatment is directly related to their stability after placement. Adequate stability of miniscrews to resist dislodgement or failure during loading is provided through mechanical retention in bone. ${ }^{50}$ It is dependent on local bone properties (quality and quantity), the engineering design of the screw and the placement technique used. ${ }^{2,51}$ Before the bone healing process occurs at the periphery of the implant, the mechanical retention of OMSs is referred to as "primary stability". In a systematic review of the literature by Chen et al, ${ }^{52}$ primary stability was identified as being the most critical assessment factor in the success of orthodontic miniscrews. The long term or "secondary stability" is dependent on the biological response of the bone surrounding the miniscrew. ${ }^{2}$ It is affected by the OMS surface composition, bone characteristics and turnover, and the mechanical retention provided by the screw design. ${ }^{2}$ Immediately after miniscrew insertion, primary stability decreases while secondary stability increases. ${ }^{2}$ The sum of both is defined as the clinical stability. ${ }^{2}$

\subsubsection{Stability Testing}

Different tests and devices are available to assess the stability of OMSs. Among the most common indirect measurement for primary stability is the moment of the force required to screw the OMS into the bone, referred to as "insertion torque". 51 Other indirect stability measures include "removal torque" and "pull-out strength" (POS), which quantify the force required for removal of the OMS. ${ }^{51}$

While these methods are useful for in vitro assessment of OMS primary stability, nondestructive test methods would be more desirable for clinical applications. ${ }^{53,54}$ Currently, there are some devices available for stability testing of dental implants in the clinical setting. ${ }^{55}$ The Periotest and Dental Fine Tester rely on an impact based technique, while Osstell® ISQ uses resonance frequency technology. ${ }^{51,54}$ These devices have started to 
gain attention within the orthodontic community and testing of their possible applications with OMSs is of current interest. ${ }^{56,57}$

\subsubsection{Insertion Torque}

A screw is a basic mechanical device that converts rotational motion into linear motion, by the engagement of its threads within the medium through which it is advancing. ${ }^{58}$ The moment of a force acting at a distance from the screw long axis is referred to as "torque". ${ }^{59}$ It is generally measured in Newton $\mathrm{x}$ meters $(\mathrm{N} \bullet \mathrm{m})$. Since orthodontic miniscrews are of small diameter, their insertion torque is more commonly measured in $\mathrm{N} \bullet \mathrm{cm} .{ }^{55}$ The torque needed to rotate the screw during its insertion into a material is referred to as "insertion torque". In biomechanical testing, the insertion torque depends on a combination of the cutting friction of the tip of the screw in bone, the friction between the screw body and the bone during insertion and the axial load needed to ensure progression of the screw. ${ }^{60}$

The insertion torque is influenced by the bone quality and quantity. ${ }^{61,62} \mathrm{~A}$ denser bone is associated with an increased torque required for screw insertion. ${ }^{62}$ Insertion torque testing is largely used in the assessment of primary stability of OMSs. ${ }^{53,61-66}$ The friction created by the advancement of the pilot drill or screw into bone (cortical and cancellous) generates heat. The heat generated has the potential to cause thermal necrosis of the surrounding bone and failure of the screw. ${ }^{58}$ As such, the screw design and the method of insertion directly influence the amount of heat being generated at insertion. ${ }^{58}$ OMSs should be inserted at a controlled force and speed to prevent failure caused by heatinduced necrosis of the bone surrounding the screw. ${ }^{67}$

\subsection{Types and Designs of OMSs}

OMSs are fabricated by multiple manufacturers and are available in multiple designs, lengths and diameters (Figure 2,3). Noble et $\mathrm{al}^{27}$ reported over 40 known manufacturers producing more than 700 different miniscrews with up to 154 screw designs possible per system. With such an extensive selection available, the choice of an OMS for orthodontic treatment can be overwhelming. Since miniscrew design influences its overall stability, ${ }^{68}$ 
a proper understanding of the different design characteristics is necessary to make the appropriate choice for a given clinical situation. ${ }^{27}$

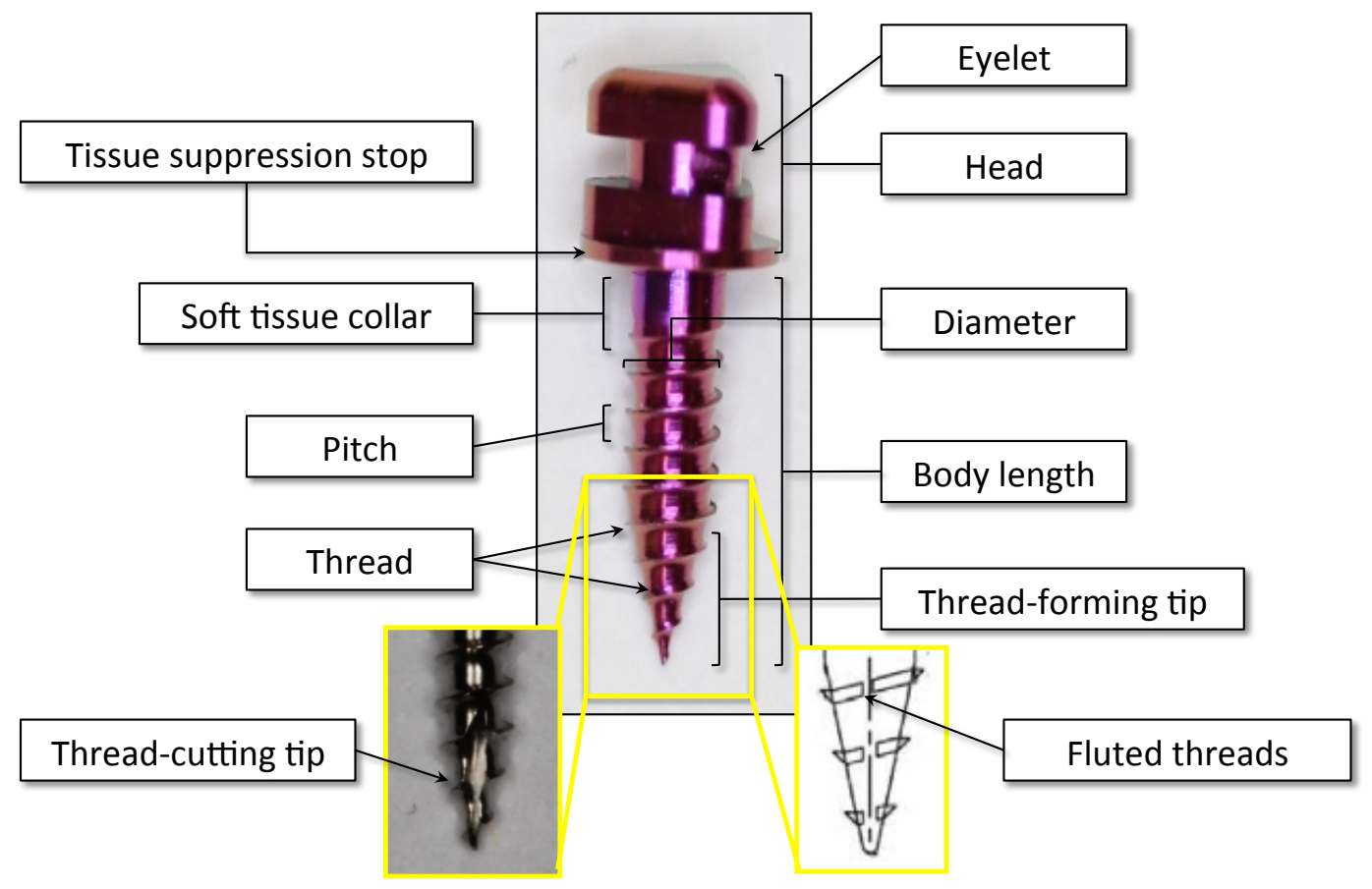

Figure 3. General OMS anatomy.

VectorTAS $^{\mathrm{TM}}, 6 \mathrm{~mm}$ (Ormco Corporation, Orange, CA, USA) used as an example.

\subsubsection{Pitch}

The pitch refers to the distance between the screw threads (Figure 3). OMS pitch is on average between 0.75 and $1.25 \mathrm{~mm} .^{27}$ The pitch is qualified as "high" or "loose" when the threads are far apart and "low" or "tight" if they are closer together. ${ }^{27}$ Its effect on primary stability is not well understood. A decrease in pitch is thought to be related to an increase in primary stability. ${ }^{27,60}$ An OMS with a low pitch also requires more revolutions at insertion associated with a slower advancement and more stress on the bone due to higher insertion torque. ${ }^{27}$ By comparison, a miniscrew with a high pitch progresses further into bone per turn and is thought to also necessitate higher torque levels for insertion. $^{60}$ 


\subsubsection{Flutes}

Flutes are defined as recessed areas in the screw's cross-sectional dimension. Their function is to carry the bone chips away from the cutting edge as the screw rotates during insertion (Figure 3). ${ }^{27,60}$ Their effect on primary stability is controversial. The presence of flutes has been reported to both increase and decrease pull out strength. ${ }^{66,69}$ It is thought that flutes of greater depth provide more mechanical interlock of the OMS and assist in increasing primary stability. ${ }^{27,65,66,70}$ This is due to the clearance of bone chips, which tend to accumulate around the threads. ${ }^{65,66,70}$ On the contrary, fluted screws exhibit decreased resistance to pull-out testing and seem to have less holding power than fully threaded screws. ${ }^{71}$

\subsubsection{OMS Length}

The length measurement comprises the threaded body and the transmucosal collar, not the entire miniscrew (Figure 3). OMSs are most commonly available in lengths of 6, 8, 10 and $12 \mathrm{~mm}$ but can be found from 4 to $21 \mathrm{~mm}^{72,73}$ The soft tissue collar length varies from 1 to $3 \mathrm{~mm} .{ }^{27}$ The determination of the appropriate length to be used is based on the quality and quantity of bone, angulation of insertion, transmucosal thickness and anatomy adjacent to insertion site. ${ }^{27}$ Based on these characteristics, different lengths are recommended in different areas of the maxilla and mandible, with a minimum of 5-6 mm preferred. ${ }^{74}$ Longer screws are recommended where bone quality is poor although few studies have assessed the effect of screw length on primary stability. ${ }^{27,75-77}$ Investigations have suggested that the thickness of cortical bone contact with the screw contributes more than the medullary bone contact in the resistance to its dislodgement. ${ }^{2}$ However, other studies have shown that the amount of contact area with the medullary bone is also a contributing factor, albeit, only minimally. ${ }^{2}$ In fact, screws of a length much shorter than thought necessary were surprisingly effective. ${ }^{78}$ Nonetheless, a long screw that passes through the alveolus reaching the opposing cortical bone does provide greater stability, but at the cost of increased invasiveness. ${ }^{79}$ 


\subsubsection{Length of screw engagement (LSE)}

The length of screw engagement (LSE), also known as the surface of the screw-bone interface, is thought to be a contributive factor to primary stability. ${ }^{80}$ Although the extent that cortical and cancellous bone contributes to stability is controversial, any increased bone contact could provide additional resistance to dislodgement under load. ${ }^{80}$ Figure 4 represents the length of screw engagement of an OMS inserted into both thick and thin bone.

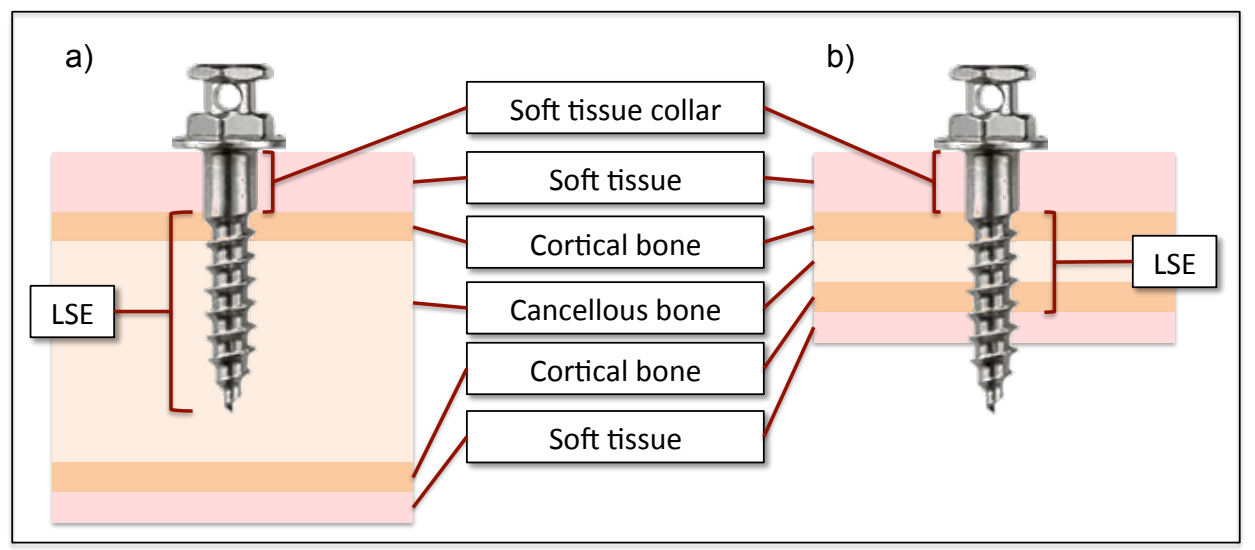

Figure 4. Length of screw engagement.

The length of screw engagement (LSE) or the surface of screw-bone interface refers to the threaded portion of the screw that is comprised between the upper and lower cortical plate border. OMS inserted in a) thicker and b) thinner material than the OMS.

\subsubsection{OMS Diameter}

The diameter of an OMS refers to the total width of the miniscrew including both its body and threads (Figure 3). OMS diameter usually ranges from 1.0 to $2.3 \mathrm{~mm}^{27}$ Selection of the proper diameter depends on the clearance between the screw and the adjacent anatomical structures (tooth roots) and the extent to which its fracture or displacement resistance is affected by a reduced diameter. ${ }^{81}$ The success rate of OMSs seems to drop drastically when the diameter is smaller than $1.3 \mathrm{~mm} .{ }^{2}$ Lee et al, ${ }^{82}$ reported increased microdamage to cortical bone when using a miniscrew of $1.5-2 \mathrm{~mm}$ diameter. Within the 1.3 to $2 \mathrm{~mm}$ range, stability and success seem to be related to the amount of cortical bone in contact with the screw rather than its diameter. ${ }^{2}$ 


\subsubsection{Taper}

Increasing OMS diameter to maximize the cortical bone-screw interface can introduce limitations at placement. The space available between roots of teeth and the anatomical structures are of primary concern. Various tapered OMSs have been designed to circumvent this inconvenience. Animal experiments have reported that tapered screws result in more microdamage to the cortical bone than cylindrical screws if head diameter exceeded that of the cylindrical screw. ${ }^{82}$ Even though primary stability is greater, microdamage might affect secondary stability of tapered screws. ${ }^{2}$ In fact, Yoo et a ${ }^{83}$ report no differences in secondary stability of conical versus cylindrical OMSs.

\subsubsection{Self-Drilling and Self-Tapping Designs}

The ease of use is one determining factor for the clinician in choosing which miniscrew to use. Some may shy away from incorporating OMSs in their practice because they may not be accustomed to performing surgical procedures. All commercially available OMSs are self-tapping, i.e. they form their own thread as they advance. ${ }^{3}$ Self-tapping miniscrews can have a thread-forming or thread-cutting tip. The thread-forming tip allows bone compression around the thread as the OMSs advance. The thread-cutting end has either a notch parallel to the miniscrew's long axis or a sharpened thread (flute) that cuts into bone as the miniscrew is inserted (Figure 3). ${ }^{27}$

Self-drilling OMSs do not necessitate the use of a pilot hole before insertion. ${ }^{2}$ The sharp edge allows an initial puncture into the cortical plate. If the cortical plate is hard to penetrate, a pilot hole may be indicated to minimize the insertion torque. ${ }^{2}$ This design is preferred by most orthodontists when compared to the pre-drilled one that necessitates a pilot hole to be drilled before insertion. This is reflected by the results of a 2008 survey developed by the American Association of Orthodontists on miniscrew usage. ${ }^{70}$ The majority of the respondents never drill a pilot hole prior to miniscrew insertion. ${ }^{84}$ In addition to a simpler surgical technique, the self-drilling design requires less time and generates less overall stress and heat in the bone. ${ }^{27}$ This may increase initial stability and decrease the number of complications resulting from the insertion technique. ${ }^{27}$ The tip of the miniscrew differs between self-drilling and self-tapping designs. Self-drilling 
miniscrews have a sharp tip with a tapered apex or a notch that allows self-drilling into denser bone. $^{27}$

\subsubsection{Screw Threads}

The screw surface characteristics do not seem to be of major influence on miniscrew stability. ${ }^{85}$ Animal studies suggest that a roughened surface (acid-etched and/or sandblasted) increases primary stability and allows immediate loading. ${ }^{86}$ Most commercially available OMSs, however, are manufactured with a smooth, machinepolished surface and still satisfy clinical requirements. This surface treatment is believed to prevent osseointegration and allow simple removal. ${ }^{27}$

The screw threads can have different designs (Figure 5). They can be symmetric, or asymmetric (buttress). The symmetric design is V-shaped, with congruent leading and trailing angles. The asymmetric design has a leading angle located toward the tip, $45^{\circ}$ to the long axis of the shaft and a trailing angle located towards the head, $90^{\circ}$ to the long axis of the shaft. ${ }^{27}$ Threads are designed to improve initial stability of TSADs increasing bone-screw surface area and to provide a better distribution of stress during insertion and removal. Although it would appear intuitive that the buttress design would provide better mechanical interlock and resistance to pullout strength test, no studies were identified in the orthodontic literature assessing the effect of the thread design on primary stability. ${ }^{27}$

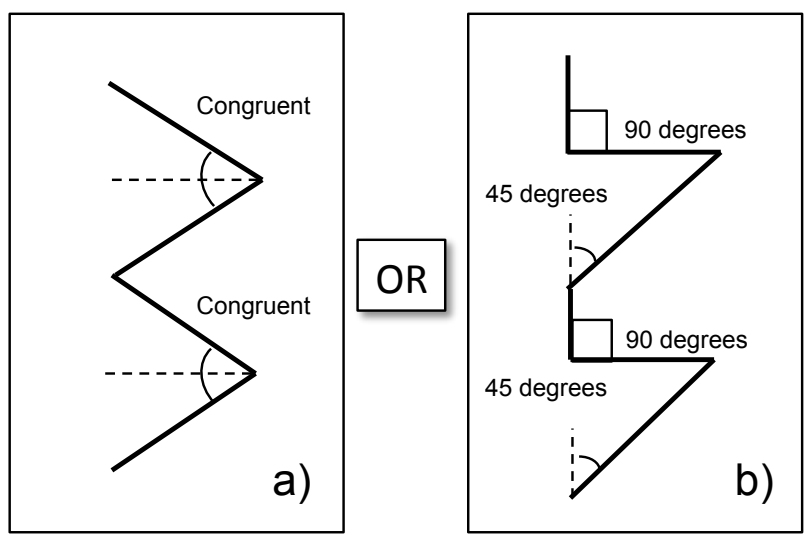

Figure 5. Different screw thread designs

a) Symmetric (V-Shaped) design and b) asymmetric (buttress) design 


\subsubsection{Head Design}

The head design is of great importance to allow attachment of coil springs, elastics or orthodontic wire (Figure 3). The head is usually designed with a button/sphere, some of which contain an eyelet or may be shaped like a bracket. Although those designs seem to be most popular, a variety of designs are available from the different manufacturers. ${ }^{27}$

\subsection{Insertion Site}

When choosing an insertion site, areas of attached keratinized gingiva are preferred to loose alveolar mucosa to decrease inflammation, tissue overgrowth and enhance patient comfort. ${ }^{87}$ In the presence of thick mucosa, the use of a tissue punch may be necessary prior to OMS insertion. ${ }^{27}$ When considering the hard tissue quality and quantity, adequate density and thickness of cortical bone are important to ensure primary stability (Figure $6)^{27}$

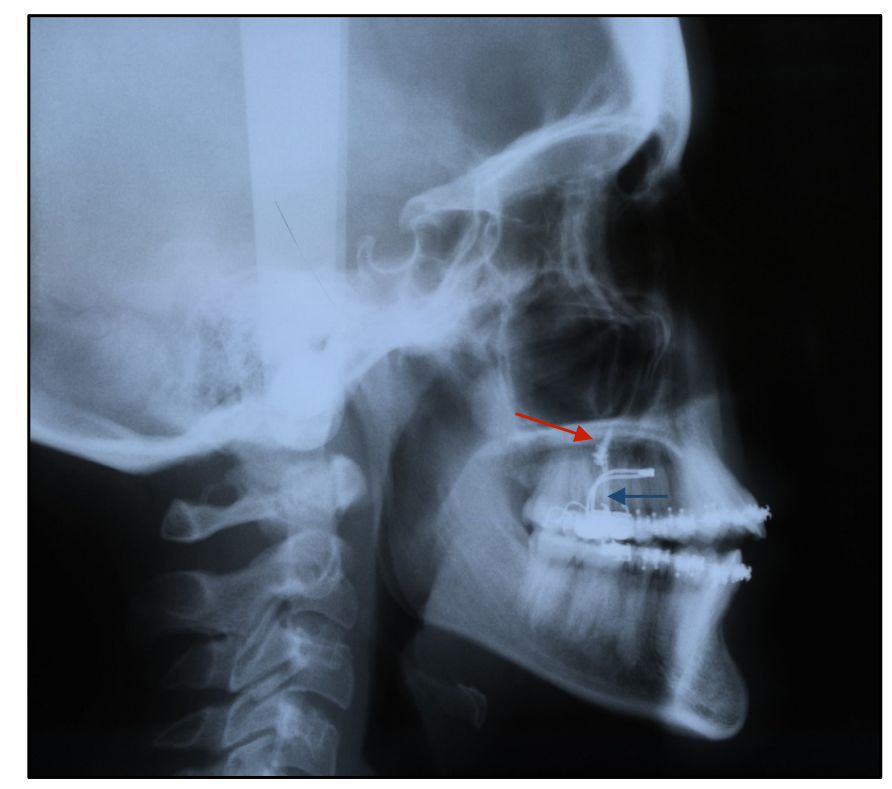

Figure 6. Lateral cephalometric radiograph of the case described in Figure 1.

The location of the OMSs is represented by the red arrow. The closed coil springs (blue arrow) are also visible and represent the force vector chosen for maxillary posterior tooth intrusion and anterior open-bite closure.

The most common sites for miniscrew insertion include the lateral aspect of the hard palate, the midpalate, interradicular sites in the anterior and posterior maxillary and 
mandibular alveolar bone, the lower anterior region, and the mandibular retromolar area. ${ }^{88}$ However, the appropriate site for miniscrew placement is ultimately determined by the clinician after careful consideration of the anchorage required to accomplish the desired tooth movement (Figure 6). When proceeding with the insertion of a miniscrew, the clinician must be aware of the anatomical limitations present including the softtissues, interradicular distance, sinus morphology, nerve and blood vessel locations and bone depth. ${ }^{89}$

\subsection{The Maxillary Hard Palate}

\subsubsection{Anatomy}

The hard palate confers significant advantages for miniscrew placement. It is surgically very accessible and offers excellent peri-implant conditions due to the presence of attached mucosa. ${ }^{46,90}$ In addition, OMSs in the palate will not hinder tooth movement during treatment. ${ }^{46,90}$ The high success rate of palatal miniscrews and the versatility of their appliance designs explain the increasing popularity of the palate as an insertion site. ${ }^{91}$ However, it is not without disadvantages. The main disadvantages are the possible lack of vertical bone thickness, and its anatomical variability among patients. ${ }^{92}$ Other concerns include the possibility of perforation into the nasal or sinus cavity, interference with the incisive canal or the roots of adjacent teeth, and the possible affect on the midpalatal suture in growing patients. ${ }^{93,94}$ When inserting a miniscrew in the maxillary hard palate, there is a need for more profound anesthesia due to the tightness of the soft tissue. $^{27}$

\subsubsection{Soft Tissue}

The palatal soft tissue is generally thick and keratinized making it a desirable site for OMS placement. ${ }^{95}$ With the increasing popularity of palatal sites for OMS placement, $\mathrm{Vu}$ et $\mathrm{al}^{95}$ measured the palatal soft tissue thickness at popular placement sites using conebeam computed tomography. They noted no antero-posterior difference in its thickness. ${ }^{95}$ However, medio-laterally the thinnest soft tissue was found at the midpalatal suture whereas the lateral area presented with thicker tissue. The thickness was reported to be approximately $1.0-1.3 \mathrm{~mm}$ along the midpalatal suture, $1.3-1.7 \mathrm{~mm}$ medially and 2.3-3.0 
$\mathrm{mm}$ laterally. They also noted no significant differences related to gender and age. Both the quality and quantity of hard and soft tissue plays a role in OMS stability. ${ }^{95}$ For maximum retention and minimum inflammation, a site with thicker cortical bone underlying thinner attached gingival tissue is recommended. ${ }^{95}$

\subsubsection{Bone Characteristics}

Palatal bone quantity refers to the amount of bone height available for OMS placement. There is considerable data in the orthodontic literature regarding palatal bone quantity. Winsauer et $\mathrm{al}^{92}$ conducted a systematic review investigating the available information on the vertical palatal bone height (quantity) available for mini-implant placement. A total of 16 studies were included. Following their investigation, they noted heterogeneity in subjects used, measurement sites and methods, and software used for data interpretation between studies. Pooling of the data was not possible due to its heterogeneity. After compilation, they suggested that the region 3-4 mm behind the incisive foramen and 3-9 $\mathrm{mm}$ lateral to the midpalatal suture should normally provide sufficient vertical bone height (VBH) for anchors. ${ }^{92}$ Ludwig et al ${ }^{96}$ provided anatomical guidelines for palatal miniscrew insertion considering both palatal hard and soft tissue as well as the presence of blood vessels and nerves. The suggested safety zone was a " $T$ " design where the horizontal part lies along the lingual cusps of the permanent first premolar and the vertical portion extends posteriorly to the level of the permanent first molars.

In spite of these recommendations, clinicians have been placing miniscrews adjacent to the midpalatal suture in a more posterior location with great success. ${ }^{15}$ These methods have been employed with the objective of meeting the anchorage requirements for the desired orthodontic movements, such as molar intrusion or anterior retraction. ${ }^{15}$ Even though the paramedian palatal bone thickness appears to decrease posteriorly, the skeletal anchorage provided by the OMSs seems to be sufficient. ${ }^{15}$

Bone quality is more ambiguous to define since there is no consensus regarding its definition. ${ }^{97}$ Bone quality comprises multiple aspects of bone physiology, its degree of mineralization, morphology and type of trabecular pattern. ${ }^{97}$ The orthodontic literature refers to bone quality as its density and is most commonly assessed radiographically. The 
current knowledge regarding bone density at the common OMS insertion sites include little information regarding the maxillary hard palate. ${ }^{61,98-100}$ Only one study was identified where Moon et $\mathrm{al}^{101}$ noted that palatal BMD decrease from anterior to posterior and medial to lateral.

All information considered, the maxillary hard palate appears to be a promising site for miniscrew insertion, where good primary stability of orthodontic miniscrews should be obtained. ${ }^{102}$ However, to the author's knowledge, there is currently no reported data on the primary stability of OMSs in the maxillary hard palate.

\subsubsection{Medical Imaging in OMS Treatment}

Palatal bone quality and quantity varies among individuals. However, it may not be feasible in orthodontic practice to obtain precise information for a given patient. ${ }^{103}$ The current methods available to aid in assessment include determination of patient's age, the performance of a clinical examination and the use of a panoramic or cephalometric radiograph. Unfortunately, these have been proven to be inadequate measures of bone quality and quantity for this purpose. ${ }^{38,104}$

The use of lateral cephalograms for the determination of palatal bone characteristics is limited to the assessment of the paramedian palatal vertical bone height (VBH). Studies have shown that cephalometric radiographs reflect the minimum rather that the maximum bone height available for paramedian miniscrew placement. ${ }^{104}$ As described by Wehrbein et $\mathrm{al}^{38}$, the true vertical bone height in the midsagittal part of the anterior and mid-section of the palate is $2 \mathrm{~mm}$ greater than estimated from a cephalometric radiograph. For that reason, a lateral radiograph has the potential to show a midsagittal miniscrew with a demonstrable perforation into the nasal cavity when, in fact, it is contained in the bony structure. ${ }^{92}$ As such, this should be accounted for when determining paramedian VBH from a cephalometric radiograph.

Cone beam computed tomography (CBCT) can give a reliable estimate of the bone quality and quantity. ${ }^{92}$ Studies comparing measures taken from anatomic or histologic specimens have validated the accuracy of $\mathrm{CBCT}$ in the measure of palatal bone 
thickness. ${ }^{92}$ Due to the increased radiation dose and expense, this radiographic technique is suggested only when an insufficient bone thickness is interpreted from a lateral radiograph. ${ }^{105}$

In vitro, micro-computed tomography (microCT) imaging and histology are considered the gold standard for assessing bone quality and quantity. ${ }^{97}$ MicroCTs utilize relatively high radiation doses to provide non-destructive 3D microscopy images of great precision. The performance, quality of images, accuracy and reproducibility of its measurements make it a superior assessment tool to conventional computed tomography (CT) and CBCT devices. ${ }^{107-109}$ As such, its use for analysis and measurement of anatomical bony structures is well documented within the orthopedic literature. ${ }^{110-112}$ However, due to the associated increased radiation dose, it is not used on living humans.

\subsection{Risks and Complications}

Several complications associated with the use of OMSs have been reported in the literature, which result from anatomical, biological and mechanical limitations. ${ }^{113,114}$ At the time of placement, injury to adjacent structures (periodontal ligament, tooth root, nerves, blood vessels, or sinus) is one such risk. ${ }^{113}$ In such situations, it is advised that the miniscrew should be removed and inserted in a different location.

The injury of a root can potentially result in devitalization, osteosclerosis or ankylosis. ${ }^{27}$ When placing a miniscrew between the roots of teeth, the clinician should ensure that enough space is present. A periapical radiograph at 90 degrees to the tooth can be taken after placement to ensure the safety of the screw location before loading. ${ }^{27}$ Since miniscrews do not osseointegrate, they are not entirely stable. Movement of $1 \mathrm{~mm}$ to 1.5 $\mathrm{mm}$ of the device can be expected during treatment. ${ }^{115}$ For this reason, it is advisable to leave a clearance of $2 \mathrm{~mm}$ from the roots of teeth, nerves, and other such structures. ${ }^{115}$

Adequate knowledge of facial anatomy is critical to prevent insertion into a nerve. The nerves close to common insertion sites include the inferior alveolar, mental, greater palatine and lingual nerves. Minor injury is usually transient and recovery occurs in 6 
months. A nerve injury manifests as a paresthesia and treatments involve corticosteroids, microneurosurgery, nerve grafting and laser therapy. ${ }^{116}$

Perforations into maxillary or nasal sinuses have also been reported following OMS insertion. A shorter OMS $(6 \mathrm{~mm})$ is suggested in areas where a risk of perforation is identified. ${ }^{27}$ If a sinus perforation of less than $2 \mathrm{~mm}$ occurs, it has been reported that healing will be without complications and the perforation is not likely to impact OMS

primary stability. ${ }^{116}$ The long-term effect of a perforation into the nasal cavity is not known.

Inflammation and infection of tissues surrounding the miniscrew are common and generally perceived as significant problems. ${ }^{113}$ Spontaneous healing usually occurs after miniscrew removal and antibiotics are rarely needed, except for extreme symptoms. ${ }^{113}$ To prevent soft tissue irritation and inflammation, a site with firm attached gingiva is usually preferred rather than movable mucosa. Other measures include the use of healing cap abutments, meticulous oral hygiene and $0.2 \%$ chlorhexidine mouth rinses. ${ }^{113}$

Other complications include fracture of the miniscrew, at insertion or removal, air embolus or emphysema and overheating of the bone. ${ }^{117}$ In order to prevent fracture, it is recommended to avoid using a miniscrew with a diameter less than $1 \mathrm{~mm}^{117}$ and to utilize a torque-limiting driver. ${ }^{118}$ To avoid embolus and emphysema in areas of loose alveolar tissue, air should not be used when drilling a pilot hole and the air-water syringe discarded. ${ }^{27}$ Finally, to control overheating of the bone, irrigation should be used when drilling a pilot hole. ${ }^{27}$

\subsection{OMS Success Rate}

Studies are inconsistent in their definition of OMS success and failure. ${ }^{27}$ Some report failure when an OMS is loose and/or there is presence of inflammation of the surrounding mucosa, even when still functional. As per Noble, ${ }^{27}$ only an OMS that must be removed prior to achievement of its purpose, regardless of mobility or inflammation, would qualify as a failure. Due to this inconsistency, published papers that report the failure rate of OMS provide a large range of results. Compiling the results of three systematic 
reviews, ${ }^{72,73,119}$ and numerous clinical trials, ${ }^{117,120,121}$ the overall success rate of OMSs appears to be approximately $80 \%$. Within the limitations of the available studies, Crismani et $\mathrm{al}^{72}$ found a mean success rate higher in the maxilla than in the mandible $(87.9 \% \pm 7.6 \%$ vs. $80.4 \% \pm 8.5 \%)$. This study also reports the high success rate of palatal implants, which was found to range from $90-95 \% .{ }^{72}$ Unfortunately, the success rate of palatal OMSs is not reported.

Factors known to influence the success rate of OMSs include the experience of the clinician, the use of a pre-drilled versus self-drilling technique, the soft tissue thickness versus the miniscrew length, angle of insertion, surgical technique, sterilization protocol, immediate loading, pressure and torque applied during insertion, the engagement of one or two cortical plates and the bone quality and quantity. ${ }^{27}$ In addition, any force vector applied in a direction that could unscrew the $\mathrm{OMS}^{33}$ or excessively load it ${ }^{122}$ can lead to its loosening.

As previously mentioned, the success of OMS stability is also influenced by the quality of the cortical bone present, the type of surrounding soft tissue, ${ }^{98}$ oral hygiene, root proximity, age of the patient, screw diameter, length and thread design. ${ }^{113,123,98,124}$

There is also a desirable range reported of IT measurements where OMS success is maximized. An IT value below the lower limit ${ }^{125,126}$ can lead to poor primary stability and miniscrew loosening during its use due to inadequate mechanical retention into bone. In contrast, an IT value above the upper limit ${ }^{14,127}$ can also lead to miniscrew loosening due to excessive microdamage of the surrounding bone and corresponding necrosis at the screw periphery. Motoyoshi et al ${ }^{127}$ suggest an IT range from 5 to $10 \mathrm{Ncm}$ to insure OMS success when pre-drilling of the bone is necessary. Ideal IT values are not available for self-drilling OMSs.

\subsection{Problem Statement}

Since the introduction of miniscrews for orthodontic anchorage, their primary stability has been extensively studied. ${ }^{54,63,100,128,129}$ Materials for testing stability have included synthetic bone blocks, animal osseous material and human cadavers. ${ }^{99,114,130}$ In vivo 
testing can be difficult due to the limited noninvasive measurement techniques available. ${ }^{53,54}$ Several studies have attempted to quantify and qualify the palatal bony structures. ${ }^{92,131}$ However, since the palate has only recently been suggested as a primary site for mini-implant insertion, limited in vivo and cadaveric studies investigating palatal OMS primary stability currently exist..$^{99,132,133}$

\subsection{Purpose}

To assess the quality (bone mineral density) and quantity (bone thickness and length of screw engagement) of bone at different regions of the maxillary hard palate in human cadavers using microCT imaging and to determine their effect on the primary stability (measured by insertion torque) of inserted OMSs.

\subsection{Null Hypothesis}

It is hypothesized that different regions of the maxillary palate will show no variations in density and thickness of bone, with corresponding similarities in primary stability of inserted OMSs. 


\section{Materials and Methods}

\subsection{Selection of Palatal Sites and Grid Design}

After a thorough review of the published literature, a grid system was created for identification of palatal sites used for bone analysis and stability testing (Figure 7). The objectives were to include the most commonly reported palatal insertion sites, as well those that could be used for OMS insertion without hindering important anatomical structures such as nerves and blood vessels. ${ }^{92}$ The midpalatal suture was excluded from analysis due its variability ${ }^{134}$ and possible growth disturbance in growing individuals. ${ }^{93,94}$ In the custom designed grid system (Figure 7), the green region represents the currently recommended areas for safe placement. ${ }^{92}$

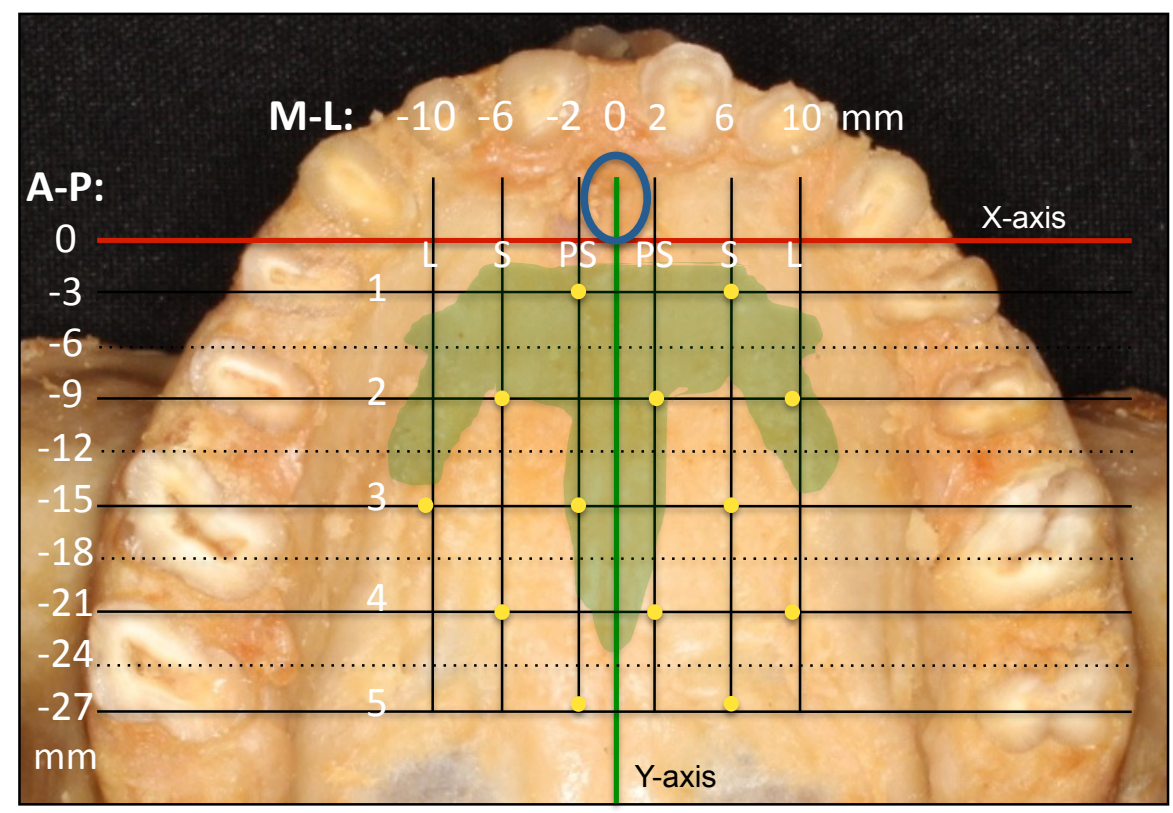

Figure 7. Grid system representing the pre-determined insertion sites.

Coordinate $(0,0)$ represents the posterior border of the incisive foramen at the midpalatal suture (blue circle). M-L: $4 \mathrm{~mm}$ increments starting $\pm 2 \mathrm{~mm}$ from the midpalatal suture. A-P: $6 \mathrm{~mm}$ increments starting

$3 \mathrm{~mm}$ posterior to the incisive foramen. The green area represents the currently reported safe area for OMSs insertion. ${ }^{\mathbf{9 2 , 9 6}}$

The grid system was designed based on a coordinate system where the $(0,0)$ coordinate represents the posterior border of the incisive foramen at the midpalatal suture. An $\mathrm{X}$ and 
Y coordinate system was constructed from this reference point. The Y-axis runs through the midpalatal suture and the $\mathrm{X}$-axis is tangent to the posterior border of the incisive foramen and perpendicular to the $\mathrm{Y}$-axis. The $\mathrm{X}$-axis is also coincident with the distal aspect of the maxillary permanent canines as found in many other studies. ${ }^{91,143}$ Parallel lines to both axes, in the antero-posterior (A-P) and medio-lateral (M-L) direction were created.

In the A-P direction, the initial line was $3 \mathrm{~mm}$ posterior to the reference line (0) with the subsequent lines in increments of $6 \mathrm{~mm}$ from the initial (-3). These reference lines were chosen to correspond with dental landmarks, and allow sufficient space between OMSs for insertion. Typically, the first line (-3) represents the level of the first premolars, the second (-9) the level of the second premolars, the third (-15) the level of the first molars, the fourth $(-21)$ the contact point between the first and second molars and the fifth $(-27)$ the level of the second molars (Figure 7).

For the M-L direction, the initial lines were $\pm 2 \mathrm{~mm}$ lateral to the reference line (0) (i.e., paramedian region), with subsequent lines located in $4 \mathrm{~mm}$ increments from the initials (2 and +2 ). In order to test all of the points on the grid system, and to preserve an acceptable distance between the miniscrews for testing, the insertion sites were staggered between the right and left side of each specimen to include all the intersection points (Figure 7). This technique was deemed acceptable since Gracco et a ${ }^{135}$ demonstrated that there was no significant difference in bone thickness between contralateral sides of the palate for the same individual. A total of 13 sites were tested on each specimen.

Once insertion sites were determined, they were renamed in order to simplify their nomenclature (Figure 7). In the M-L direction the right and left lines were named according to their proximity to the midpalatal suture. The closest is the para-sagittal line (PS), the middle is the sagittal line (S) and the most lateral line was termed lateral (L). This nomenclature applies to the right and left hemi-palate. In the A-P direction, a numeric order (1-5) was given according to their proximity with the incisive foramen. 


\subsection{Specimen Specification and Preparation}

All cadaveric specimens were obtained with permission from the body bequeathal program at Western University (London ON, Canada), in accordance with the Anatomy Act of Ontario and Western's Committee for Cadaveric Use in Research. A total of ten embalmed human cadaveric heads ( 7 Males, 3 Females) were obtained from the Department of Anatomy and Cell Biology of Western University. Specimen gender was not a specific requirement as Gracco et $\mathrm{al}^{135}$ showed no statistically significant difference in palatal bone thickness between genders. The Western University preservative solution is composed of ethanol, propylene glycol, methanol, phenol and formaldehyde (Wessels \& Associated, Cambridge, ON, Canada).

For inclusion in this study, specimens were required to meet the following criteria: intact and complete (right and left) maxillary palatal bone, full or partial dentition with at least four anterior teeth present, absence of palatal torus and bony pathology involving the maxilla. The presence of the anterior dentition is important to insure comparable anatomical incisive canal outlines between specimens. ${ }^{136}$ Age at death was not a specific criterion due to the limited number of specimens available. The different samples were assigned an identification number, which was used to retrieve specimen medical information. Specimen information is depicted in Appendix 1.

The embalmed human heads were sectioned using a $B I R O_{\circledast}$ meat saw (Model \#22, Marblehead, Ohio, USA). Cuts were performed such that the maxilla, including the palatal bone, the alveolar process, portion of the frontal and zygomatic process, the nasal septum and the teeth were separated from the rest of the skull (Figure 8).

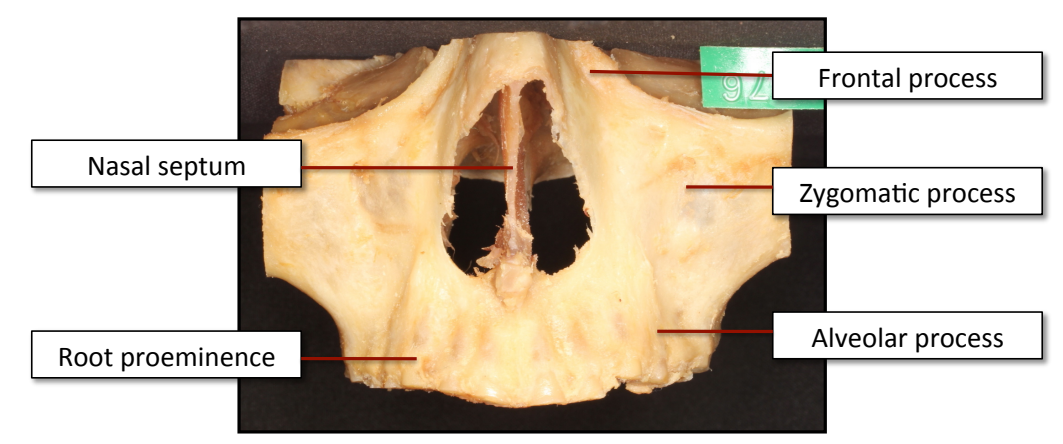

Figure 8. Anterior view of a specimen after isolation and dissection. 
Attention was directed towards preserving enough bony structure coronal to the maxillary palate for embedment support in acrylic (Figure 8-10). The first cut was oriented horizontally and coronal to the orbital floor. The second and third cuts were oriented vertically and about $1 \mathrm{~cm}$ lateral to the alveolar process on both right and left side. The maxilla was then separated from the rest of the skull by cutting the soft tissues posteriorly. The remaining soft tissues were dissected with basic hand dissection instruments (surgical scalpel and blade no.10, periosteal elevator, hemostats and scissors) to eliminate specimen variability and standardize the length of screw engagement (LSE) during miniscrew placement. Special care was taken to avoid damaging the underlying bone. The crowns of the teeth were subsequently removed using a Stryker autopsy saw (Model \#810, MOPEC, Oak Park, MI, USA), with the objective of eliminating any metal substance from dental fillings that could interfere with X-Ray transmission during microCT imaging.

Once the specimens were fully dissected, they were embedded into acrylic blocks with the teeth facing superiorly. This was accomplished by securing the specimens in the centre of a square plastic container using boxing wax strips $\left(\mathrm{KaVo}, \mathrm{Kerr}^{\mathrm{TM}}\right.$, Orange, CA, USA), ensuring that the palatal plane was approximately horizontal, and pouring selfcure Orthodontic Resin (DENTSPLY Caulk, Woodbridge, ON, Canada) into the plastic container around the specimens. The plastic container served as a template to standardize the acrylic bases. The acrylic level was carefully controlled leaving approximately $1 \mathrm{~cm}$ of clearance below the nasal floor (Figure 9).

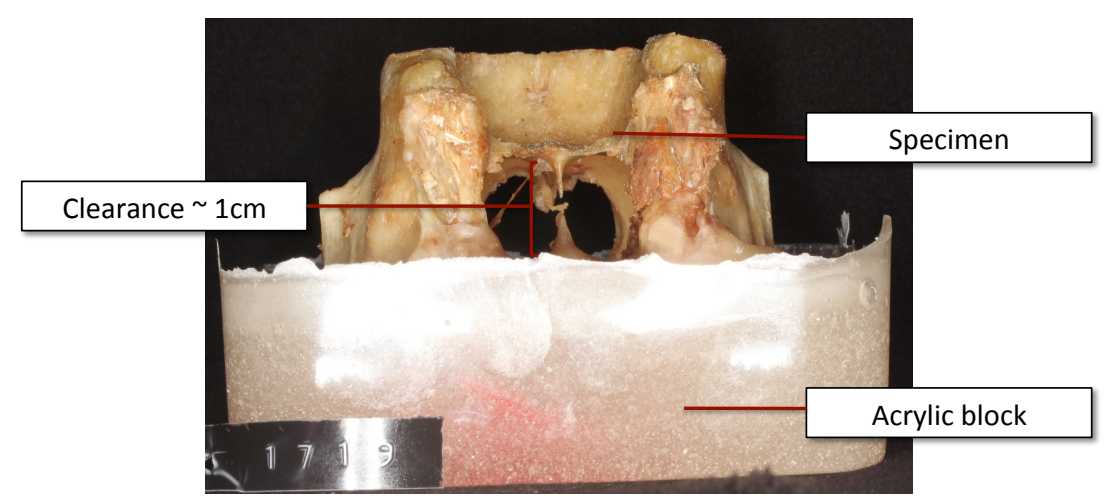

Figure 9. Posterior view of a specimen embedded in acrylic block. Note the $1 \mathrm{~cm}$ clearance between the nasal floor and the acrylic level. 
Preserving access to the palate and nasal floor was important in order to assess any penetration of the miniscrews into the nasal cavity and to avoid interferences during insertion. The bases were placed in a cool water bath to dissipate any heat generated during curing of the acrylic. Once cured, the acrylic blocks were removed from the plastic container.

Two radio-opaque stainless steel beads $0.5 \mathrm{~mm}$ in diameter were placed at anterior and posterior locations on the midpalatal suture of each specimen, with the objective of identifying the midpalatal suture on subsequent microCT images (Figure 10). The anterior bead was positioned at the anterior border of the incisive foramen and the posterior bead on the posterior nasal spine.

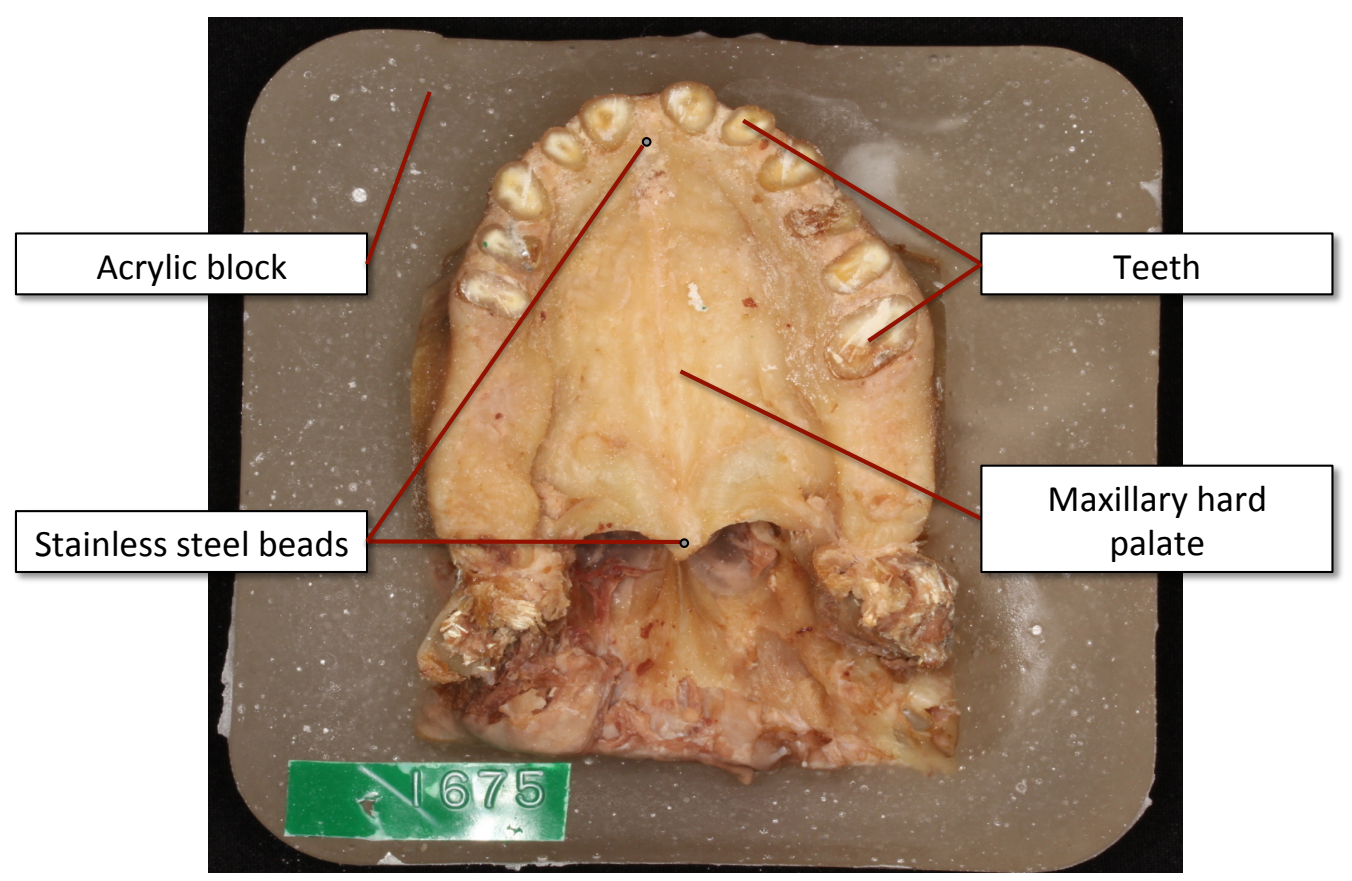

Figure 10. Occlusal view of a specimen embedded in acrylic block.

A 3/8-inch poly(methyl methacrylate) (PMMA) sheet was used to fabricate a stencil for accurate reproduction of the grid system onto the specimens (See Appendix 2). Each specimen was fixed onto a multiaxis clamp used to orient the maxillary hard palate parallel to the horizontal. The grid stencil was mounted at a distance of approximately 5 $\mathrm{cm}$ above the specimen and a level placed on the stencil ensured fully horizontal positioning of the grid over the specimen (Figure 11). The specimens were centered 
under the grid and visual inspection was carried out to ensure correct positioning before grid transfer. Stainless steel (ss) wires and fabric paint (Tulip ${ }^{\circledR}$, Fresno, CA, USA) were used for marking the pre-determined insertion sites onto the specimens (Figure 12). A different colour was used for each of the previously described sites; PSs (orange), Ss (blue), Ls (green) (Figure 13).

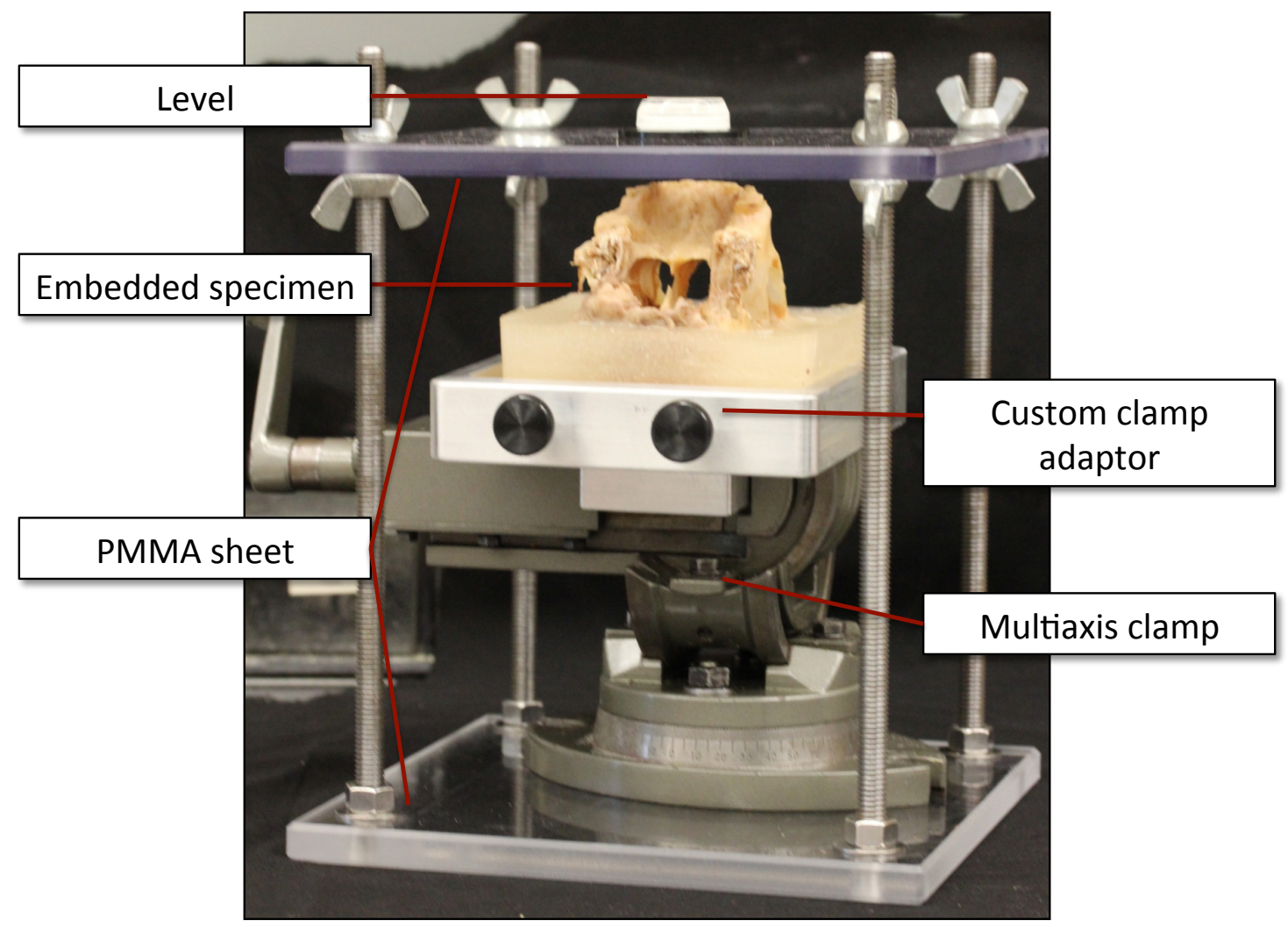

Figure 11. Position of the specimen under PMMA stencil. 


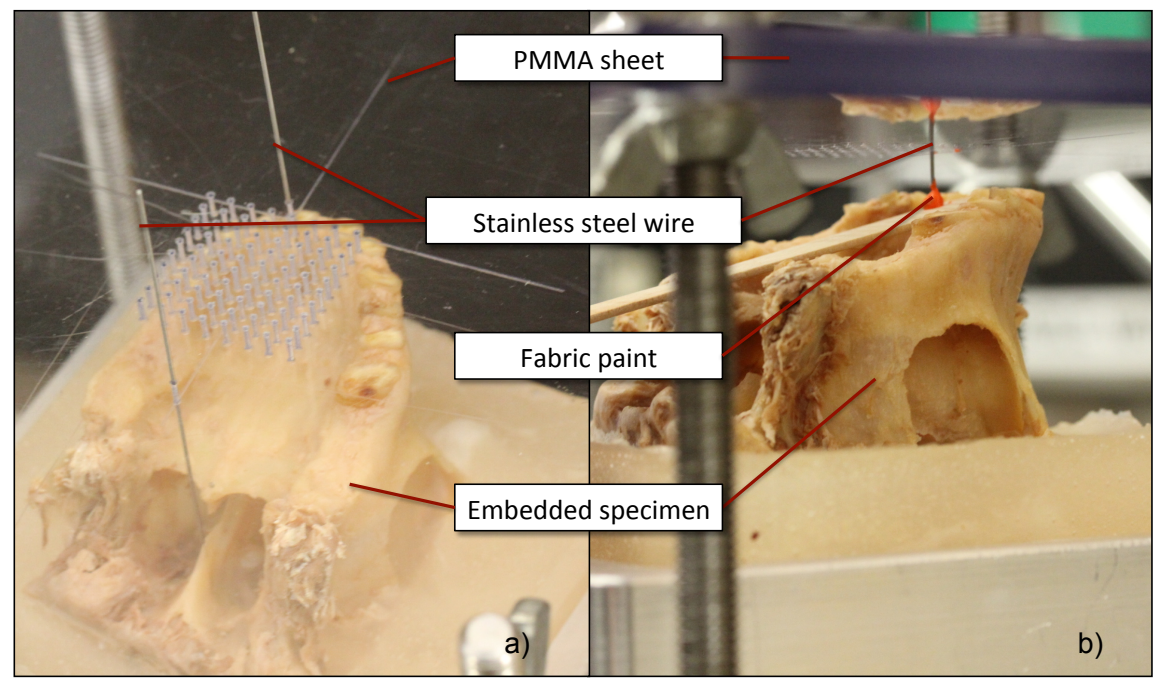

Figure 12. Methodology for transferring of the grid system onto the specimens.

a) Alignment of the specimen with the $\mathrm{X}$ and $\mathrm{Y}$ axes using ss wire.

b) Transfer of the grid system using fabric paint and ss wire.

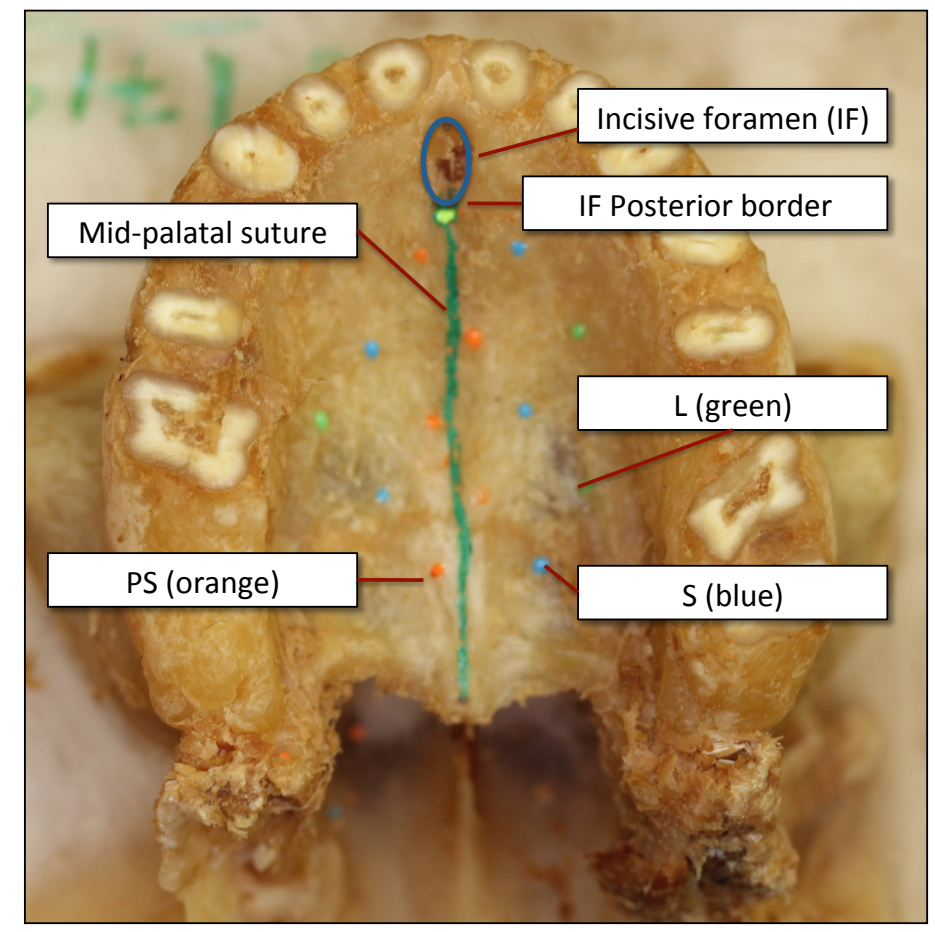

Figure 13. Insertion sites marked on specimen with fabric paint.

The lateral sites (L) are identified in green, the parasagittal sites (PS) in orange, and the sagittal sites (S) in blue. 


\subsection{Orthodontic Miniscrews}

One hundred and thirty (130) self-drilling VectorTAS $^{\mathrm{TM}}$ miniscrews (length $=6 \mathrm{~mm}$, diameter $=1.4 \mathrm{~mm})$ were used for insertion at the pre-determined insertion sites $(\mathrm{n}=10)$ of the specimens (Figure 14, Appendix 3). All miniscrews were self-drilling, and as such, pre-drilling of the cortical bone was not required.

To replicate the average human palatal soft tissue thickness determined by $\mathrm{Vu}$ et $\mathrm{al}^{95}$, a silicone spacer (thickness $=1 \mathrm{~mm}$ ) was installed on each miniscrew before insertion (Figure 15). The spacer covered the soft tissue collar of the miniscrew, leaving $5 \mathrm{~mm}$ of the body length available for insertion into bone. The miniscrews were manually inserted by a single operator (CB) simulating typical clinical technique with a rate of approximately 20-30 RPM and a minimum compressive load capable of inducing selfdrilling and screw thread engagement. The corresponding peak torque value reached during OMS insertion was recorded in $\mathrm{Ncm}$.

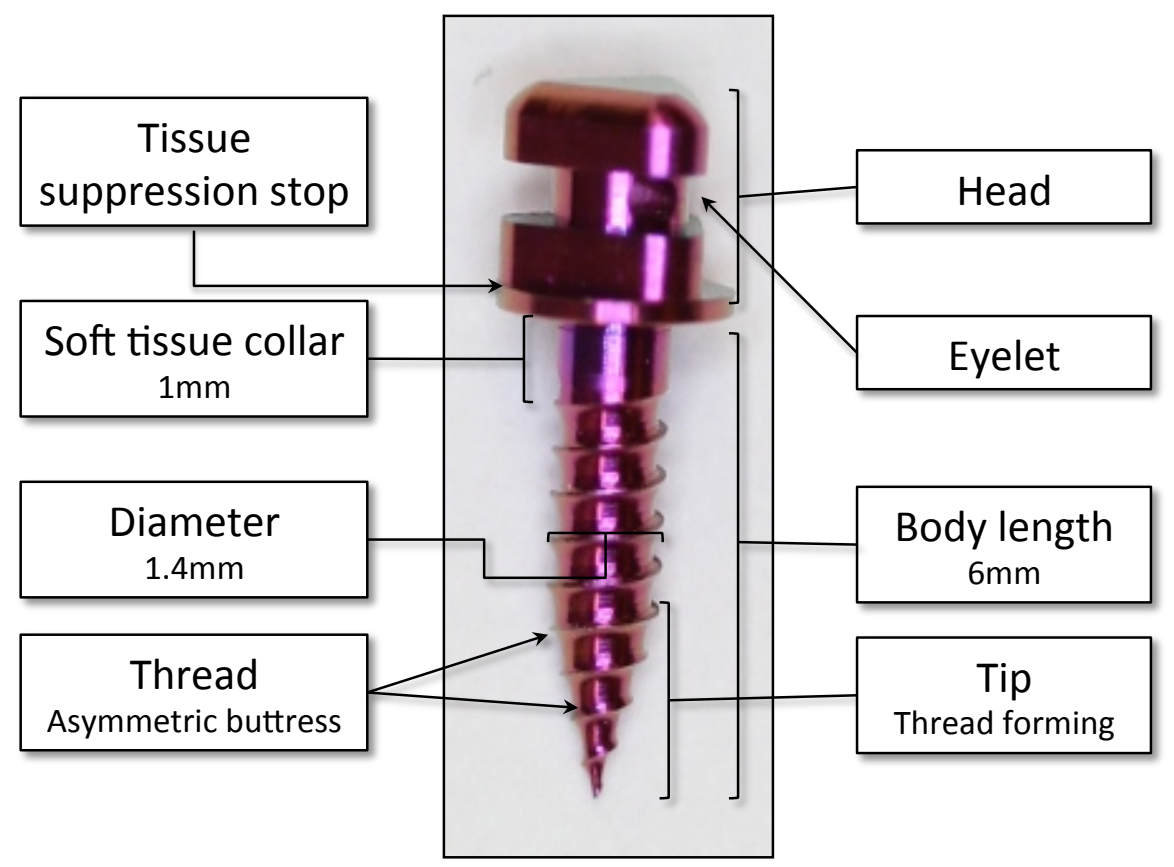

Figure 14. VectorTAS ${ }^{\mathrm{TM}} 6 \mathrm{~mm}$ OMS anatomy. 


\subsection{Insertion Mechanics and Primary Stability}

All specimens were scanned prior to and after miniscrew insertion using microCT imaging (eXplore Locus Ultra ${ }^{\circledR}$, General Electric Healthcare, Milwaukee, WI, USA) (See section 2.5). Insertion testing of the OMSs, and all related manipulations, were performed at the Biomechanical Testing Laboratory, Thompson Engineering Building, Western University. The custom-made device used for manual insertion of the miniscrews is illustrated in Figure 15.

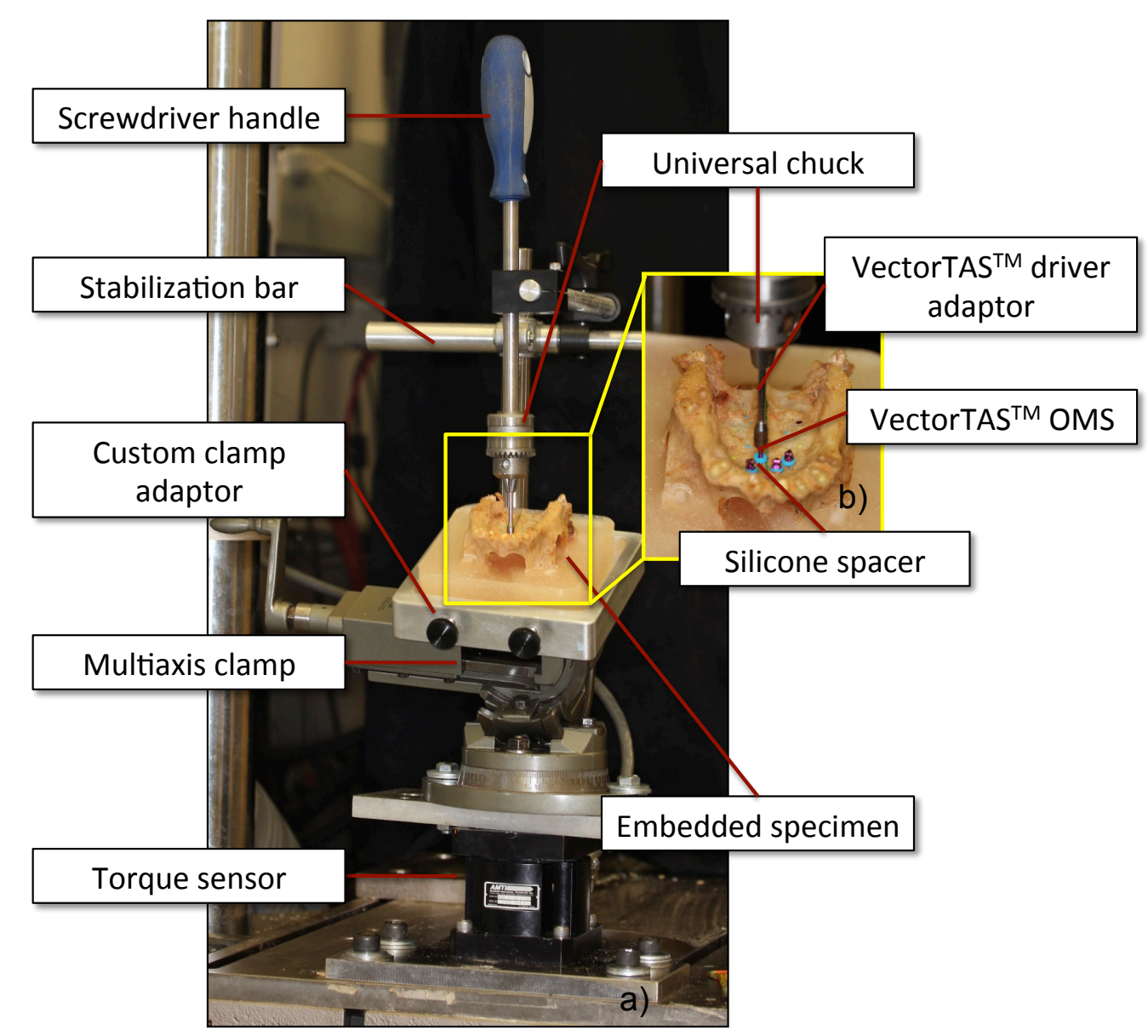

Figure 15. Custom apparatus used for OMS insertion.

a) Specimen mounted on the apparatus.

b) Close-up of a VectorTAS ${ }^{\mathrm{TM}}$ miniscrew during insertion.

The insertion device consisted of a screwdriver with chuck that secured the manufacturer's specific driver adaptor and was used to engage the miniscrew heads 
(VectorTAS Driver Tip, Orange, CA, USA). The screwdriver handle was held in place by a stabilizing bar, which was specifically designed to support the driver shaft and prevent oblique forces during manual screw placement. This allowed the miniscrews to be inserted vertically, without introducing off-axis loading along their length.

For insertion of miniscrews, the embedded specimens were fixed at the base of the insertion device within the custom adaptor, and secured onto the torque sensor. A multiaxis clamp was used to position the specimens at the centre of a torque sensor (6 DOF load cell, Advanced Mechanical Technology Inc., Watertown, ME, USA), and adjusted prior to each miniscrew insertion, to ensure that the miniscrew was inserted perpendicular to the bone surface. The torque sensor and associated software program (Instron WaveMatrix Software, Instron ${ }^{\circ}$ Norwood, MA, USA) measured and recorded maximum torque during miniscrew insertion (i.e., insertion torque) (Figure 16). Calibration of the sensor was completed before insertion of each OMS to reduce any systematic errors in the setup.

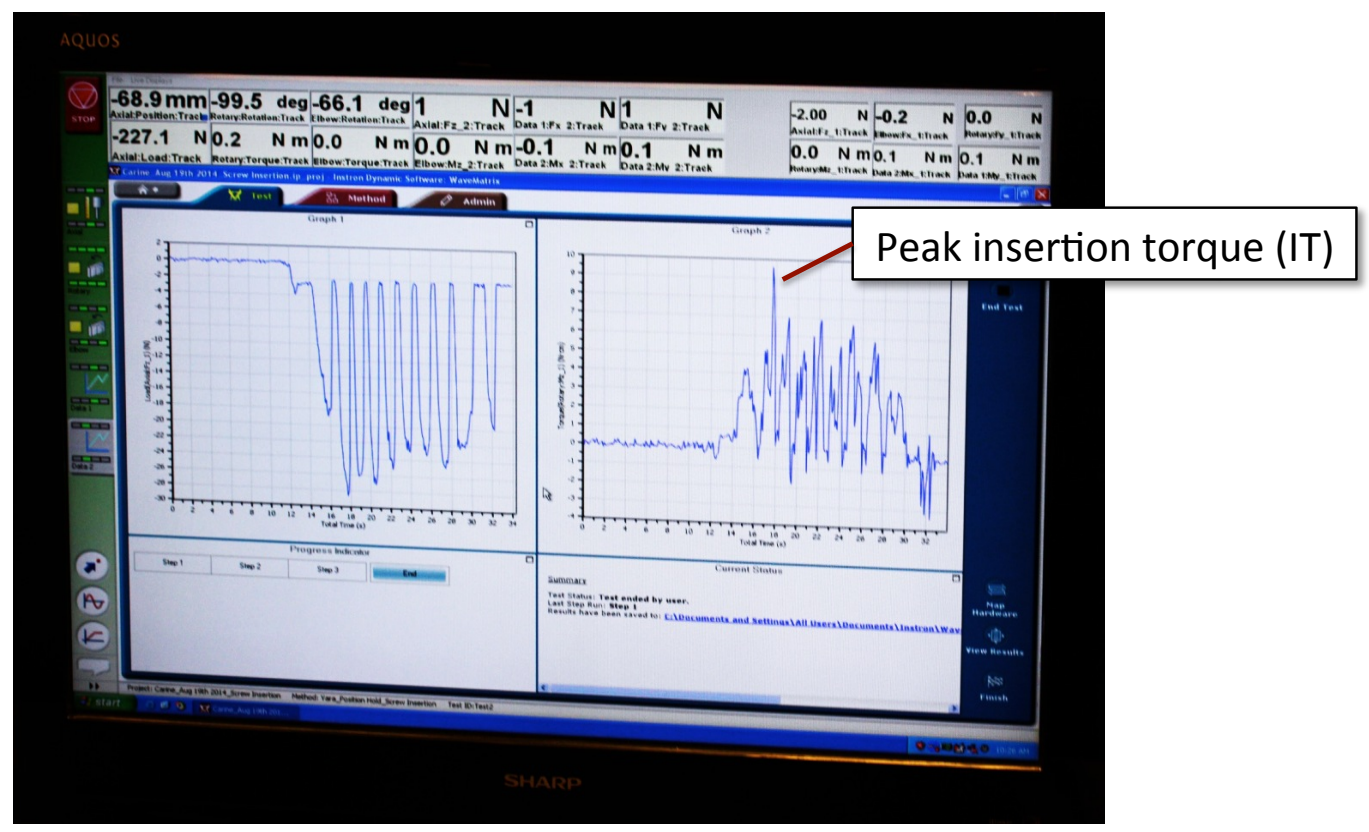

Figure 16. Computer software program used for collection of insertion data.

The left half of the screen represents the axial load during insertion. The right half depicts the variation in torque as the miniscrew penetrates bone. 


\subsection{Imaging and Data Analysis}

\subsubsection{Image Acquisition}

Scanning of the specimens before and after miniscrew insertion was performed at the Robarts Research Institute, Western University. Images were acquired using the volumetric cone-beam microCT scanner previously described. An anatomical scan mode was used to acquire 1000 projection images, of matrix size $1024 \times 680$, obtained over a single 16 seconds rotation $(120 \mathrm{kVp}, 20 \mathrm{~mA})$. These source images were back-projected to reconstruct a 3D volume, $1024 \times 1024 \times 680$ voxels in size and reconstructed with an isotropic voxel spacing of $150 \mu \mathrm{m}$. Du et $\mathrm{al}^{110}$ have previously described this scanner characteristics and protocol. Each specimen was scanned with two known density calibrators. The first was water, corresponding to a mineral density of $0 \mathrm{mgHA} / \mathrm{cm}^{-3}$ and the second was SB3 (Gammex-RMI, Middleton, WI, USA), a bone simulating material with a density of $1073 \mathrm{mgHA} / \mathrm{cm}^{-3}$.

\subsubsection{Image Analysis}

Image analysis was performed using 3D analysis software (MicroView 2.2, GE, Healthcare, London, ON, Canada). To identify screw insertion sites for bone analysis on the pre-insertion microCT images, scans obtained after miniscrew insertion were registered to the initial scans using a rigid-body registration algorithm. The registration consisted of manually selecting six anatomical landmarks on each specimen, located as far apart as possible, and involving all 3-image planes. These landmarks were specimen specific and selected based on individual anatomical structures of each maxilla. Identical landmarks were identified on the pre and post-miniscrew insertion images of a given specimen. Subsequently, a six-degrees-of-freedom rigid-body transformation was applied, resulting in the generation of two anatomically co-registered 3D volume images. To ensure that the registration was accurate, the registered scan was overlaid on the matching initial scan for visual inspection. A single investigator performed data registration and reorientation $(\mathrm{CB})$. Sabo et $\mathrm{al}^{111}$ validated the accuracy of this registration technique. 
Once registration of the images was complete, the centre $(x, y, z)$ coordinates of the head and the tip of each OMS obtained from the registered image were recorded, and used to represent the longitudinal miniscrew trajectory in bone. Custom written software was used to create $2 \mathrm{~mm}$ diameter cylindrical regions of interest (ROIs) within the bone, with length specified by the coordinate points previously described. The ROIs were created in separate binary mask volumes, without modification of the original pre-insertion data. These mask volumes were used by the software to identify voxels for inclusion in subsequent calculation of BMD using the pre-insertion registered scans. Visual confirmation of the correct placement of the cylindrical ROIs was performed by their superimposition onto the original (pre-insertion) scans (Figure 17). Prior to calculating the BMD within the regions of interest, the scans were rescaled into Hounsfield units (HU), using known water and air in the volumes. Values for water (0 HU), air ( -1000 $\mathrm{HU})$, and SB3 (1970 HU) were measured from the calibrators that were scanned with the maxillas. For the purpose of BMD measurement, voxels with HU value of -200 or less were completely excluded from the calculations since it was assumed that they represented air. This is depicted by the truncated cylindrical ROIs in Figure 17. In addition, voxels with HU values greater than $-200 \mathrm{HU}$ but smaller than $-50 \mathrm{HU}$ were included but forced to have a value of $0 \mathrm{mg} \mathrm{HA} \mathrm{cm}^{-3}$, as this probably corresponded to water, fat or preservation medium.

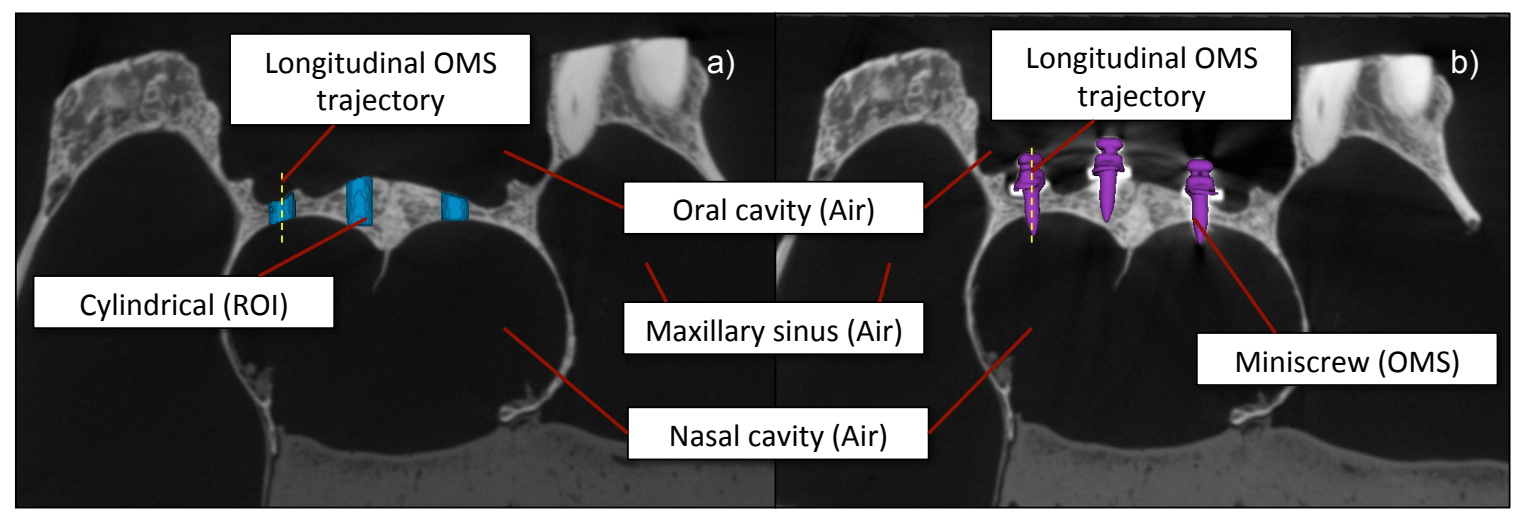

Figure 17. Computer software depicting the cylindrical ROI and the longitudinal OMS trajectory used for BMD and BT analysis.

a) Initial, pre-insertion scan. The cylindrical ROIs are truncated at the air boundaries, and represent the actual regions used in the BMD analysis.

b) Registered scan used for identification of the longitudinal OMS trajectory. 
For bone thickness measurements, each longitudinal miniscrew trajectory described above was projected through the entire bone length using custom software. A line profile was constructed for each screw trajectory, showing greylevel in Hounsfield Units (HU) for each position sample along the screw trajectory line. This data was plotted for graphical evaluation of thickness measurements ( $\mathrm{x}$-axis), where the transition in greylevel from air to bone and bone to air was used to identify the bone entrance and exit of each OMS (Figure 18).

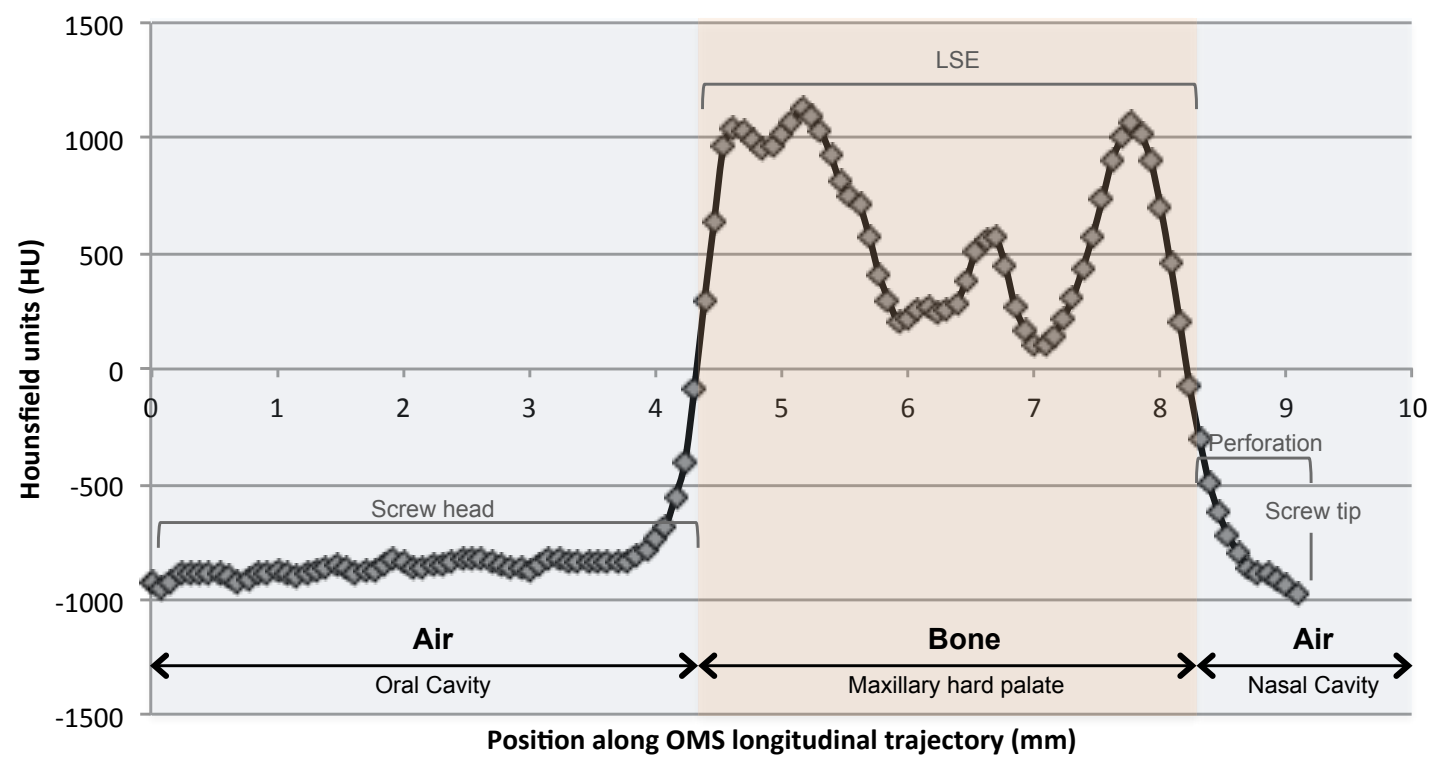

Figure 18. Line profile along the longitudinal OMS trajectory.

Line profile of an insertion site for a given specimen taken from the pre-screw insertion scan. The graph shows greylevel values (HU) sampled along a line that represents the screw trajectory, where highlighted regions differentiate between air (blue) and bone (orange).

In addition to the bone density and thickness measurements obtained from the microCT images, miniscrew perforations into the nasal cavity were calculated and confirmed visually (Appendix 4). Subtraction of the OMS threaded body length $(5 \mathrm{~mm}$ ) from BT revealed the magnitude of the perforation (negative values).

\section{Perforation $=B T-$ Threaded body length}


Perforations of more than $1 \mathrm{~mm}$ (results of $\leq-1 \mathrm{~mm}$ from calculations) were judged clinically significant and were therefore reported. When perforation was present, the length of screw engagement was equal to BT. If the OMS was fully included into bone; the engaged portion of the screw was assigned a value of $5 \mathrm{~mm}$.

\subsection{Statistical Analysis}

Descriptive and inferential statistics including mean, median value, standard error and standard deviation were determined for the different insertion sites using the Statistical Package for Social Sciences statistical software (IBM SPSS Statistics 22.0, IBM Corporation, Armonk, NY, USA). To assess the presence of outliers and the normality of the data, a Shapiro-Wilk test $(\mathrm{p}<0.05)$ was performed. This test revealed the presence of outliers and non-normality of the data distribution. Therefore, the Kruskal-Wallis nonparametric test $(p<0.05)$ was used to compare the differences in the median insertion torque, bone density, bone thickness and length of screw engagement at the different insertion sites. Pairwise comparisons were performed using Dunn's procedure with a Bonferroni correction for multiple comparisons $(\mathrm{p}<0.004)$. The association between the individual insertion sites and the frequency of perforations was assessed using a Fisher's exact test $(\mathrm{p}<0.05)$. Finally, the influence of bone density, thickness and screw engagement on the measures of insertion torque was calculated using the Spearman's rank-order correlation test. 


\section{Results}

Descriptive statistics representing the IT, BMD, BT, LSE and perforation values for each insertion site are depicted in Table 1. Statistical analysis revealed that IT, BT and LSE data were not normally distributed. Although BMD was normally distributed, the presence of outliers was detected. The median values were therefore interpreted since there was a potential for the mean values to be influenced by the data distribution and the presence of outliers. Boxplots representing the median values of BMD, BT, LSE and IT are shown in Figure 19-22.

The palatal BMD values showed a general tendency to increase from anterior to posterior until the level of the first molar, then decrease in a more posterior location for both the $\mathrm{S}$ and L insertion sites. The PS area showed an A-P increase in bone density up to the contact point between the first and second molars, then decreased further posteriorly (Figure 19). In the M-L direction, BMD was found highest in the parasagittal area and decreasing laterally. Although general trends were observed, statistical analysis revealed similarity between the sites $(p=0.004)$, i.e. Kruskal-Wallis $\mathrm{H}$ test was statistically significant, while pairwise comparison failed to demonstrate statistically significant differences.

Both BT and LSE values were generally higher in the parasagittal and lateral area, (Figure 20,21) when compared to sagittal values. The anterior palate had significantly thicker bone; there was an immediate drop in BT from the level of the first premolars to second premolars. The decrease was more gradual posterior to the second premolars. Sites S4, L4 and S5 showed lower BT than PS1, S1, PS2 and L2; S3 showed lower BT than PS1, S1 and L2; and PS5 and L3 showed lower BT than S1 (all $p<0.0005$ ) (Figure 20). The differences in LSE among insertion sites were similar to those for BT ( $p<$ 0.0005). However, the LSE values at PS5 and L3 were not different from those at S1; and S5 experienced lower LSE than PS4 $(p<0.0005)$ (Figure 21). 
The IT values showed a tendency to decrease from anterior to posterior and medial to lateral with the exception of sites PS2 and S2 (Figure 22). Statistical analysis revealed that the values were not similar between the sites $(p<0.0005)$. Insertion site S5 demonstrated lower IT than PS1, S1, S2, L2, PS3 and PS4, with L4 also demonstrating lower IT than S1.

The percentage of miniscrew perforation $(>1 \mathrm{~mm})$ in the nasal cavity is represented in Figure 23. The frequency of perforation was almost non-existent at sites PS1, S1 and L2 where only one perforation $(10 \%)$ was reported in each group. In general, the region anterior to the second premolars showed a smaller frequency $(\leq 60 \%)$ than the posterior area. All OMSs (100\%) perforated at sites S3, S4, L4, PS5 and S5. There was a statistically significant association between insertion sites and percentage of perforation $(p<0.0005)$.

Finally, when testing the influence of bone quality and quantity on OMS stability, statistical analysis revealed a moderate correlation between IT and BMD $\left(r_{s}=0.42, p<\right.$ $0.0005)$ (Figure 24); IT and BT $\left(r_{s}=0.58, p<0.0005\right)$ (Figure 25); and IT and LSE $\left(r_{s}=\right.$ $0.58, p<0.0005$ ) (Figure 26). There was a higher correlation for the combined effect of BMD and LSE on IT measurements $(R=0.65, p<0.0005)$. 
Table 1. Descriptive statistics for BMD, BT, LSE, IT and perforation at each insertion site.

\begin{tabular}{|c|c|c|c|c|c|c|c|}
\hline $\begin{array}{l}\text { Insertion } \\
\text { Site }\end{array}$ & $n$ & $\begin{array}{l}\text { Descriptive } \\
\text { Statistics }\end{array}$ & $\begin{array}{c}B M D \\
(m g / c c)\end{array}$ & $\begin{array}{l}B T \\
(\mathrm{~mm})\end{array}$ & $\begin{array}{l}L S E \\
(\mathrm{~mm})\end{array}$ & $\begin{array}{c}I T \\
(\mathrm{Ncm})\end{array}$ & $\begin{array}{c}\text { Perforation } \\
(\%)\end{array}$ \\
\hline \multirow[t]{4}{*}{ PS1 } & 10 & Median & 318.77 & 7.58 & 5.00 & 13.05 & 10 \\
\hline & & Mean & 338.03 & 7.88 & 4.63 & 16.48 & \\
\hline & & S.D. & 104.10 & 3.17 & 1.17 & 8.15 & \\
\hline & & S.E. & 32.92 & 1.01 & 0.37 & 2.58 & \\
\hline \multirow[t]{4}{*}{ S1 } & 10 & Median & 303.12 & 9.35 & 5.00 & 15.45 & 10 \\
\hline & & Mean & 283.88 & 8.82 & 4.68 & 15.53 & \\
\hline & & S.D. & 84.10 & 2.74 & 1.02 & 4.41 & \\
\hline & & S.E. & 26.60 & 0.86 & 0.32 & 1.40 & \\
\hline \multirow[t]{4}{*}{ PS2 } & 10 & Median & 381.14 & 4.42 & 4.42 & 9.75 & 40 \\
\hline & & Mean & 373.67 & 4.68 & 4.33 & 9.39 & \\
\hline & & S.D. & 109.94 & 1.27 & 0.69 & 3.94 & \\
\hline & & S.E. & 34.77 & 0.40 & 0.22 & 1.25 & \\
\hline \multirow[t]{4}{*}{ S2 } & 10 & Median & 408.68 & 3.73 & 3.73 & 15.15 & 60 \\
\hline & & Mean & 410.50 & 3.65 & 3.45 & 14.68 & \\
\hline & & S.D. & 103.99 & 1.69 & 1.37 & 7.25 & \\
\hline & & S.E. & 32.88 & 0.53 & 0.43 & 2.29 & \\
\hline \multirow[t]{4}{*}{ L2 } & 10 & Median & 300.43 & 6.16 & 5.00 & 14.50 & 10 \\
\hline & & Mean & 321.39 & 5.58 & 4.41 & 14.44 & \\
\hline & & S.D. & 91.29 & 2.07 & 1.20 & 6.42 & \\
\hline & & S.E. & 28.87 & 0.65 & 0.38 & 2.03 & \\
\hline \multirow[t]{4}{*}{ PS3 } & 10 & Median & 416.41 & 3.15 & 3.15 & 13.10 & 70 \\
\hline & & Mean & 426.59 & 3.42 & 3.42 & 13.83 & \\
\hline & & S.D. & 123.32 & 0.98 & 0.98 & 3.91 & \\
\hline & & S.E. & 39.00 & 0.31 & 0.31 & 1.24 & \\
\hline \multirow[t]{4}{*}{ S3 } & 10 & Median & 422.77 & 1.96 & 1.96 & 9.00 & 100 \\
\hline & & Mean & 441.99 & 1.78 & 1.78 & 12.27 & \\
\hline & & S.D. & 134.13 & 0.81 & 0.81 & 6.99 & \\
\hline & & S.E. & 42.42 & 0.26 & 0.26 & 2.21 & \\
\hline \multirow[t]{4}{*}{ L3 } & 10 & Median & 384.29 & 2.46 & 2.46 & 8.55 & 80 \\
\hline & & Mean & 393.18 & 2.64 & 2.59 & 11.16 & \\
\hline & & S.D. & 150.65 & 1.54 & 1.43 & 7.43 & \\
\hline & & S.E. & 47.64 & 0.49 & 0.45 & 2.35 & \\
\hline \multirow[t]{4}{*}{ PS4 } & 10 & Median & 519.49 & 3.50 & 3.50 & 14.55 & 60 \\
\hline & & Mean & 482.88 & 3.71 & 3.64 & 13.86 & \\
\hline & & S.D. & 135.96 & 1.18 & 1.07 & 5.57 & \\
\hline & & S.E. & 43.00 & 0.37 & 0.34 & 1.76 & \\
\hline \multirow[t]{4}{*}{ S4 } & 10 & Median & 337.69 & 1.31 & 1.31 & 8.10 & 100 \\
\hline & & Mean & 319.02 & 1.31 & 1.31 & 8.63 & \\
\hline & & S.D. & 144.33 & 0.52 & 0.52 & 4.86 & \\
\hline & & S.E. & 45.64 & 0.16 & 0.16 & 1.54 & \\
\hline \multirow[t]{4}{*}{ L4 } & 10 & Median & 256.67 & 1.04 & 1.04 & 7.05 & 100 \\
\hline & & Mean & 271.01 & 1.27 & 1.27 & 7.05 & \\
\hline & & S.D. & 134.14 & 0.67 & 0.67 & 3.60 & \\
\hline & & S.E. & 42.42 & 0.21 & 0.21 & 1.14 & \\
\hline \multirow[t]{4}{*}{ PS5 } & 10 & Median & 435.01 & 2.54 & 2.54 & 6.75 & 100 \\
\hline & & Mean & 421.42 & 2.47 & 2.47 & 8.19 & \\
\hline & & S.D. & 103.70 & 0.94 & 0.94 & 5.13 & \\
\hline & & S.E. & 32.79 & 0.30 & 0.30 & 1.62 & \\
\hline \multirow[t]{4}{*}{ S5 } & 10 & Median & 314.04 & 0.96 & 0.96 & 4.65 & 100 \\
\hline & & Mean & 311.93 & 1.12 & 1.12 & 5.38 & \\
\hline & & S.D. & 95.48 & 0.44 & 0.44 & 2.84 & \\
\hline & & S.E. & 30.19 & 0.14 & 0.14 & 0.90 & \\
\hline Total & 130 & $p$-value & 0.004 & $<0.0005$ & $<0.0005$ & $<0.0005$ & $<0.0005$ \\
\hline
\end{tabular}

BMD, Bone mineral density; BT, Bone thickness; LSE, Length of screw engagement; IT, Insertion torque 


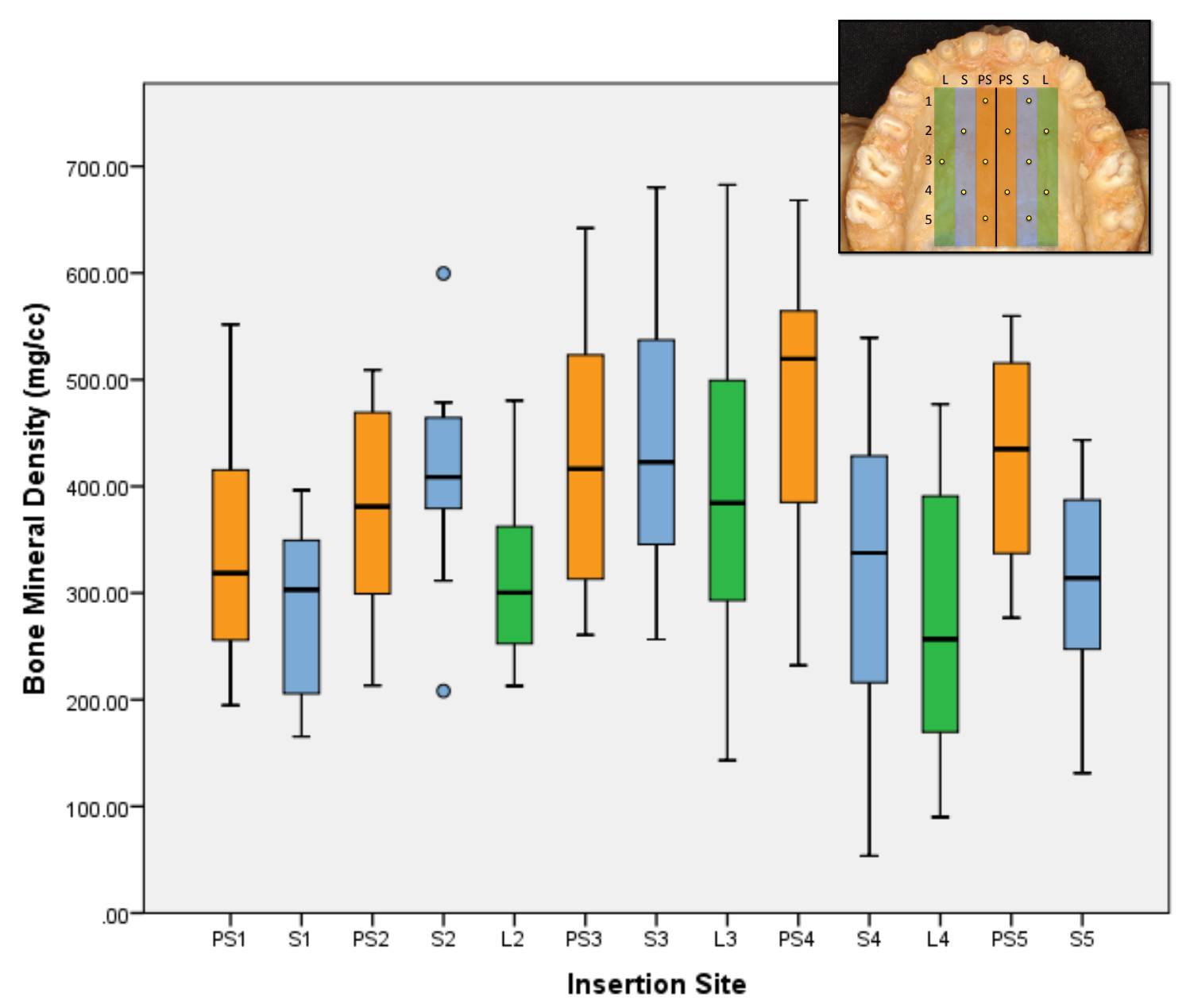

Figure 19. Box and Whisker plots for BMD at each insertion site.

The parasagittal (PS) sites are identified in orange, the sagittal sites (S) in blue and the lateral sites (L) in green. No statistically significant differences were found between sites $p=0.004$, i.e. Kruskal-Wallis H test was statistically significant, while pairwise comparison failed to demonstrate statistically significant differences. 


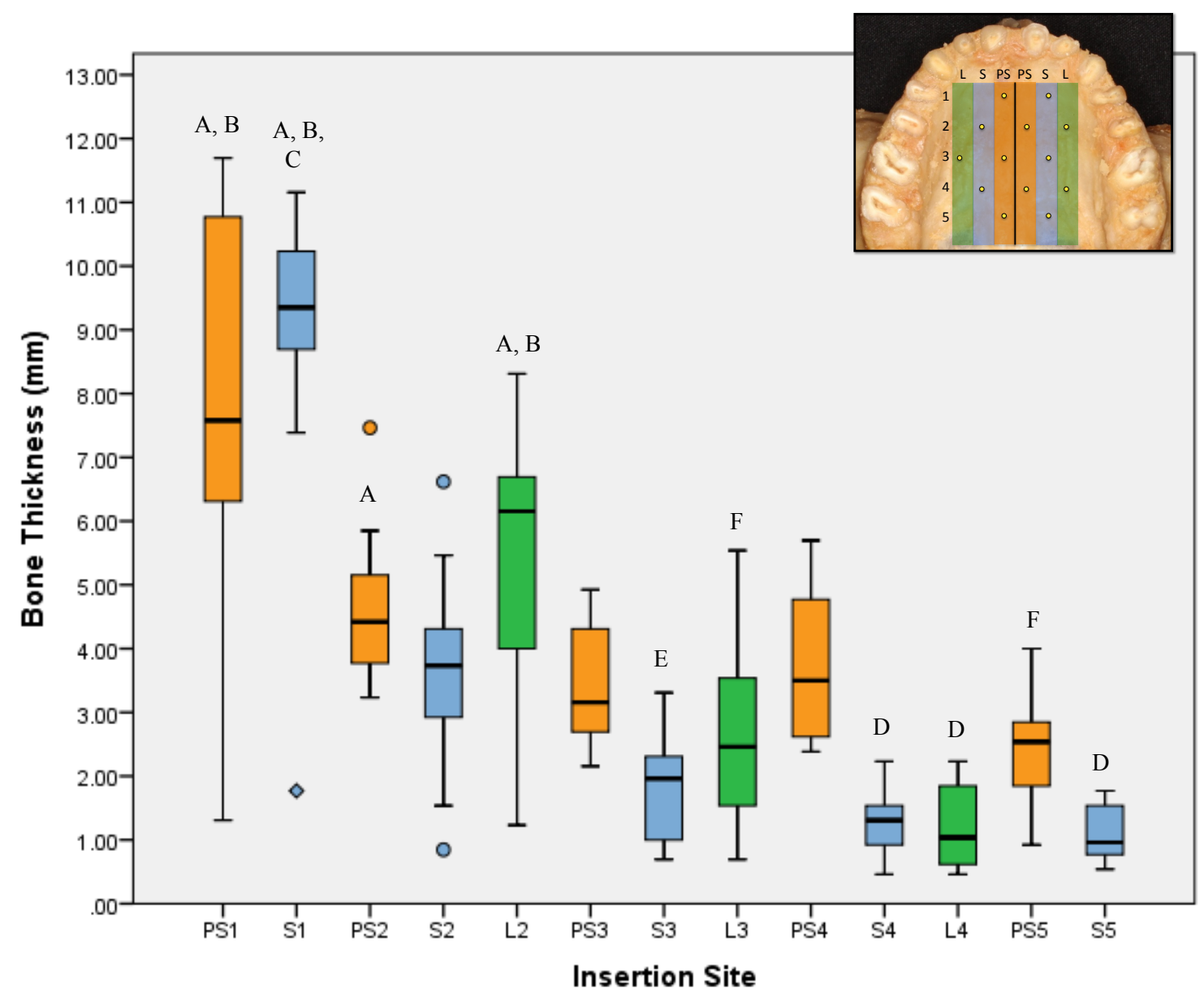

Figure 20. Box and Whisker plots for BT at each insertion site.

The parasagittal sites (PS) are identified in orange, the sagittal sites (S) in blue and the lateral sites (L) in green. Statistically significant differences $(p<0.0005)$ only exist between sites labeled A and D; B and E; as well as $\mathrm{C}$ and $\mathrm{F}$. 


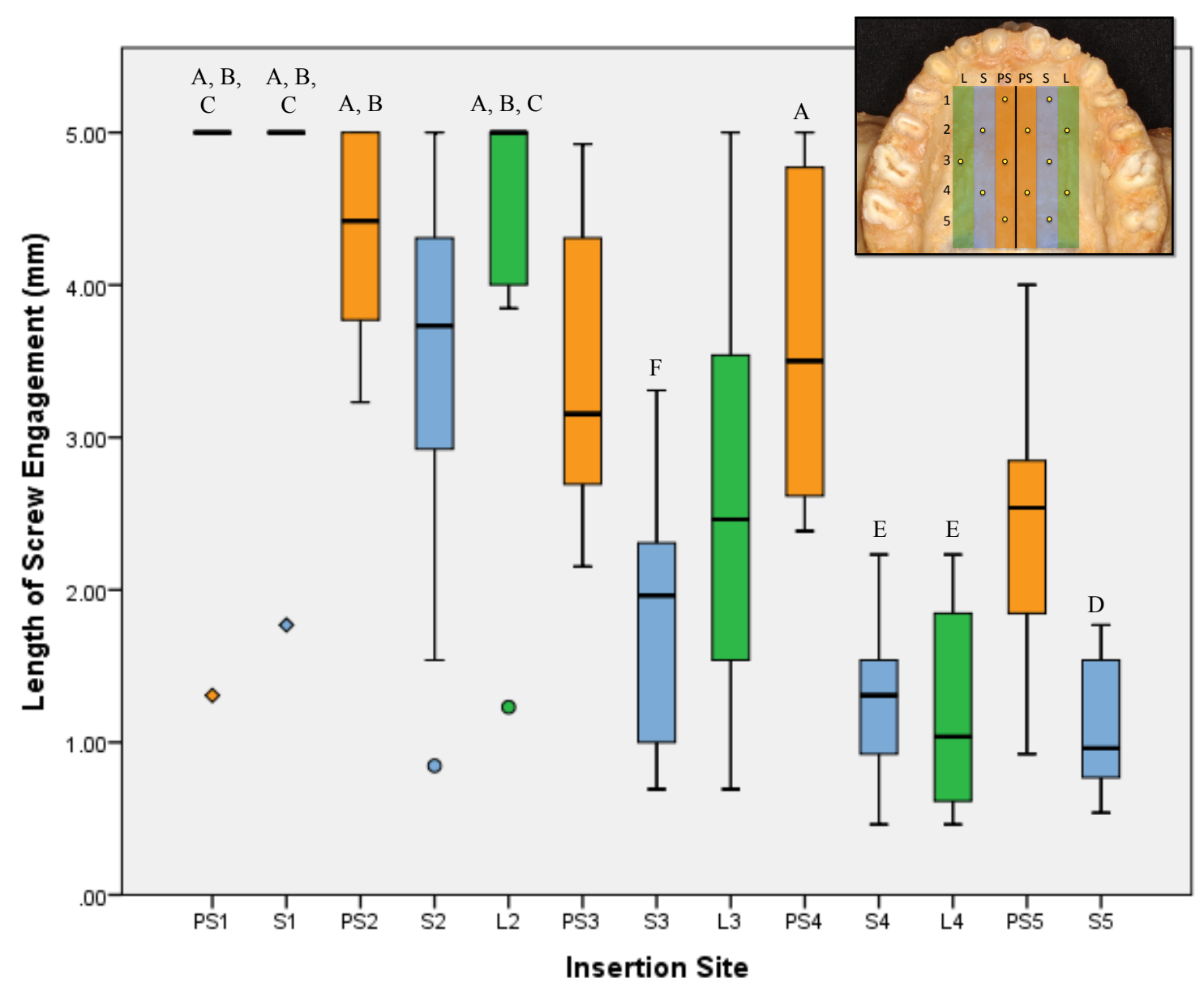

Figure 21. Box and Whisker plots for LSE at each insertion site.

The parasagittal sites (PS) are identified in orange, the sagittal sites (S) in blue and the lateral sites (L) in green. Statistically significant differences $(p<0.0005)$ only exist between sites labeled A and D; B and E; as well as $\mathrm{C}$ and $\mathrm{F}$. 


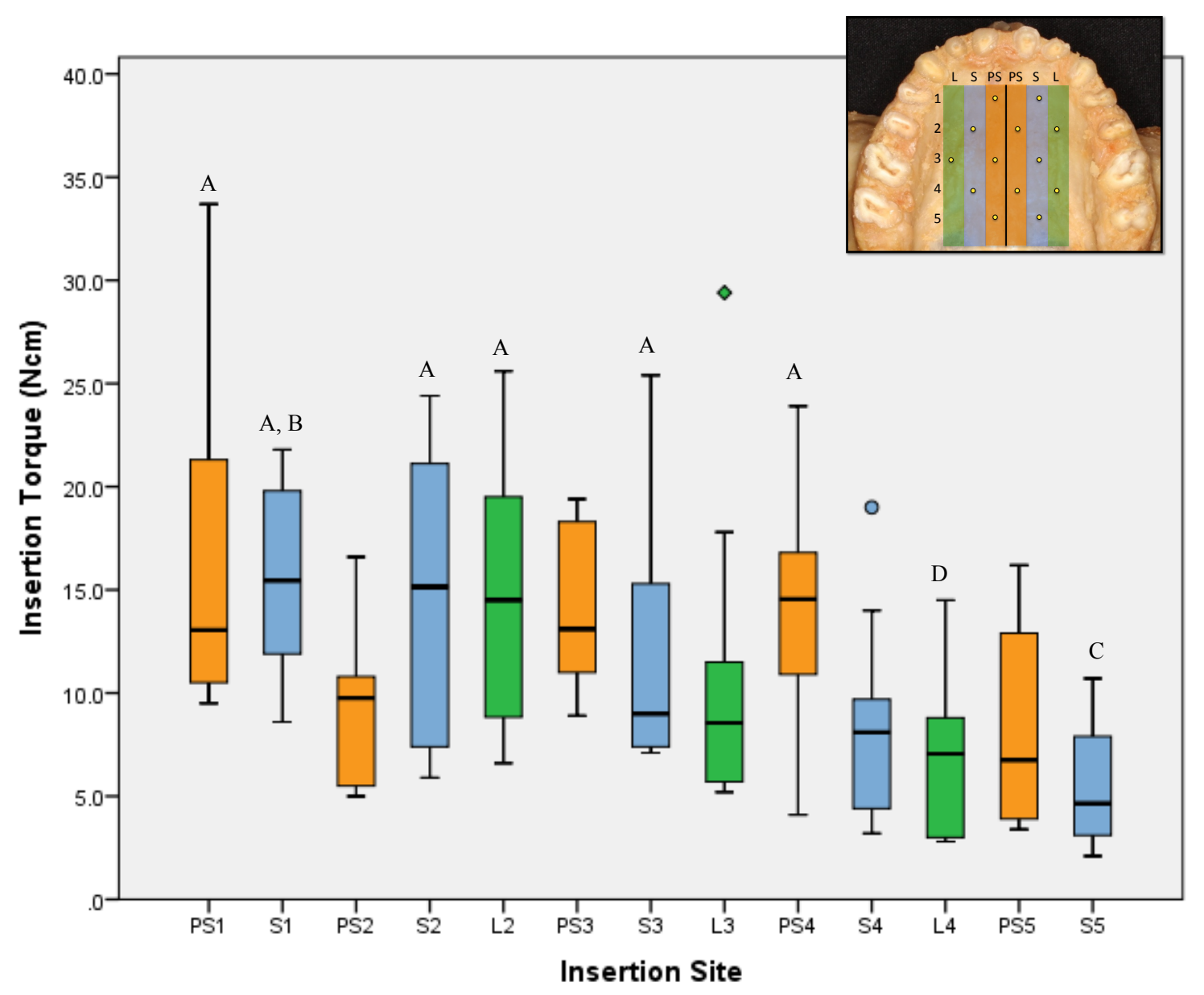

Figure 22. Box and Whisker plots for IT at each insertion site.

The parasagittal sites (PS) are identified in orange, the sagittal sites (S) in blue and the lateral sites (L) in green. Statistically significant differences $(p<0.0005)$ only exist between site labeled A and C; as well as $\mathrm{B}$ and $\mathrm{D}$. 


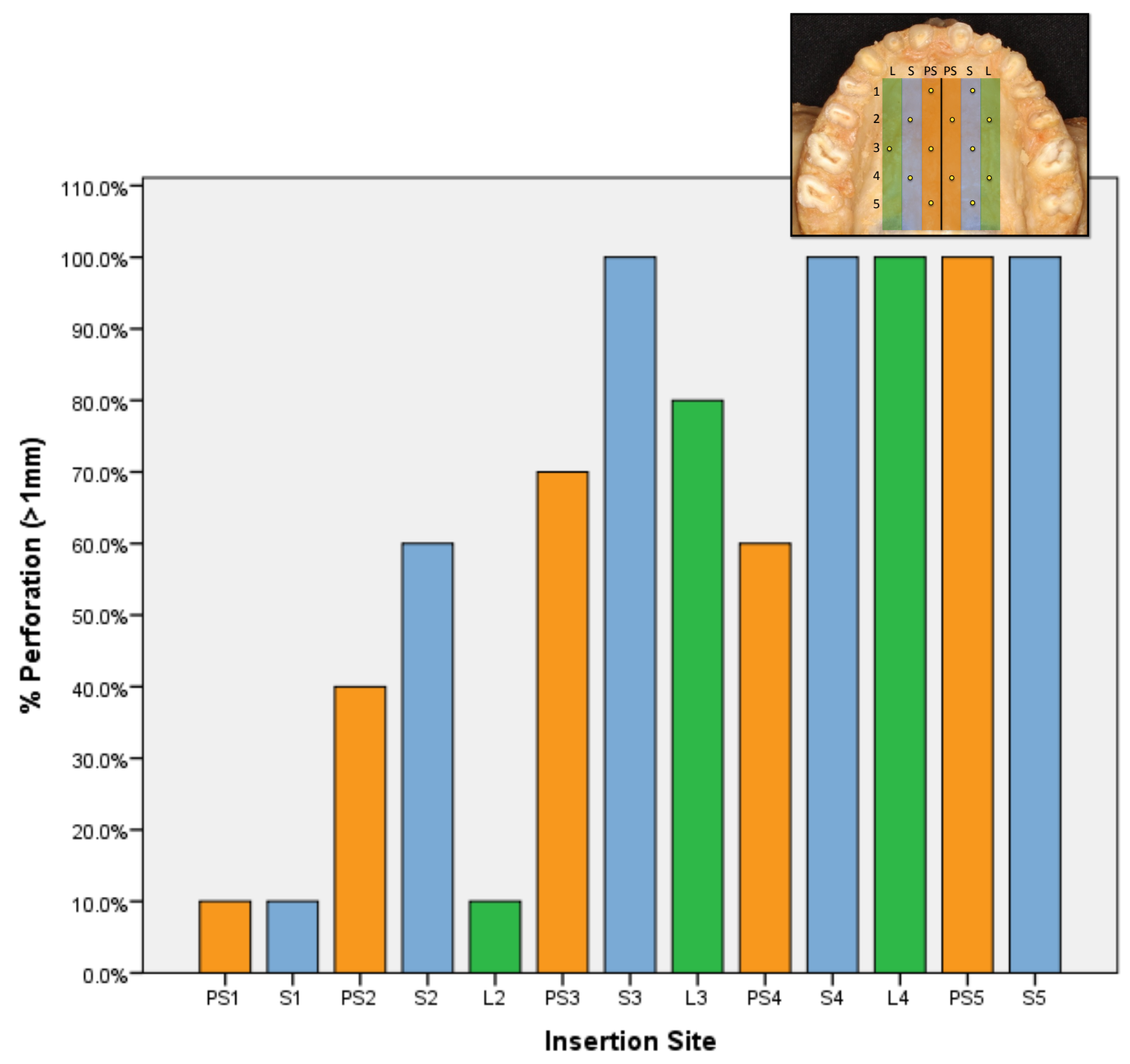

Figure 23. Percentage of perforations for each insertion site.

The parasagittal sites (PS) are identified in orange, the sagittal sites (S) in blue and the lateral sites (L) in green. A statistically significant association between insertion sites and percentage of perforation $(p<$ $0.0005)$ is present. 


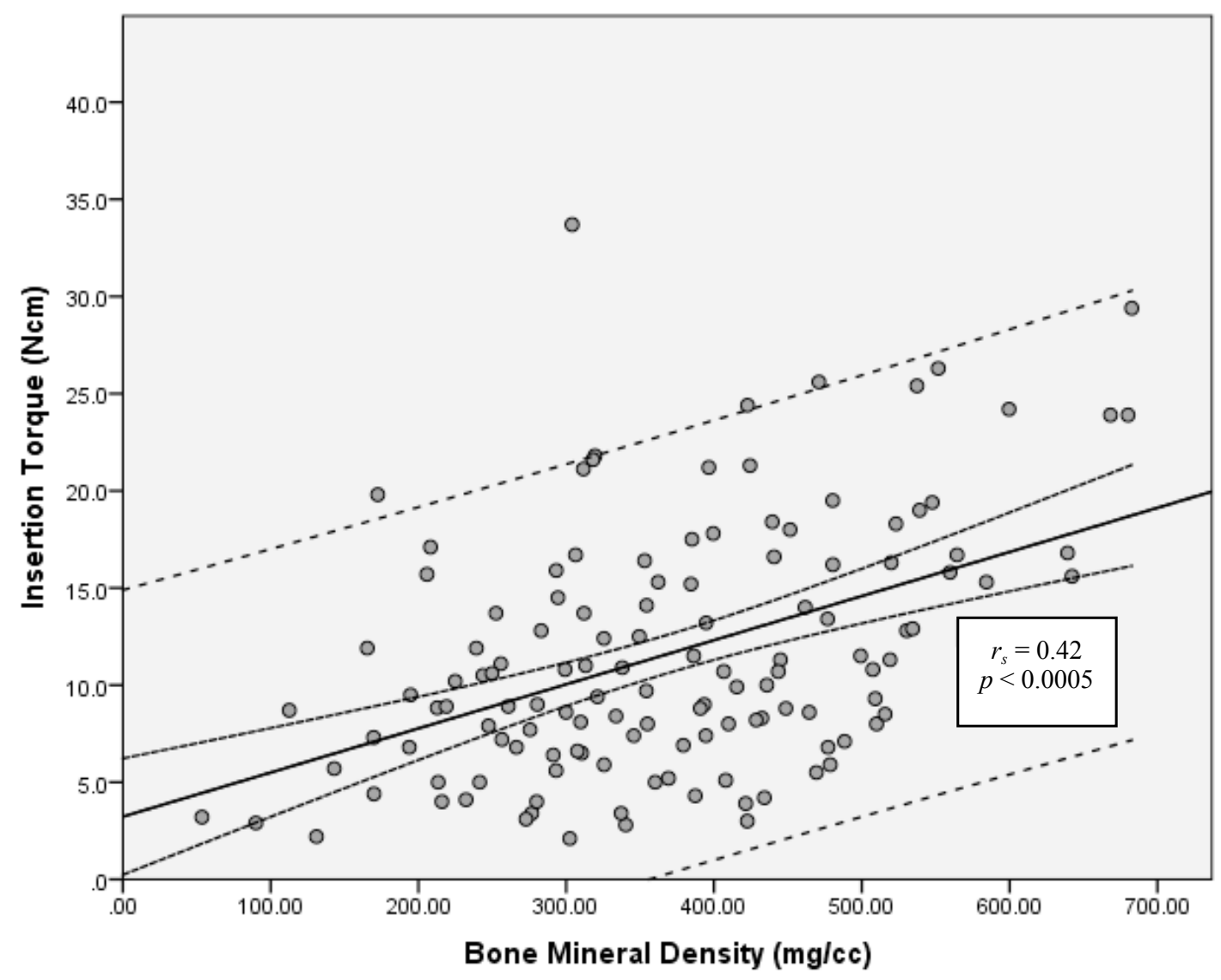

Figure 24. Correlation between BMD and IT. 


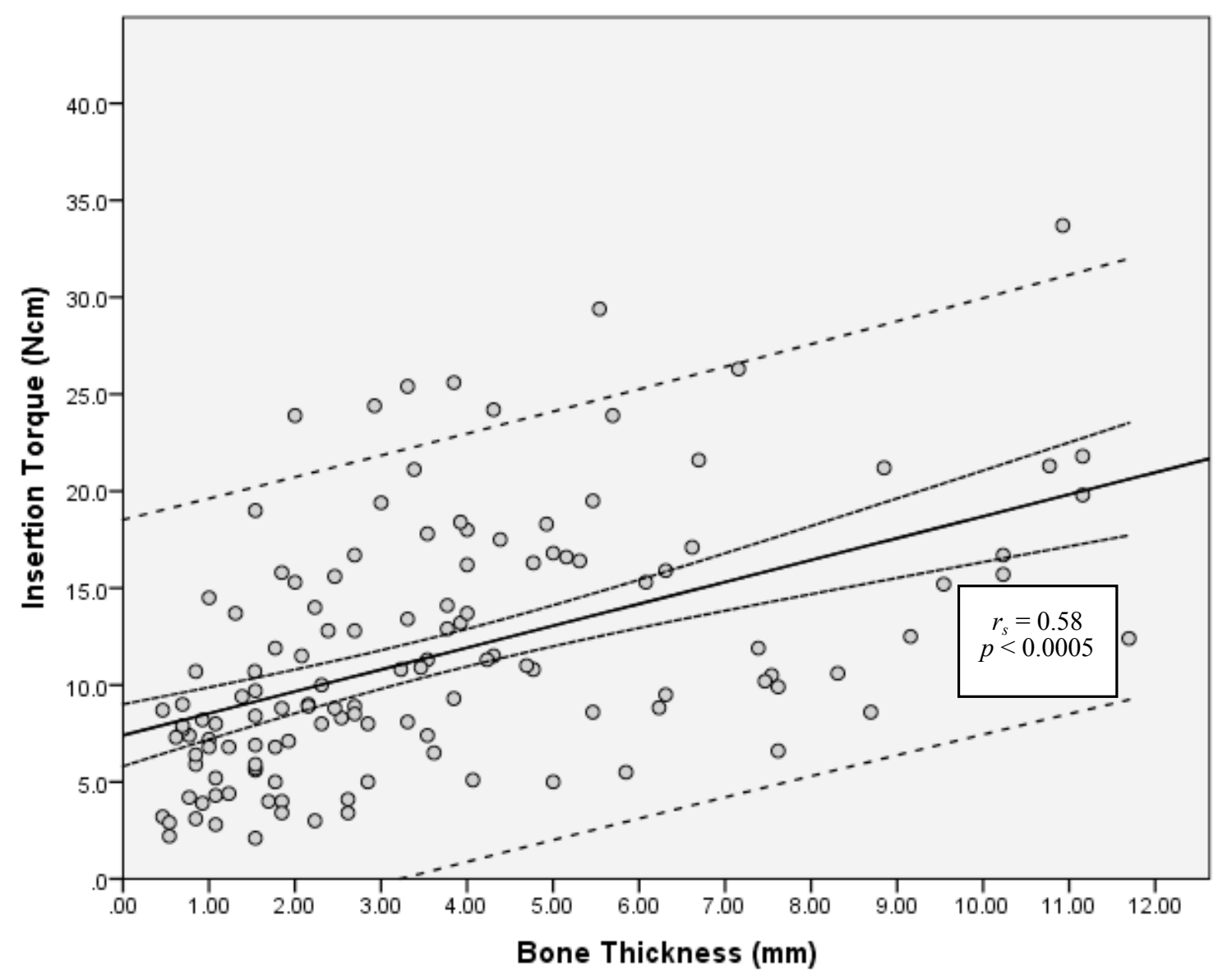

Figure 25. Correlation between BT and IT. 


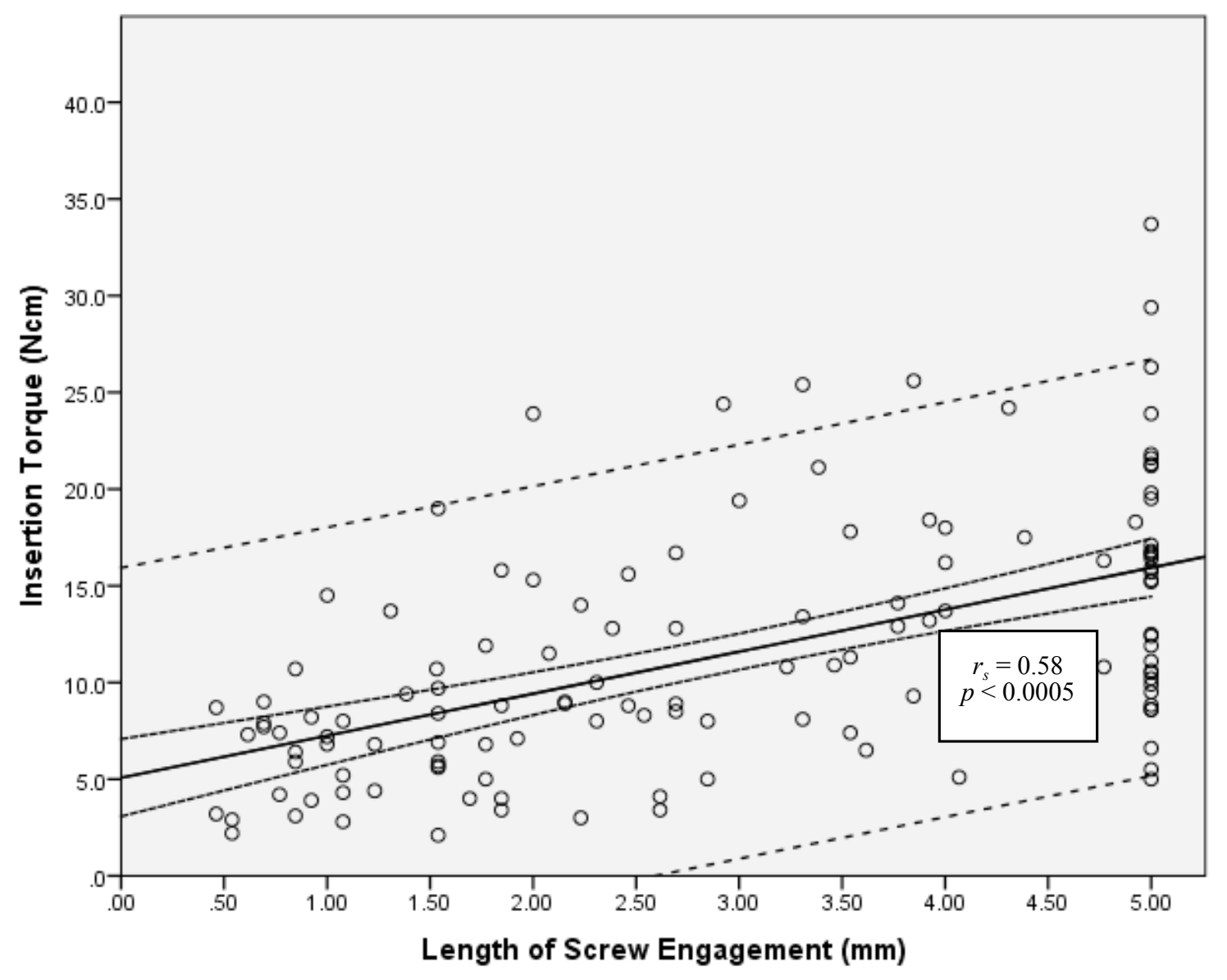

Figure 26. Correlation between LSE and IT. 


\section{Discussion}

The primary stability of miniscrews for orthodontic anchorage has been extensively studied with the ultimate goal of determining the probability of miniscrew success in clinical practice. ${ }^{54,63,128,129,137}$ With the increased use of the maxillary hard palate for skeletal anchorage purposes, several studies have attempted to quantify and qualify the palatal bony structures as predictors of primary stability. ${ }^{92,131}$ However, limited in vivo and cadaveric studies specifically investigating the primary stability of palatal OMSs

currently exist..$^{99,132,133}$ Therefore, the purpose of this study was to assess the quality and quantity of bone at different regions of the maxillary hard palate in human cadavers using microCT imaging, and to determine their effect on the primary stability of inserted OMSs.

Results of this study showed that bone quality and quantity varied depending on the insertion site. Although no statistically significant differences were found for BMD values, there was a general tendency observed in both A-P and M-L direction. The trend included an increase in BMD from anterior to posterior until the level of the first molar, with decreased BMD in a more posterior location for both the $\mathrm{S}$ and $\mathrm{L}$ insertion sites. The PS area showed an A-P increase in bone density up to the contact point between the first and second molars, followed by a decrease further posteriorly. In the M-L direction, BMD was highest in the parasagittal area with decrease moving laterally.

The literature contains limited data regarding BMD at different palatal sites. Among these studies, BMD is reported using both Hounsfield Units $(\mathrm{HU})^{101,131,138}$ and bone volume per tissue ratio values. ${ }^{139}$ Imaging techniques also vary, including conventional computed tomography and cone beam computed tomography. The HU is a grey scale value obtained from 3D images but it is not an absolute content measurement of material density. In addition, the assigned grey scale values for the same material can vary between different radiographic techniques. ${ }^{140}$ The use of $\mathrm{HU}$ in quantifying BMD is therefore limited due to the lack of standardization. For accuracy, uniformity and ease in data comparison, Pauwels et al $^{97}$ have suggested a paradigm shift toward using structural 
bone analysis rather than a strict density measurement in predicting the stability of dental implants. To accomplish this, they suggest the use of microCT rather than CBCT for research purposes until the improvement of $\mathrm{CBCT}$ devices makes their performance comparable to microCT. ${ }^{97}$ Nonetheless, using $\mathrm{HU}$ and $\mathrm{CT}$ images for density evaluation of 80 palatal sites, Moon et $\mathrm{al}^{101}$ reported that BMD tended to decrease from the anterior to posterior and median to lateral areas. These results partially support those of the current study where no significant differences were found in BMD among the palatal sites evaluated although there was a tendency for BMD values to decrease from median to lateral and increase from anterior to the first molar level, then decrease posteriorly.

The BT values were found to be highest anteriorly with PS1, S1 and L2 having median values above $5 \mathrm{~mm}$. The general trend observed is in agreement with Baumgaertel et al ${ }^{141}$ who noted a M-L decrease in BT from "parasagittal" to "sagittal" regions and a slight increase at the "lateral" region as the alveolar bone is approached. In the A-P direction $\mathrm{BT}$ decreases with a more posterior insertion site. This suggests that $\mathrm{BT}$ is highest at the level of the permanent first premolar level and laterally at the level of the permanent second premolars. Statistically significant differences in BT were found between PS1, S1, PS2 and L2 showing higher BT than S4, L4 and S5. PS1, S1 and L2 also demonstrated significantly higher $\mathrm{BT}$ than $\mathrm{S} 3$ while $\mathrm{S} 1$ showed significantly higher $\mathrm{BT}$ values than $\mathrm{L} 3$ and PS5. These findings suggest that BT is the thinnest "sagittally" starting at the level of the permanent first molar, and also "laterally" posterior to this point. Site S1 showed the highest BT value, which is in agreement with the findings of Winsauer et al ${ }^{92}$ who reported that highest $\mathrm{BT}$ was found at the point half way between the permanent first premolar and the midpalatal suture along a transverse line passing through the palatal cusp of the first premolars. This anatomically corresponds to the transition from palatal bone to alveolar bone. The differences in LSE among insertion sites were similar to those for BT, which would be expected, as BT is a contributive factor to LSE. The difference noted between BT and LSE were that the LSE values at PS5 and L3 were not different from those at S1, and S5 experienced lower LSE than PS4.

When comparing miniscrew primary stability in the hard palate, results showed significant variations in insertion torques depending on the location of the insertion site. 
The median IT values were found to be highest $(>10.0 \mathrm{Ncm})$ at insertion sites PS1, S1, S2, L2, PS3 and PS4. These sites correspond to the previously mentioned "green zone", which the current literature recommends for safe OMS placement (Figure 7). ${ }^{92,96}$ Based on the results of insertion torque within this study, it was determined that primary stability was highest in those areas. These regions are comprised of the palatal region anterior to the $2^{\text {nd }}$ premolars and the parasagittal region adjacent to the permanent first molars. Although higher values were recorded, statistical significance was found only between the aforementioned regions and site S5 as well as between S1 and L4. This suggests a comparable primary stability in almost all palatal areas except distal to the permanent first molar in a more lateral position. Overall, this is the first known study to compare OMS IT values in the maxillary hard palate, and show a tendency for IT values to decrease from anterior to posterior and medial to lateral, with the exception of site PS2 that showed lower values than the predominant trend. This may be simply due to variability in human specimens.

With regards to the effect of bone density on OMS stability, it was found that IT was mildly influenced by $\operatorname{BMD}\left(r_{s}=0.423\right)$ at the various insertion sites. The current literature investigating the effect of BMD on primary stability of OMSs is limited and somewhat conflicting. ${ }^{138,142,143}$ Findings from Samrit et $\mathrm{al}^{98}$ and Marquezan et $\mathrm{al}^{100}$ reported that self-drilling OMS primary stability was not affected by BMD of cancellous bone, but was rather influenced only by cortical bone. On the contrary, another study by Marquezan et $\mathrm{al}^{61}$ reported a higher correlation between total BMD and IT ( $r=0.763$ ) compared to cortical BMD and IT $(r=0.008)$, indicating that cancellous BMD also influences primary stability. However, the results of this study did not suggest as strong a correlation as that reported by Marquezan et al. ${ }^{61}$ This may be explained by the different bone samples used, where a higher variability is expected in human cadaveric specimens. In a study investigating BMD with simulated bone blocks, Chen et al ${ }^{144}$ reported a tendency for higher IT values when total BMD increased but did not report a correlation. In a cadaveric study, Lemieux et $\mathrm{al}^{99}$ reported a moderate correlation between maximum anchorage force and BMD $(r=0.42)$. This correlation was similar to the present study, although it was conducted using unembalmed cadaveric specimens and maximum anchorage force as a primary stability measurement. 
When determining the effect of bone quantity on OMS stability, IT was moderately influenced by BT $\left(r_{s}=0.58\right)$ and LSE $\left(r_{s}=0.58\right)$. Within the literature, reports of correlations between total BT and IT as well as LSE and IT are limited. Studies using synthetic material, animal models and cadaveric specimens report the effect of cortical bone thickness, OMS length as well as depth of insertion and IT. ${ }^{77,99,145}$ None report the length of screw engagement as it was analyzed here or a correlation coefficient. Song et al ${ }^{145}$ report no effect of increased cortical bone thickness with IT values for cylindrical as opposed to tapered OMS. In addition, Lim et a $1^{77}$ reported an increase in IT value with an increased OMS length. Lemieux et $\mathrm{al}^{99}$ reported a correlation between maximum anchorage force for both OMS length $(r=0.45)$, and placement depth $(r=0.29)$ using unembalmed cadaveric specimens.

Cadaveric studies present with inherent limitations including the alteration in bone substance by the preservation medium, the absence of bone remodeling and factors related to the age or cause of death. The preservation medium can alter the bone characteristics and influence IT values. A study investigating dental implants using human cadavers reported higher insertion torque values in formalin-fixed bone than fresh-frozen human bone. ${ }^{146}$ However, the objective of the current study was to identify the most favorable palatal insertion sites with regards to IT and to determine the effects of BMD, BT and LSE on these values rather than to report palatal IT values that might be expected clinically. While IT values may be affected by specimen preparation, the findings provide some insight into palatal sites that may be more optimal for OMS primary stability. In addition, any error relating to bone preservation should influence all insertion sites and the comparisons made within the study remain valid. Extrapolation of the findings from this study to living individuals is limited, and as such, the use of freshfrozen human specimens may be more favorable for OMS stability testing.

In addition to embalming effects, the age of the specimens (average 77.6 years) used in this study may have influenced the variability in palatal bone quantity and quality observed. Advanced age is often associated with the development of systemic disorders and increased medication intake, which may affect palatal BMD. ${ }^{147}$ Although the specimens were screened for known systemic disorders, it is not impossible that 
undiagnosed situations were present. Advanced age is also associated with partial edentulism (average number of teeth in this study $=9.9$ ), decreased masticatory function and softer diet. ${ }^{148}$ This may further influence the BMD of the jaws in the elderly. ${ }^{149}$ Conversely, advanced age has also been reported to be associated with increased mandibular bone density in dentate individuals. ${ }^{149}$ Nonetheless, these factors do not influence the comparative purpose of the current study, since insertion sites were assessed relative to one another.

This study also presents with limitations relating to materials. The number of specimens was limited due to the rarity of human donors. In addition, the conclusions may be limited to the single OMS type used, VectorTAS ${ }^{\mathrm{TM}}$ (1.4 mm diameter, $6 \mathrm{~mm}$ length). However, due to its popularity among the orthodontic community, ${ }^{150}$ the results of this study can benefit a large number of practitioners. In order to extend the conclusions to other OMS designs, lengths and diameters, further investigations are suggested.

OMS stability testing is rarely done using thin samples of bone, where miniscrews can possibly perforate beyond the testing material with a portion not embedded in bone. Most commonly, different lengths of miniscrews are tested within a thicker material than the screw length. ${ }^{99,120}$ It is reported that longer miniscrews penetrate deeper into bone and as a result provide higher mechanical retention and resistance to dislodgement. ${ }^{151}$ Another study by Petrey et al ${ }^{152}$ investigated the effect of variable insertion depths into bone on miniscrew retention. They concluded that for a fixed length, a deeper insertion of the screw (or placement depth) and a smaller abutment to cortical bone distance leads to increased resistance on pull-out testing. ${ }^{152}$ In this study, the distance from the abutment to the cortical bone remained constant. It is therefore not possible to compare LSE results to those of previous studies using insertion depth. It was thought that LSE was more appropriate than BT or placement depth for analysis of bone quantity since a high number of miniscrews perforated into the nasal cavity after full insertion, such that the inferior portion of their threaded body penetrated past the second layer of cortical bone. As such, the length of bone engaged with the screw (LSE) may be more useful when attempting to predict OMS stability. Nonetheless, LSE showed similar trends to BT at the various insertion sites. 
In addition to bone thickness, OMS length will also affect LSE and resultant OMS stability. The factors to consider in choosing OMS length include the soft tissue thickness, bone thickness and proximity of anatomical structures. In the presence of thin soft tissues, perhaps a shorter OMS $(4 \mathrm{~mm})$ should be used distal to the $2^{\text {nd }}$ premolar to prevent perforations since it is hypothesized that the excess screw thread may not provide any additional stability. Taking palatal bone thickness into consideration, an ideal length of screw-bone engagement for a $6 \mathrm{~mm}$ OMS was found at sites situated anterior to, and at the level of the permanent second premolars (A-P line 1 and 2). In these regions the entire screw thread length $(5 \mathrm{~mm})$ was almost always contained within bone. Although microCT imaging was used to determine bone quality and quantity in this study, other radiographic tools are available for clinical use. When adequate BT is in question for OMS insertion, additional information can be obtained through a cephalometric radiograph or CBCT scan. However, the clinician should be well informed of the limitations these imaging techniques have in the assessment of palatal BT. ${ }^{37,92,153}$

When considering OMS insertion depth, Winsauer et $\mathrm{a}^{92}$ noted a high risk of perforation into the nasal cavity with a minimum insertion depth of $5 \mathrm{~mm}$. This is in agreement with the current study where a high number of perforations were identified. Sites PS1, S1 and L2 showed the least number of perforation (10\%), with a significantly increased risk in the more posterior locations. Even though miniscrews inserted distal to the permanent maxillary second premolar showed a high number of perforations into the nasal cavity, this may not imply an increased risk of complications. The number of studies reporting nasal cavity perforation related to TSAD use is very limited. However, studies have discussed maxillary sinus perforation. If a sinus perforation of less than $2 \mathrm{~mm}$ in diameter occurs, it has been reported that healing will be without complications and the perforation is not likely to impact implant stability. ${ }^{116}$

Among the few studies reporting the effect of nasal floor perforation, Crismani et al ${ }^{104}$ investigated palatal implants up to $6 \mathrm{~mm}$ in length and of $3.3 \mathrm{~mm}$ in diameter and reported that a perforation depth of less than $1.3 \mathrm{~mm}$ did not necessarily lead to mucosal perforation. In addition, Fah et $\mathrm{a}^{154}$ investigated the possible complications and adverse effects associated with insertion and removal of palatal implants. They reported that nasal 
floor perforation during implant removal is a significant occurrence that can lead to oronasal fistula that may persist and necessitate surgical closure. The findings from these two studies, however, may not directly translate to OMSs since they have smaller diameters, do not osseointegrate (to any significant extent) and are generally less invasive than traditional palatal implants. Since the long-term effect of a perforation into the nasal cavity with OMSs has not been reported, efforts should be directed toward limiting perforations. If failure in obtaining primary stability occurs due to a suspected perforation into the nasal cavity, removal and relocation of the OMS is recommended. Appropriate follow-up should be provided until adequate healing of the failed insertion site occurs.

In summary, the findings of this study suggest a combined contribution of both bone quality and quantity on the primary stability of palatal OMSs. This study used microCT imaging to confirm this. In the absence of radiographic imaging, it is suggested that the anterior palate, overall, is a suitable site for OMS placement. When considering OMS placement in a more posterior region of the palate, the parasagittal region seems more appropriate in providing adequate primary stability. Additionally, should clinicians have doubts regarding adequate bone characteristics or when choosing an alternative site after OMS failure, $\mathrm{CBCT}$ imaging may provide valuable information about the quality and quantity of bone prior to insertion. 


\section{Conclusions}

This study provides important information regarding the effect of bone quality and quantity on the primary stability of orthodontic miniscrews (OMSs) placed in the maxillary hard palate as evaluated by insertion torque (IT). The findings of this study are as follows:

1. Comparable insertion torques of OMSs can be found in almost all palatal areas except distal to the permanent first molar in a more lateral position.

2. Insertion sites anterior to the $2^{\text {nd }}$ premolars and parasagittally adjacent to the permanent first molars showed the highest insertion torque values indicating that a higher primary stability may be obtained in these regions for orthodontic skeletal anchorage.

3. OMS insertion torque is moderately affected by both bone quality and quantity, as increased bone density and thickness correlated with higher insertion torques experienced upon OMS insertion.

4. A significantly increased risk for perforation into the nasal cavity was noted posterior to the $2^{\text {nd }}$ premolar region. 


\section{Future Directions}

The work of this study provides a framework for investigation of primary stability of palatal OMS. It is the first study using microCT imaging for the determination of palatal bone quality and quantity. Future studies should consider comparing the accuracy of microCT vs CBCT in the determination of palatal bone characteristics as CBCT imaging of the oral cavity is the most common 3D imaging modality in use today.

This study is also the first known study to investigate the primary stability of OMS in a thin material (where the OMS can perforate considerably beyond the testing material) and the first to incorporate LSE in the analysis as a potential influential factor of primary stability. Future studies could focus on determining the effect of the length of screw that passes through the testing material on the primary stability of OMSs. Recommendations regarding the optimal OMS length usable in the maxillary hard palate could be investigated with the objective of preventing complications related to perforation into the nasal cavity. Clinical follow-up on the long-term consequences of nasal perforation could be undertaken.

Considering the limitations encountered in this study with regards to the sample size and the use of embalmed human bone, future investigations should consider replicating this study utilizing either a larger sample size to increase statistical power or fresh frozen human bone to better extrapolate the findings to living humans. 


\section{Significance}

Overall, the findings from this study will assist orthodontic clinicians in choosing appropriate insertion sites for stable OMS placement in the palate, and provide evidence of the effect of bone properties on the resultant OMS stability. As such, it is expected that this thesis will provide information that will contribute to improve orthodontic treatment, limiting the chances of OMS failure. 


\section{References}

1. Nanda R KS, ed. Current therapy in orthodontics. 1st ed. [edited by] Ravindra Nanda, ed. St. Louis, Mo: Mosby Elsevier; 2010.

2. Proffit WR, Fields HW, Sarver DM. Contemporary orthodontics. 5th ed. ed. St. Louis: Mo.: Mosby Elsevier; 2013.

3. Higuchi KW, Slack JM. The use of titanium fixtures for intraoral anchorage to facilitate orthodontic tooth movement. Int J Oral Maxillofac Implants. 1991;6(3):338-344.

4. Heymann GC, Tulloch JF. Implantable devices as orthodontic anchorage: A review of current treatment modalities. J Esthet Restor Dent. 2006;18(2):68-79; discussion 80.

5. Cope JB. Temporary anchorage devices in orthodontics: A paradigm shift. Seminars in orthodontics. 2005;11(1).

6. Mizrahi E, Mizrahi B. Mini-screw implants (temporary anchorage devices): Orthodontic and pre-prosthetic applications. J Orthod. 2007;34(2):80-94. doi: 10.1179/146531207225021987.

7. Lin YS, Chang YZ, Yu JH, Lin CL. Do dual-thread orthodontic mini-implants improve bone/tissue mechanical retention? Implant Dent. 2014. doi: 10.1097/ID.0000000000000144.

8. Cha JY, Hwang CJ, Kwon SH, Jung HS, Kim KM, Yu HS. Strain of bone-implant interface and insertion torque regarding different miniscrew thread designs using an artificial bone model. Eur J Orthod. 2014. doi: 10.1093/ejo/cju037.

9. Dobranszki A, Faber J, Scatolino IV, Dobranszki NP, Toledo OA. Analysis of factors associated with orthodontic microscrew failure. Braz Dent J. 2014;25(4):346-351.

10. Zawawi KH. Acceptance of orthodontic miniscrews as temporary anchorage devices. Patient Prefer Adherence. 2014;8:933-937. doi: 10.2147/PPA.S66133; 10.2147/PPA.S66133.

11. Kaipatur N, Wu Y, Adeeb S, Stevenson T, Major P, Doschak M. A novel rat model of orthodontic tooth movement using temporary skeletal anchorage devices: 3D finite element analysis and in vivo validation. Int J Dent. 2014;2014:917535. doi: 10.1155/2014/917535; $10.1155 / 2014 / 917535$.

12. Mah J, Bergstrand F. Temporary anchorage devices: A status report. J Clin Orthod. 2005;39(3):132-6; discussion 136; quiz 153.

13. Choo H, Kim SH, Huang JC. TAD, a misnomer? Am J Orthod Dentofacial Orthop. 2009;136(2):145-146. doi: 10.1016/j.ajodo.2009.06.011; 10.1016/j.ajodo.2009.06.011.

14. AlSamak S, Bitsanis E, Makou M, Eliades G. Morphological and structural characteristics of orthodontic mini-implants. J Orofac Orthop. 2012;73(1):58-71. doi: 10.1007/s00056-011-0061-0; 10.1007/s00056-011-0061-0. 
15. Kang YG, Kim JY, Nam JH. Control of maxillary dentition with 2 midpalatal orthodontic miniscrews. Am J Orthod Dentofacial Orthop. 2011;140(6):879-885. doi: 10.1016/j.ajodo.2010.02.040; 10.1016/j.ajodo.2010.02.040.

16. Park YC, Lee HA, Choi NC, Kim DH. Open bite correction by intrusion of posterior teeth with miniscrews. Angle Orthod. 2008;78(4):699-710. doi: 2; 2.

17. Ko DI, Lim SH, Kim KW. Treatment of occlusal plane canting using miniscrew anchorage. World J Orthod. 2006;7(3):269-278.

18. Oh SY, Kwon S, Lee KG, et al. Outcomes of minimally invasive surgery for early gastric cancer are comparable with those for open surgery: Analysis of 1,013 minimally invasive surgeries at a single institution. Surg Endosc. 2013. doi: 10.1007/s00464-013-3256-1.

19. Dalli M, Colak H, Mustafa Hamidi M. Minimal intervention concept: A new paradigm for operative dentistry. J Investig Clin Dent. 2012;3(3):167-175. doi: 10.1111/j.20411626.2012.00117.x; 10.1111/j.2041-1626.2012.00117.x.

20. Johnson JC, Bullock GA. Indirect fabrication of a transpalatal arch supported by a temporary anchorage device. J Clin Orthod. 2010;44(4):266-8; quiz 252.

21. Xun C, Zeng X, Wang X. Microscrew anchorage in skeletal anterior open-bite treatment. Angle Orthod. 2007;77(1):47-56. doi: 10.2319/010906-14R.1.

22. Razavi MR. Molar intrusion using miniscrew palatal anchorage. J Clin Orthod. 2012;46(8):493-8; quiz 492.

23. Kravitz ND, Kusnoto B, Tsay TP, Hohlt WF. The use of temporary anchorage devices for molar intrusion. J Am Dent Assoc. 2007;138(1):56-64.

24. Park HS, Lee SK, Kwon OW. Group distal movement of teeth using microscrew implant anchorage. Angle Orthod. 2005;75(4):602-609. doi: 2.

25. Sugawara J, Daimaruya T, Umemori M, et al. Distal movement of mandibular molars in adult patients with the skeletal anchorage system. Am J Orthod Dentofacial Orthop. 2004;125(2):130138. doi: 10.1016/S0889540603006826.

26. Reichert I, Figel P, Winchester L. Orthodontic treatment of anterior open bite: A review article--is surgery always necessary? Oral Maxillofac Surg. 2014;18(3):271-277. doi: $10.1007 / \mathrm{s} 10006-013-0430-5 ; 10.1007 / \mathrm{s} 10006-013-0430-5$.

27. Noble J. Evidence-based use of orthodontic TSADs. In: Miles PG, Rinchuse DJ, Rinchuse DJ, eds. Evidence-based clinical orthodontics. Illinois, US: Quintessence; 2012:107-126.

28. Gainsfort BL HL. A study of orthodontic anchorage possibilities in basal bone. Am J Orthod Oral Surg. 1945;31:406-416.

29. Branemark PI, Adell R, Breine U, Hansson BO, Lindstrom J, Ohlsson A. Intra-osseous anchorage of dental prostheses. I. experimental studies. Scand J Plast Reconstr Surg.

1969;3(2):81-100. 
30. Linkow LI. Implanto-orthodontics. J Clin Orthod. 1970;4(12):685-90.

31. Creekmore TD, Eklund MK. The possibility of skeletal anchorage. J Clin Orthod. 1983;17(4):266-269.

32. Kanomi R. Mini-implant for orthodontic anchorage. J Clin Orthod. 1997;31(11):763-767.

33. Costa A, Raffainl M, Melsen B. Miniscrews as orthodontic anchorage: A preliminary report. Int J Adult Orthodon Orthognath Surg. 1998;13(3):201-209.

34. Block MS, Hoffman DR. A new device for absolute anchorage for orthodontics. Am J Orthod Dentofacial Orthop. 1995;107(3):251-258.

35. Armbruster PC, Block MS. Onplant-supported orthodontic anchorage. Atlas Oral Maxillofac Surg Clin North Am. 2001;9(1):53-74.

36. Arcuri C, Muzzi F, Santini F, Barlattani A, Giancotti A. Five years of experience using palatal mini-implants for orthodontic anchorage. J Oral Maxillofac Surg. 2007;65(12):2492-2497. doi: 10.1016/j.joms.2007.06.651.

37. Benson PE, Tinsley D, O'Dwyer JJ, Majumdar A, Doyle P, Sandler PJ. Midpalatal implants vs headgear for orthodontic anchorage--a randomized clinical trial: Cephalometric results. $A m J$ Orthod Dentofacial Orthop. 2007;132(5):606-615. doi: 10.1016/j.ajodo.2006.01.040.

38. Wehrbein H, Feifel H, Diedrich P. Palatal implant anchorage reinforcement of posterior teeth: A prospective study. Am J Orthod Dentofacial Orthop. 1999;116(6):678-686.

39. Wehrbein H, Merz BR, Diedrich P, Glatzmaier J. The use of palatal implants for orthodontic anchorage. design and clinical application of the orthosystem. Clin Oral Implants Res. 1996;7(4):410-416.

40. Douglass JB, Killiany DM. Dental implants used as orthodontic anchorage. J Oral Implantol. 1987;13(1):28-38.

41. Huang LH, Shotwell JL, Wang HL. Dental implants for orthodontic anchorage. Am J Orthod Dentofacial Orthop. 2005;127(6):713-722. doi: 10.1016/j.ajodo.2004.02.019.

42. Kokich VG. Managing complex orthodontic problems: The use of implants for anchorage. Semin Orthod. 1996;2(2):153-160.

43. Roberts WE, Helm FR, Marshall KJ, Gongloff RK. Rigid endosseous implants for orthodontic and orthopedic anchorage. Angle Orthod. 1989;59(4):247-256. doi: 2.

44. Roberts WE, Marshall KJ, Mozsary PG. Rigid endosseous implant utilized as anchorage to protract molars and close an atrophic extraction site. Angle Orthod. 1990;60(2):135-152. doi: 2.

45. Rozencweig G, Rozencweig S. Use of implants and ankylosed teeth in orthodontics. review of the literature. J Parodontol. 1989;8(2):179-184.

46. Jung BA, Kunkel M, Gollner P, Liechti T, Wehrbein H. Success rate of second-generation palatal implants. Angle Orthod. 2009;79(1):85-90. doi: 10.2319/010708-8.1; 10.2319/010708-8.1. 
47. Bae SM, Park HS, Kyung HM, Kwon OW, Sung JH. Clinical application of micro-implant anchorage. J Clin Orthod. 2002;36(5):298-302.

48. Chung K, Kim SH, Kook Y. C-orthodontic microimplant for distalization of mandibular dentition in class III correction. Angle Orthod. 2005;75(1):119-128. doi: 2.

49. Cope JB, McFadden D. Temporary replacement of missing maxillary lateral incisors with orthodontic miniscrew implants in growing patients: Rationale, clinical technique, and long-term results. J Orthod. 2014;41 Suppl 1:s62-74. doi: 10.1179/1465313314Y.0000000112; $10.1179 / 1465313314$ Y.0000000112.

50. Melsen B, Costa A. Immediate loading of implants used for orthodontic anchorage. Clin Orthod Res. 2000;3(1):23-28.

51. Meredith N. Assessment of implant stability as a prognostic determinant. Int J Prosthodont. 1998;11(5):491-501.

52. Chen Y, Kyung HM, Zhao WT, Yu WJ. Critical factors for the success of orthodontic miniimplants: A systematic review. Am J Orthod Dentofacial Orthop. 2009;135(3):284-291. doi: 10.1016/j.ajodo.2007.08.017; 10.1016/j.ajodo.2007.08.017.

53. Suzuki EY, Suzuki B. Placement and removal torque values of orthodontic miniscrew implants. Am J Orthod Dentofacial Orthop. 2011;139(5):669-678. doi: 10.1016/j.ajodo.2010.11.017; 10.1016/j.ajodo.2010.11.017.

54. Suzuki EY, Suzuki B, Aramrattana A, Harnsiriwattanakit K, Kowanich N. Assessment of miniscrew implant stability by resonance frequency analysis: A study in human cadavers. $J$ Oral Maxillofac Surg. 2010;68(11):2682-2689. doi: 10.1016/j.joms.2010.05.083; 10.1016/j.joms.2010.05.083.

55. Filho LC, Cirano FR, Hayashi F, et al. Assessment of the correlation between insertion torque and resonance frequency analysis of implants placed in bone tissue of different densities. $J$ Oral Implantol. 2014;40(3):259-262. doi: 10.1563/AAID-JOI-D-11-00183; 10.1563/AAID-JOI-D-1100183.

56. Inaba M. Evaluation of primary stability of inclined orthodontic mini-implants. J Oral Sci. 2009;51(3):347-353.

57. Nienkemper M, Wilmes B, Panayotidis A, et al. Measurement of mini-implant stability using resonance frequency analysis. Angle Orthod. 2013;83(2):230-238. doi: 10.2319/043012-354.1; 10.2319/043012-354.1.

58. Ruedi TP, Buckley RE, Moran CG. AO principles of fracture management. . Accessed 2014$08,2014$.

59. Serway RA, Jewett JJW. Physics for scientists and engineers. 6th ed. Brooks Cole; 2003.

60. Brinley CL, Behrents R, Kim KB, Condoor S, Kyung HM, Buschang PH. Pitch and longitudinal fluting effects on the primary stability of miniscrew implants. Angle Orthod. 2009;79(6):1156-1161. doi: 10.2319/103108-554R.1; 10.2319/103108-554R.1. 
61. Marquezan M, Lima I, Lopes RT, Sant'anna EF, de Souza MM. Is trabecular bone related to primary stability of miniscrews? Angle Orthod. 2013. doi: 10.2319/052513-39.1.

62. Marquezan M, Lau TC, Mattos CT, et al. Bone mineral density. Angle Orthod. 2012;82(1):62-66. doi: 10.2319/031811-192.1; 10.2319/031811-192.1.

63. Migliorati M, Benedicenti S, Signori A, et al. Miniscrew design and bone characteristics: An experimental study of primary stability. Am J Orthod Dentofacial Orthop. 2012;142(2):228-234. doi: 10.1016/j.ajodo.2012.03.029; 10.1016/j.ajodo.2012.03.029.

64. Florvaag B, Kneuertz P, Lazar F, et al. Biomechanical properties of orthodontic miniscrews. an in-vitro study. J Orofac Orthop. 2010;71(1):53-67. doi: 10.1007/s00056-010-9933-y; 10.1007/s00056-010-9933-y.

65. Johnson NL, Galuppo LD, Stover SM, Taylor KT. An in vitro biomechanical comparison of the insertion variables and pullout mechanical properties of ao $6.5-\mathrm{mm}$ standard cancellous and 7.3-mm self-tapping, cannulated bone screws in foal femoral bone. Vet Surg. 2004;33(6):681690. doi: 10.1111/j.1532-950x.2004.04093.x.

66. Yerby S, Scott CC, Evans NJ, Messing KL, Carter DR. Effect of cutting flute design on cortical bone screw insertion torque and pullout strength. J Orthop Trauma. 2001;15(3):216-221.

67. Clabaugh III RA. An evaluation of thermal changes during insertion of self-drillind miniscrew implants as measured by infrared thermography, Saint Louis University; 2013.

68. Wilmes B, Drescher D. Impact of bone quality, implant type, and implantation site preparation on insertion torques of mini-implants used for orthodontic anchorage. Int J Oral Maxillofac Surg. 2011;40(7):697-703. doi: 10.1016/j.ijom.2010.08.008;

10.1016/j.ijom.2010.08.008.

69. Koranyi E, Bowman CE, Knecht CD, Janssen M. Holding power of orthopedic screws in bone. Clin Orthop Relat Res. 1970;72:283-286.

70. Uhl RL. The biomechanics of screws. Orthop Rev. 1989;18(12):1302-1307.

71. Fanuscu MI, Chang TL. Three-dimensional morphometric analysis of human cadaver bone: Microstructural data from maxilla and mandible. Clin Oral Implants Res. 2004;15(2):213-218.

72. Crismani AG, Bertl MH, Celar AG, Bantleon HP, Burstone CJ. Miniscrews in orthodontic treatment: Review and analysis of published clinical trials. Am J Orthod Dentofacial Orthop. 2010;137(1):108-113. doi: 10.1016/j.ajodo.2008.01.027; 10.1016/j.ajodo.2008.01.027.

73. Schatzle M, Mannchen R, Zwahlen M, Lang NP. Survival and failure rates of orthodontic temporary anchorage devices: A systematic review. Clin Oral Implants Res. 2009;20(12):13511359. doi: 10.1111/j.1600-0501.2009.01754.x; 10.1111/j.1600-0501.2009.01754.x.

74. Chen $\mathrm{CH}$, Chang CS, Hsieh $\mathrm{CH}$, et al. The use of microimplants in orthodontic anchorage. $J$ Oral Maxillofac Surg. 2006;64(8):1209-1213. doi: 10.1016/j.joms.2006.04.016. 
75. Holm L, Cunningham SJ, Petrie A, Cousley RR. An in vitro study of factors affecting the primary stability of orthodontic mini-implants. Angle Orthod. 2012;82(6):1022-1028. doi: 10.2319/011912-47.1; 10.2319/011912-47.1.

76. Kim YK, Kim YJ, Yun PY, Kim JW. Effects of the taper shape, dual-thread, and length on the mechanical properties of mini-implants. Angle Orthod. 2009;79(5):908-914. doi: 10.2319/071808-374.1; 10.2319/071808-374.1.

77. Lim SA, Cha JY, Hwang CJ. Insertion torque of orthodontic miniscrews according to changes in shape, diameter and length. Angle Orthod. 2008;78(2):234-240. doi: 10.2319/121206-507.1; 10.2319/121206-507.1.

78. Park HS, Jeong SH, Kwon OW. Factors affecting the clinical success of screw implants used as orthodontic anchorage. Am J Orthod Dentofacial Orthop. 2006;130(1):18-25. doi: 10.1016/j.ajodo.2004.11.032.

79. Brettin BT, Grosland NM, Qian F, et al. Bicortical vs monocortical orthodontic skeletal anchorage. Am J Orthod Dentofacial Orthop. 2008;134(5):625-635. doi: 10.1016/j.ajodo.2007.01.031; 10.1016/j.ajodo.2007.01.031.

80. Vibhute PJ, Shenoy U. Rationalization of mechanical factors affecting primary stability of orthodontic miniscrew using engineering principles of simple machines. The Journal of Indian Orthodontic Society. October-December 2013;47(4):190-198.

81. Chatzigianni A, Keilig L, Reimann S, Eliades T, Bourauel C. Effect of mini-implant length and diameter on primary stability under loading with two force levels. Eur J Orthod. 2011;33(4):381-387. doi: 10.1093/ejo/cjq088; 10.1093/ejo/cjq088.

82. Lee NK, Baek SH. Effects of the diameter and shape of orthodontic mini-implants on microdamage to the cortical bone. Am J Orthod Dentofacial Orthop. 2010;138(1):8.e1-8; discussion 8-9. doi: 10.1016/j.ajodo.2010.02.019; 10.1016/j.ajodo.2010.02.019.

83. Yoo SH, Park YC, Hwang CJ, Kim JY, Choi EH, Cha JY. A comparison of tapered and cylindrical miniscrew stability. Eur J Orthod. 2014;36(5):557-562. doi: 10.1093/ejo/cjt092; 10.1093/ejo/cjt092.

84. Buschang PH, Carrillo R, Ozenbaugh B, Rossouw PE. 2008 survey of AAO members on miniscrew usage. J Clin Orthod. 2008;42(9):513-518.

85. Chaddad K, Ferreira AF, Geurs N, Reddy MS. Influence of surface characteristics on survival rates of mini-implants. Angle Orthod. 2008;78(1):107-113. doi: 10.2319/100206-401.1; 10.2319/100206-401.1.

86. Kim SH, Cho JH, Chung KR, Kook YA, Nelson G. Removal torque values of surface-treated mini-implants after loading. Am J Orthod Dentofacial Orthop. 2008;134(1):36-43. doi: 10.1016/j.ajodo.2006.07.038; 10.1016/j.ajodo.2006.07.038.

87. Maino B, Mura P, Bednar J. Miniscrew implants: The spider screw anchorage system. Seminars in Orthodontics. 2005;11(1). 
88. Farnsworth D, Rossouw PE, Ceen RF, Buschang PH. Cortical bone thickness at common miniscrew implant placement sites. Am J Orthod Dentofacial Orthop. 2011;139(4):495-503. doi: 10.1016/j.ajodo.2009.03.057; 10.1016/j.ajodo.2009.03.057.

89. Baumgaertel S, Hans MG. Buccal cortical bone thickness for mini-implant placement. Am J Orthod Dentofacial Orthop. 2009;136(2):230-235. doi: 10.1016/j.ajodo.2007.10.045; 10.1016/j.ajodo.2007.10.045.

90. Bernhart T, Freudenthaler J, Dortbudak O, Bantleon HP, Watzek G. Short epithetic implants for orthodontic anchorage in the paramedian region of the palate. A clinical study. Clin Oral Implants Res. 2001;12(6):624-631.

91. Nienkemper M, Wilmes B, Pauls A, Drescher D. Multipurpose use of orthodontic miniimplants to achieve different treatment goals. J Orofac Orthop. 2012;73(6):467-476. doi: 10.1007/s00056-012-0107-y; 10.1007/s00056-012-0107-y.

92. Winsauer H, Vlachojannis C, Bumann A, Vlachojannis J, Chrubasik S. Paramedian vertical palatal bone height for mini-implant insertion: A systematic review. Eur J Orthod. 2012. doi: 10.1093/ejo/cjs068.

93. Bernhart T, Vollgruber A, Gahleitner A, Dortbudak O, Haas R. Alternative to the median region of the palate for placement of an orthodontic implant. Clin Oral Implants Res. 2000;11(6):595-601.

94. Wehrbein H, Glatzmaier J, Mundwiller U, Diedrich P. The orthosystem--a new implant system for orthodontic anchorage in the palate. J Orofac Orthop. 1996;57(3):142-153.

95. Vu T, Bayome M, Kook YA, Han SH. Evaluation of the palatal soft tissue thickness by conebeam computed tomography. Korean J Orthod. 2012;42(6):291-296. doi: 10.4041/kjod.2012.42.6.291; 10.4041/kjod.2012.42.6.291.

96. Ludwig B, Glasl B, Bowman SJ, Wilmes B, Kinzinger GS, Lisson JA. Anatomical guidelines for miniscrew insertion: Palatal sites. J Clin Orthod. 2011;45(8):433-41; quiz 467.

97. Pauwels R, Jacobs R, Singer SR, Mupparapu M. CBCT-based bone quality assessment: Are hounsfield units applicable? Dentomaxillofac Radiol. 2014:20140238. doi: $10.1259 / \mathrm{dmfr} .20140238$

98. Samrit V, Kharbanda OP, Duggal R, Seith A, Malhotra V. Bone density and miniscrew stability in orthodontic patients. Aust Orthod J. 2012;28(2):204-212.

99. Lemieux G, Hart A, Cheretakis C, et al. Computed tomographic characterization of miniimplant placement pattern and maximum anchorage force in human cadavers. Am J Orthod Dentofacial Orthop. 2011;140(3):356-365. doi: 10.1016/j.ajodo.2010.05.024; 10.1016/j.ajodo.2010.05.024.

100. Marquezan M, Souza MM, Araujo MT, Nojima LI, Nojima Mda C. Is miniscrew primary stability influenced by bone density? Braz Oral Res. 2011;25(5):427-432. 
101. Moon SH, Park SH, Lim WH, Chun YS. Palatal bone density in adult subjects: Implications for mini-implant placement. Angle Orthod. 2010;80(1):137-144. doi: 10.2319/011909-40.1; 10.2319/011909-40.1.

102. Wehrbein $\mathrm{H}$. Anatomic site evaluation of the palatal bone for temporary orthodontic anchorage devices. Clin Oral Implants Res. 2008;19(7):653-656. doi: 10.1111/j.16000501.2008.01535.x; 10.1111/j.1600-0501.2008.01535.x.

103. King, Keith S., et al. Predictive factors of vertical bone depth in the paramedian palate of adolescents. The Angle Orthodontist. 2006;76(5):745-751.

104. Crismani, Adriano G., et al. Nasal cavity perforation by palatal implants: False-positive records on the lateral cephalogram. The International journal of oral \& maxillofacial implants. 2004;20(2):267-273.

105. Jung BA, Wehrbein H, Heuser L, Kunkel M. Vertical palatal bone dimensions on lateral cephalometry and cone-beam computed tomography: Implications for palatal implant placement. Clin Oral Implants Res. 2011;22(6):664-668. doi: 10.1111/j.1600-0501.2010.02021.x; 10.1111/j.1600-0501.2010.02021.x.

106. de Oliveira MA, Asahi DA, Silveira CA, Lima LA, Glick M, Gallottini M. The effects of zoledronic acid and dexamethasone on osseointegration of endosseous implants: Histological and histomorphometrical evaluation in rats. Clin Oral Implants Res. 2014. doi: 10.1111/clr.12335; $10.1111 /$ clr.12335.

107. Mangione F, Meleo D, Talocco M, Pecci R, Pacifici L, Bedini R. Comparative evaluation of the accuracy of linear measurements between cone beam computed tomography and 3D microtomography. Ann Ist Super Sanita. 2013;49(3):261-265. doi: DOI: 10.4415/ANN_13_03_05; DOI: 10.4415/ANN_13_03_05.

108. Sheikhi M, Ghorbanizadeh S, Abdinian M, Goroohi H, Badrian H. Accuracy of linear measurements of galileos cone beam computed tomography in normal and different head positions. Int J Dent. 2012;2012:214954. doi: 10.1155/2012/214954; 10.1155/2012/214954.

109. Wood R, Sun Z, Chaudhry J, et al. Factors affecting the accuracy of buccal alveolar bone height measurements from cone-beam computed tomography images. Am J Orthod Dentofacial Orthop. 2013;143(3):353-363. doi: 10.1016/j.ajodo.2012.10.019; 10.1016/j.ajodo.2012.10.019.

110. Du LY, Umoh J, Nikolov HN, Pollmann SI, Lee TY, Holdsworth DW. A quality assurance phantom for the performance evaluation of volumetric micro-CT systems. Phys Med Biol. 2007;52(23):7087-7108. doi: 10.1088/0031-9155/52/23/021.

111. Sabo MT, Pollmann SI, Gurr KR, Bailey CS, Holdsworth DW. Use of co-registered highresolution computed tomography scans before and after screw insertion as a novel technique for bone mineral density determination along screw trajectory. Bone. 2009;44(6):1163-1168. doi: 10.1016/j.bone.2009.02.007; 10.1016/j.bone.2009.02.007.

112. Granton PV, Pollmann SI, Ford NL, Drangova M, Holdsworth DW. Implementation of dualand triple-energy cone-beam micro-CT for postreconstruction material decomposition. Med Phys. 2008;35(11):5030-5042. 
113. Papageorgiou SN, Zogakis IP, Papadopoulos MA. Failure rates and associated risk factors of orthodontic miniscrew implants: A meta-analysis. Am J Orthod Dentofacial Orthop. 2012;142(5):577-595.e7. doi: 10.1016/j.ajodo.2012.05.016; 10.1016/j.ajodo.2012.05.016.

114. Smith A. An in-vitro study evaluating the fracture resistance and insertion torque of selfdrilling mini-implants upon insertion into synthetic high density mandibular bone. Western University; 2013.

115. Liou EJ, Pai BC, Lin JC. Do miniscrews remain stationary under orthodontic forces? Am J Orthod Dentofacial Orthop. 2004;126(1):42-47. doi: 10.1016/S0889540604002057.

116. Kravitz ND, Kusnoto B. Risks and complications of orthodontic miniscrews. Am J Orthod Dentofacial Orthop. 2007;131(4 Suppl):S43-51. doi: 10.1016/j.ajodo.2006.04.027.

117. Miyawaki S, Koyama I, Inoue M, Mishima K, Sugahara T, Takano-Yamamoto T. Factors associated with the stability of titanium screws placed in the posterior region for orthodontic anchorage. Am J Orthod Dentofacial Orthop. 2003;124(4):373-378. doi: 10.1016/S0889540603005651.

118. Pauls A, Nienkemper M, Drescher D. Accuracy of torque-limiting devices used for miniimplant placement--an in vitro study. J Orofac Orthop. 2013;74(2):124-136. doi: $10.1007 / \mathrm{s} 00056-012-0127-7 ; 10.1007 / \mathrm{s} 00056-012-0127-7$.

119. Reynders R, Ronchi L, Bipat S. Mini-implants in orthodontics: A systematic review of the literature. Am J Orthod Dentofacial Orthop. 2009;135(5):564.e1-19; discussion 564-5. doi: 10.1016/j.ajodo.2008.09.026; 10.1016/j.ajodo.2008.09.026.

120. Cheng SJ, Tseng IY, Lee JJ, Kok SH. A prospective study of the risk factors associated with failure of mini-implants used for orthodontic anchorage. Int J Oral Maxillofac Implants. 2004;19(1):100-106.

121. Kinzinger G, Gulden N, Yildizhan F, Hermanns-Sachweh B, Diedrich P. Anchorage efficacy of palatally-inserted miniscrews in molar distalization with a periodontally/miniscrew-anchored distal jet. J Orofac Orthop. 2008;69(2):110-120. doi: 10.1007/s00056-008-0736-3; 10.1007/s00056-008-0736-3.

122. Reicheneder C, Rottner K, Bokan I, et al. Mechanical loading of orthodontic miniscrews significance and problems: An experimental study. Biomed Tech (Berl). 2008;53(5):242-245. doi: 10.1515/BMT.2008.038; 10.1515/BMT.2008.038.

123. Watanabe H, Deguchi T, Hasegawa M, Ito M, Kim S, Takano-Yamamoto T. Orthodontic miniscrew failure rate and root proximity, insertion angle, bone contact length, and bone density. Orthod Craniofac Res. 2013;16(1):44-55. doi: 10.1111/ocr.12003; 10.1111/ocr.12003.

124. Pithon MM, Figueiredo DS, Oliveira DD. Mechanical evaluation of orthodontic miniimplants of different lengths. J Oral Maxillofac Surg. 2013;71(3):479-486. doi: 10.1016/j.joms.2012.10.002; 10.1016/j.joms.2012.10.002.

125. Motoyoshi M, Hirabayashi M, Uemura M, Shimizu N. Recommended placement torque when tightening an orthodontic mini-implant. Clin Oral Implants Res. 2006;17(1):109-114. doi: 10.1111/j.1600-0501.2005.01211.x. 
126. Motoyoshi M, Uemura M, Ono A, Okazaki K, Shigeeda T, Shimizu N. Factors affecting the long-term stability of orthodontic mini-implants. Am J Orthod Dentofacial Orthop.

2010;137(5):588.e1-5; discussion 588-9. doi: 10.1016/j.ajodo.2009.05.019; 10.1016/j.ajodo.2009.05.019.

127. Wilmes B, Rademacher C, Olthoff G, Drescher D. Parameters affecting primary stability of orthodontic mini-implants. J Orofac Orthop. 2006;67(3):162-174. doi: 10.1007/s00056-0060611-z.

128. McManus MM, Qian F, Grosland NM, Marshall SD, Southard TE. Effect of miniscrew placement torque on resistance to miniscrew movement under load. Am J Orthod Dentofacial Orthop. 2011;140(3):e93-8. doi: 10.1016/j.ajodo.2011.04.017; 10.1016/j.ajodo.2011.04.017.

129. Cha JY, Kil JK, Yoon TM, Hwang CJ. Miniscrew stability evaluated with computerized tomography scanning. Am J Orthod Dentofacial Orthop. 2010;137(1):73-79. doi: 10.1016/j.ajodo.2008.03.024; 10.1016/j.ajodo.2008.03.024.

130. Pithon MM, Nojima MG, Nojima LI. Primary stability of orthodontic mini-implants inserted into maxilla and mandible of swine. Oral Surg Oral Med Oral Pathol Oral Radiol. 2012;113(6):748-754. doi: 10.1016/j.tripleo.2011.06.021; 10.1016/j.tripleo.2011.06.021.

131. Han S, Bayome M, Lee J, Lee YJ, Song HH, Kook YA. Evaluation of palatal bone density in adults and adolescents for application of skeletal anchorage devices. Angle Orthod. 2012;82(4):625-631. doi: 10.2319/071311-445.1; 10.2319/071311-445.1.

132. Holst AI, Karl M, Karolczak M, Goellner M, Holst S. Quantitative assessment of orthodontic mini-implant displacement: The effect of initial force application. Quintessence Int. 2010;41(1):59-66.

133. Nakahara K, Matsunaga S, Abe S, et al. Evaluation of the palatal bone for placement of orthodontic mini-implants in japanese adults. Cranio. 2012;30(1):72-79.

134. Stockmann P, Schlegel KA, Srour S, Neukam FW, Fenner M, Felszeghy E. Which region of the median palate is a suitable location of temporary orthodontic anchorage devices? A histomorphometric study on human cadavers aged 15-20 years. Clin Oral Implants Res. 2009;20(3):306-312. doi: 10.1111/j.1600-0501.2008.01647.x; 10.1111/j.16000501.2008.01647.x.

135. Gracco A, Lombardo L, Cozzani M, Siciliani G. Quantitative cone-beam computed tomography evaluation of palatal bone thickness for orthodontic miniscrew placement. Am J Orthod Dentofacial Orthop. 2008;134(3):361-369. doi: 10.1016/j.ajodo.2007.01.027; 10.1016/j.ajodo.2007.01.027.

136. Song WC, Jo DI, Lee JY, et al. Microanatomy of the incisive canal using three-dimensional reconstruction of microCT images: An ex vivo study. Oral Surg Oral Med Oral Pathol Oral Radiol Endod. 2009;108(4):583-590. doi: 10.1016/j.tripleo.2009.06.036; 10.1016/j.tripleo.2009.06.036.

137. Marquezan M, Souza MM, Araujo MT, Nojima LI, Nojima Mda C. Is miniscrew primary stability influenced by bone density? Braz Oral Res. 2011;25(5):427-432. 
138. Park HS, Lee YJ, Jeong SH, Kwon TG. Density of the alveolar and basal bones of the maxilla and the mandible. Am J Orthod Dentofacial Orthop. 2008;133(1):30-37. doi: 10.1016/j.ajodo.2006.01.044; 10.1016/j.ajodo.2006.01.044.

139. Siddiqi A, Kieser JA, De Silva RK, McNaughton A, Zafar S, Duncan WJ. Trabecular bone microarchitecture in the median palate and maxillary premolar alveolar sites of edentulous elderly cadavers. J Oral Maxillofac Surg. 2013;71(11):1852.e1-1852.e11. doi: 10.1016/j.joms.2013.07.019; 10.1016/j.joms.2013.07.019.

140. Halperin-Sternfeld M, Machtei EE, Horwitz J. Diagnostic accuracy of cone beam computed tomography for dimensional linear measurements in the mandible. Int J Oral Maxillofac Implants. 2014;29(3):593-599. doi: 10.11607/jomi.3409.

141. Baumgaertel S. Quantitative investigation of palatal bone depth and cortical bone thickness for mini-implant placement in adults. Am J Orthod Dentofacial Orthop. 2009;136(1):104-108. doi: 10.1016/j.ajodo.2008.11.020; 10.1016/j.ajodo.2008.11.020.

142. Chugh T, Ganeshkar SV, Revankar AV, Jain AK. Quantitative assessment of interradicular bone density in the maxilla and mandible: Implications in clinical orthodontics. Prog Orthod. 2013;14:38-1042-14-38. doi: 10.1186/2196-1042-14-38; 10.1186/2196-1042-14-38.

143. Chun YS, Lim WH. Bone density at interradicular sites: Implications for orthodontic miniimplant placement. Orthod Craniofac Res. 2009;12(1):25-32. doi: 10.1111/j.16016343.2008.01434.x; 10.1111/j.1601-6343.2008.01434.x.

144. Chen Y, Kyung HM, Gao L, Yu WJ, Bae EJ, Kim SM. Mechanical properties of self-drilling orthodontic micro-implants with different diameters. Angle Orthod. 2010;80(5):821-827. doi: 10.2319/103009-607.1; 10.2319/103009-607.1.

145. Song YY, Cha JY, Hwang CJ. Mechanical characteristics of various orthodontic miniscrews in relation to artificial cortical bone thickness. Angle Orthod. 2007;77(6):979-985. doi: 10.2319/090606-363.1.

146. Comert A, Kokat AM, Akkocaoglu M, Tekdemir I, Akca K, Cehreli MC. Fresh-frozen vs. embalmed bone: Is it possible to use formalin-fixed human bone for biomechanical experiments on implants? Clin Oral Implants Res. 2009;20(5):521-525. doi: 10.1111/j.16000501.2008.01682.x; 10.1111/j.1600-0501.2008.01682.x.

147. Panday K, Gona A, Humphrey MB. Medication-induced osteoporosis: Screening and treatment strategies. Ther Adv Musculoskelet Dis. 2014;6(5):185-202. doi: 10.1177/1759720X14546350; 10.1177/1759720X14546350.

148. Iinuma T, Arai Y, Fukumoto M, et al. Maximum occlusal force and physical performance in the oldest old: The tokyo oldest old survey on total health. J Am Geriatr Soc. 2012;60(1):68-76. doi: 10.1111/j.1532-5415.2011.03780.x; 10.1111/j.1532-5415.2011.03780.x.

149. Zhou Y, Zhou S, Li G. The effects of local stress on bone mass of mandibles in ovariectomized rats. Zhonghua Kou Qiang Yi Xue Za Zhi. 2000;35(6):470-473.

150. H. Ferran AC. Townie choice awards. http://www.orthotown.com/Orthotown/Survey.aspx. Updated 2014. Accessed 11/15, 2014. 
151. Tseng YC, Hsieh CH, Chen CH, Shen YS, Huang IY, Chen CM. The application of miniimplants for orthodontic anchorage. Int J Oral Maxillofac Surg. 2006;35(8):704-707. doi: 10.1016/j.ijom.2006.02.018.

152. Petrey JS, Saunders MM, Kluemper GT, Cunningham LL, Beeman CS. Temporary anchorage device insertion variables: Effects on retention. Angle Orthod. 2010;80(4):446-453. doi: 10.2319/070309-376.1; 10.2319/070309-376.1.

153. Wehrbein H, Merz BR, Diedrich P. Palatal bone support for orthodontic implant anchorage-a clinical and radiological study. Eur J Orthod. 1999;21(1):65-70.

154. Fah R, Schatzle M. Complications and adverse patient reactions associated with the surgical insertion and removal of palatal implants: A retrospective study. Clin Oral Implants Res. 2014;25(6):653-658. doi: 10.1111/clr.12152; 10.1111/clr.12152. 
Appendices 


\section{Appendix 1. Specimen Information}

\begin{tabular}{|c|c|c|c|c|c|c|c|}
\hline \multirow[b]{2}{*}{ Specimens } & \multirow[b]{2}{*}{ Gender } & \multirow[b]{2}{*}{ Age } & \multicolumn{3}{|c|}{ Number of teeth } & \multirow[b]{2}{*}{ Torus } & \multirow[b]{2}{*}{ Cause of Death } \\
\hline & & & Total & Ant & Post & & \\
\hline 1513 & $\mathrm{M}$ & 78 & 7 & 4 & 3 & $\mathrm{~N}$ & $\begin{array}{l}\text { Cardiac Arrest, Pulmonary Edema, } \\
\text { Cardiogenic Shock, Myocardial } \\
\text { Infarction, Chronic Renal Failure. }\end{array}$ \\
\hline 1517 & M & 86 & 9 & 6 & 3 & $\mathrm{~N}$ & $\begin{array}{l}\text { Myocardial Infarction, CAD, CHF, } \\
\text { Acute Renal Failure }\end{array}$ \\
\hline 1576 & M & 57 & 14 & 6 & 8 & $\mathrm{~N}$ & Prostate Cancer \\
\hline 1589 & M & 98 & 12 & 6 & 6 & $\mathrm{~N}$ & $\begin{array}{l}\text { ASHD, Atrial Fibrillation, CHF, } \\
\text { Peripheral Vascular Disease }\end{array}$ \\
\hline 1605 & M & 54 & 13 & 6 & 7 & $\mathrm{~N}$ & $\begin{array}{l}\text { Aspiration Pneumonia, Huntington's } \\
\text { Chorea }\end{array}$ \\
\hline 1615 & M & 80 & 6 & 5 & 1 & $\mathrm{~N}$ & $\begin{array}{l}\text { Complications of Lung Injury from } \\
\text { MVC, Pneumonia, ARDS, Rib Fracture, } \\
\text { Pneumothorax, Pulmonary Embolus, } \\
\text { CHF, CAD }\end{array}$ \\
\hline 1672 & $\mathrm{~F}$ & 93 & 7 & 5 & 2 & $\mathrm{~N}$ & $\begin{array}{l}\text { End Stage Dementia, CVA, } \\
\text { Hypertension }\end{array}$ \\
\hline 1683 & $\mathrm{~F}$ & 93 & 12 & 6 & 6 & $\mathrm{~N}$ & Cardiorespiratory Failure, $\mathrm{CHF}$ \\
\hline 1706 & M & 61 & 6 & 6 & 0 & $\mathrm{~N}$ & $\begin{array}{l}\text { Hepatic Failure, Alcoholic Liver } \\
\text { Cirrhosis }\end{array}$ \\
\hline 1719 & $\mathrm{~F}$ & 76 & 13 & 6 & 7 & $\mathrm{~N}$ & $\begin{array}{l}\text { Pneumonia, Pulmonary Fibrosis, } \\
\text { Methotrexate Usage, Giant Cell Arteritis }\end{array}$ \\
\hline
\end{tabular}


Appendix 2. PMMA stencil used for grid reproduction onto the specimens.

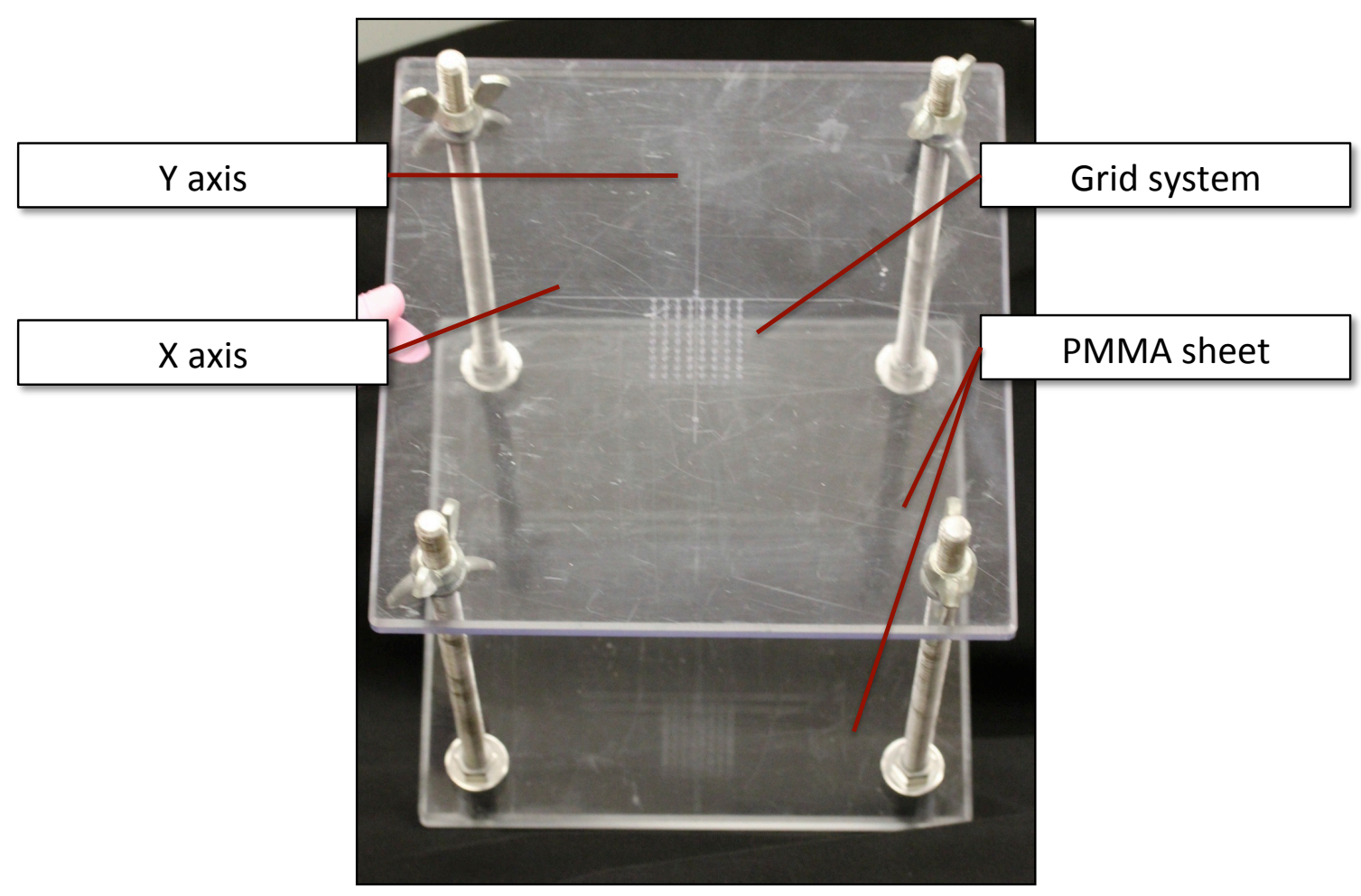


Appendix 3: Occlusal view of specimens after OMSs insertion

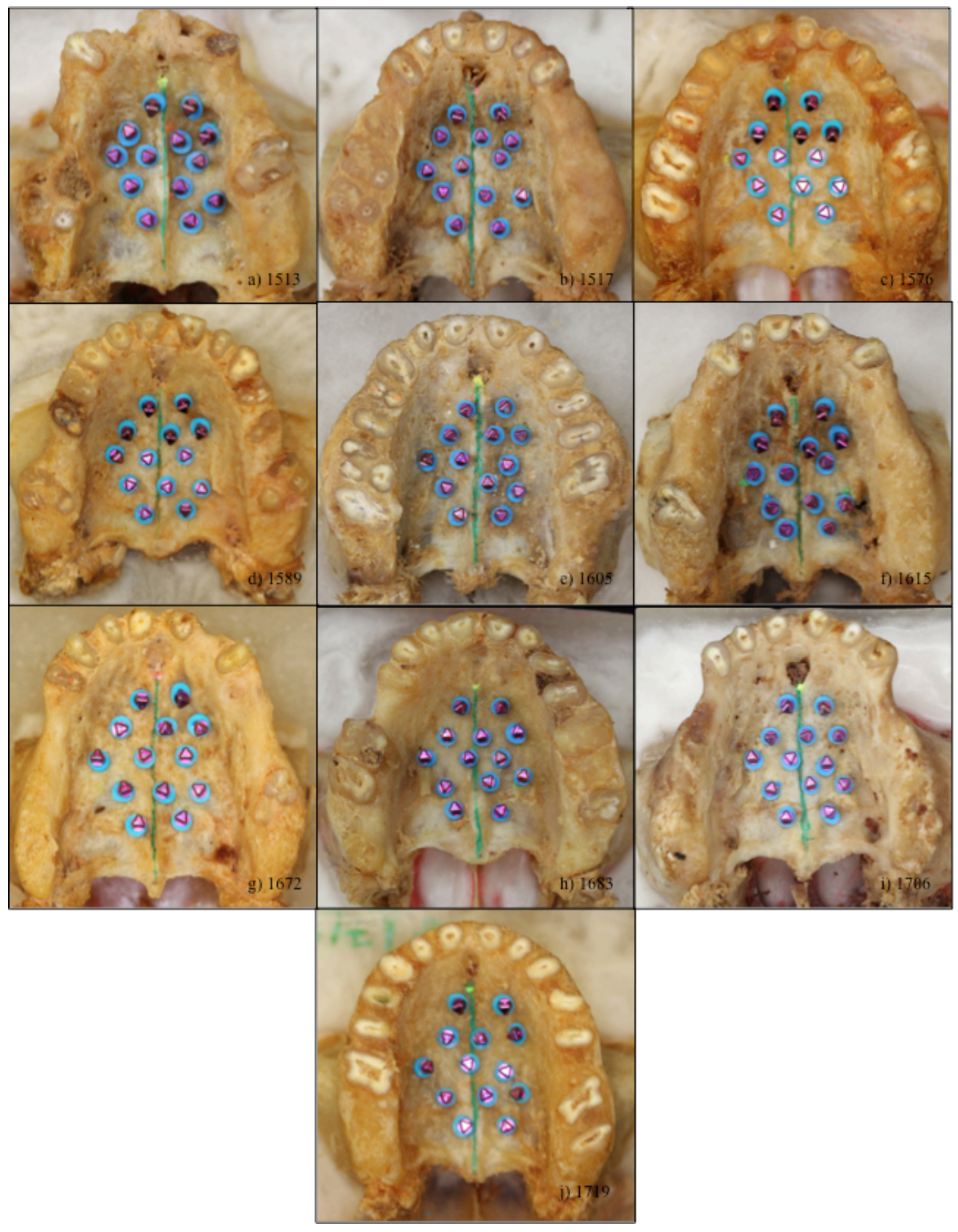


Appendix 4. Visual inspection of OMS perforation into nasal cavity.

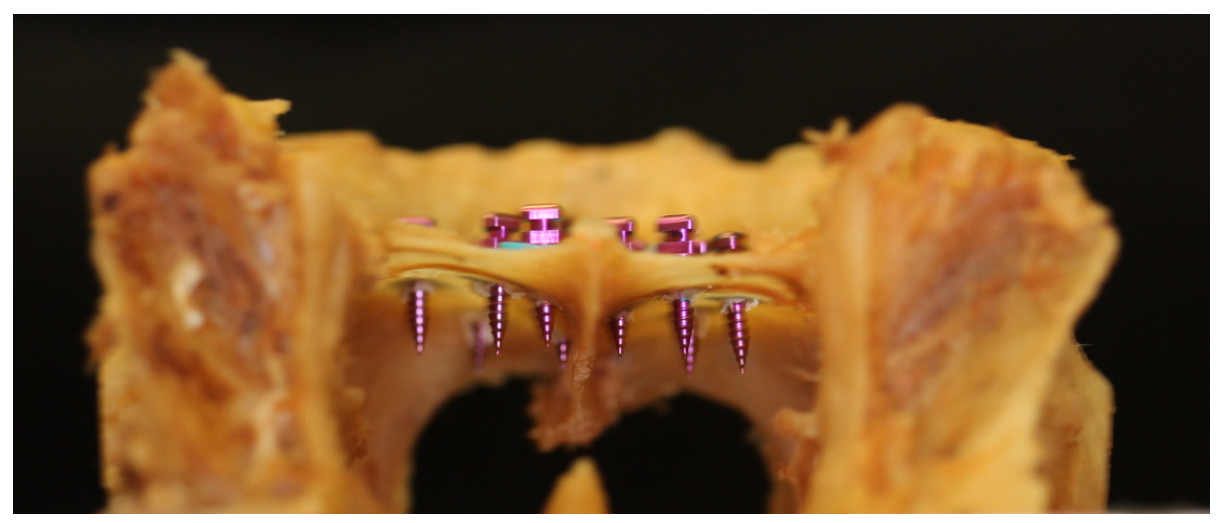




\section{Curriculum Vitae}

Name:

Post-secondary Education and Degrees:

Honours and Awards:
Carine Bourassa

Western University

London, Ontario, Canada

2012-2015 M.Cl.D (expected)

McGill University, Montreal Children's Hospital

Montréal, Québec, Canada

2010-2011 General Practice Residency Diploma

Université Laval

Québec, Québec, Canada

2006-2010 DMD

Université Laval

Québec, Québec, Canada

2005-2006 BSc. Kinesiology, abandoned

CÉGEP de Trois-Rivières

Trois-Rivières, Québec, Canada

2003-2005 Diploma of Collegial Studies, Health Sciences

Merit Awards, Dental Research day Western University 2014

Dr. Bruce Dobby Award for Excellence in the GPR Program 2011

Alpha Omega/Mount Royal Dental Society Prize 2011

Prize for Stand-up Case Presentation 2011

American Association of Orthodontics Prize 2010

Academy of General Dentistry Award.

2010

Dean's Prize, $27^{\text {th }}$ Research Day: Excellence in research Université Laval 2010 
Related Work Experience
Dentist, Cree Board of Health and Social Services

Eastmain, Québec, Canada

2012

Dentist, Montreal Children's Hospital

Montréal, Québec, Canada

2011-2012

Volunteer Dentist, Dentist Without Borders

Ricaurte, Azuay, Ecuador

2012

Demo for GPR program, McGill University, Montreal Children's

Hospital

Montréal, Québec, Canada

2011-2012

Dental Assistant, Dr. Serge Baril Orthodontic Clinic

Québec, Québec, Canada

2008-2009 